\title{
The Seasonal and Interannual Variability of the West Greenland Current System in the Labrador Sea
}

\author{
by \\ Tatiana Rykova \\ B.S., Moscow Institute of Physics and Technology, Russia, 2003 \\ Submitted in partial fulfillment of the requirements for the degree of \\ Doctor of Philosophy \\ at the \\ MASSACHUSETTS INSTITUTE OF TECHNOLOGY \\ and the \\ WOODS HOLE OCEANOGRAPHIC INSTITUTION
}

June 2010

(c) Tatiana A. Rykova. All rights reserved.

The author hereby grants to MIT and WHOI permission to reproduce and to distribute publicly paper and electronic copied of this thesis document in whole or in part in any medium now known or hereafter created.

Author

Joint Program in Physical Oceanography Massachusetts Institute of Technology Woods Hole Oceanographic Institution

May 14, 2010

Certified by

Dr. Fiammetta Straneo Associate Scientist Woods Hole Oceanographic Institution

Thesis Supervisor

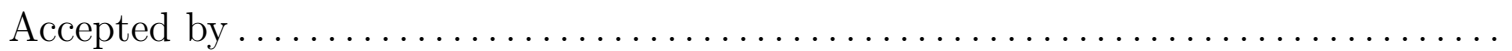

Dr. Karl Helfrich

Chairman, Joint Committee for Physical Oceanography Massachusetts Institute of Technology Woods Hole Oceanographic Institution 


\title{
The Seasonal and Interannual Variability
}

\section{of the West Greenland Current System in the Labrador Sea}

\author{
by \\ Tatiana Rykova \\ Submitted to the Massachusetts Institute of Technology \\ and the Woods Hole Oceanographic Institution \\ in partial fulfillment of the requirements for the degree of \\ Doctor of Philosophy
}

\begin{abstract}
The Labrador Sea, as one of a few places of deep water formation, plays an important role in the Meridional Overturning Circulation. While the interior of the Labrador Sea, where the deepest convection takes place, is known to experience variability on time scales ranging from days to decades, little is known about the variability of the other components of the Labrador Sea circulation - the boundary current system and the eddies that connect it with the interior.

Using various types of in situ data combined with the surface flux and satellite altimetry data products, I studied the variability of both the boundary current system and the eddies on different time scales as well as their influence on the post-convective restratification of the Labrador Sea interior. The analysis presented in the thesis supports the result of the previous theoretical studies that argue that lateral fluxes, driven by the boundary current/interior gradients, play an important role in the post-convective restratification of the Labrador Sea. I found that both components of the boundary current, the surface West Greenland Current and the subsurface Irminger Current, have a strong seasonal cycle. In the spring both the West Greenland and Irminger Currents are colder and fresher than in the fall. However, the West Greenland Current is faster and thicker in the spring while the Irminger Current is the fastest and thickest in the fall. My analysis suggests that the observed seasonal changes in the velocity are primarily due to the baroclinic component of the current while the barotropic component remains nearly unchanged.

The Subpolar Gyre, and the Labrador Sea in particular, have experienced a decline in the circulation accompanied by the warming of the water column over the last decades. I found that a similar trend is seen in the West Greenland Current system which slowed down from 1992 to 2004, primarily due to a decrease in the barotropic flow. At the same time, the subsurface Irminger Current has become warmer, saltier, and lighter, something that is also reflected in the properties of the eddies. Two years exhibited pronounced anomalies: in 1997 and 2003 the velocity, temperature and salinity of the Irminger Current abruptly increase with respect to the overall trend. Finally, I discuss the impacts of the boundary current changes on the lateral
\end{abstract}


fluxes that are responsible for the restratification of the Labrador Sea and the properties of the interior.

Thesis Supervisor: Dr. Fiammetta Straneo

Title: Associate Scientist

Woods Hole Oceanographic Institution 


\section{Acknowledgements}

I am heartily thankful to my adviser, Fiamma Straneo, for her encouragement, guidance and support during my time as a student. I am really lucky that my adviser was not only my teacher but also my mentor and friend. I am indebted to Fiamma for her patience with which she supported even the risky decisions that I made along the way: from moving away from MIT/WHOI and finishing long-distance to having a family during graduate school.

It is a pleasure to thank all my committee members: Amy Bower, Sonya Legg, Jonathan Lilly, Robert Pickart, Carl Wunsch and the thesis defense chair - Jim Price. My thesis would not have been possible without each of you. I want to thank you for the long and interesting discussions, for the new ideas and challenging problems that I had to solve to make my work better. I am grateful to Glenn Flierl, my first-year advisor, for introducing me to the concepts of physical oceanography and for always being available for advice.

I would like to thank Marsha, Julia, Valerie, Ronni, Carol and Danielle for all their help and for making my time in the Joint Program enjoyable. It is a great feeling to know that any problem would be solved and that they would do everything possible to make my life easier.

I owe a big thank-you to all my classmates and friends, in particular to Stephanie, Kjetil, Sophie, Hristina, Evgeny, Matt, Yohai, Ariane, Bea, Katie, Holly, Melanie and Anna.

Finally, the biggest thanks goes to my family. I will always remember that nothing would have been accomplished without the encouragement from my relatives who supported me from the day I applied for the graduate school abroad to the day of the thesis submission. I want to thank my parents, Tatiana and Anatoly, my aunt Valentina and my brother Anatoly for all their love, care and support.

Most of all I would like to thank my dear husband, Maxim Nikurashin, who has been always by my side regardless of the situation with my thesis and who helped me survive these most stressful years of my life. I owe a big thank-you for being always 
available for the discussions, advice and help, and for being the first proof-reader of the numerous drafts. A special thank you goes to our three-year old son Denis for being a good boy and for helping us maintain sanity no matter how busy we were. Lastly, I thank our soon-to-be-born daughter for being nice to me over the last 9 months and for not arriving before the due date and letting me finish my thesis! The financial support for my research came from the Academic Programs Office and from the NSF grants OCE-0424492 and OCE-0137023. 


\section{Contents}

$\begin{array}{lll}1 & \text { Introduction } & 9\end{array}$

1.1 The circulation of the Labrador Sea: Mean state . . . . . . . . . . . 11

1.1.1 Interior and convection . . . . . . . . . . . . . . 11

1.1.2 Boundary current svstem . . . . . . . . . . . . . . . . . 12

1.1 .3 Eddies . . . . . . . . . . . . . . . . . . 13

1.2 Seasonal changes in the Labrador Sea . . . . . . . . . . . 15

1.3 Interannual changes in the Labrador Sea . . . . . . . . . . . 17

1.4 Implications . . . . . . . . . . . . . . . . . . . . . . . . . . 19

1.5 Overview of the thesis $\ldots \ldots \ldots \ldots \ldots$

2 Irminger Current Anticyclones in the Hydrographic Record, 1990-2004 27

2.1 Introduction . . . . . . . . . . . . . . . . . . . 27

2.2 Background: Characteristics of the eddies . . . . . . . . . 29

2.3 ICAs in the hydrographic data . . . . . . . . . . . . . . 31

2.3 .1 Data . . . . . . . . . . . . . . . . . . . . . 31

2.3.2 Criteria for finding the ICAs . . . . . . . . . . . . 31

2.3 .3 Eddv Characteristics . . . . . . . . . . . . . . . . . 33

2.3.4 Spatial distribution . . . . . . . . . . . . . . . . 35

2.4 Wintertime modification of an ICA $\ldots \ldots \ldots \ldots \ldots$

2.5 Interannual variations of the ICAs . . . . . . . . . . . . 40

2.5.1 Water mass propertv variabilitv . . . . . . . . . . . . 42

2.5.2 Heat and freshwater anomaly variability . . . . . . . . 43

2.6 Summarv and discussion $\ldots \ldots \ldots \ldots \ldots \ldots$ 
3 West Greenland Current system: seasonal and interannual variability 61

3.1 Introduction . . . . . . . . . . . . . . . . . . 61

3.2 Data . . . . . . . . . . . . . . . . . . . 62

3.2 .1 Hvdrographic data . . . . . . . . . . . . . 62

3.2.2 Satellite altimetrv data product . . . . . . . . . . . 63

3.3 Results . . . . . . . . . . . . . . . . . . . . . 66

3.3.1 Climatologv . . . . . . . . . . . . . . . . . 66

3.3 .2 Seasonal variabilitv . . . . . . . . . . . . . . 70

3.3 .3 Interannual variability . . . . . . . . . . . . . . . 74

3.4 Uncertainties $\ldots \ldots \ldots \ldots \ldots$

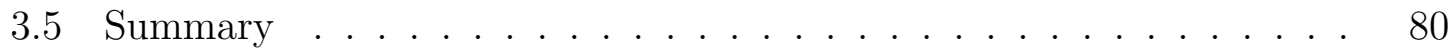

4 The impact of the boundary current changes on the interior: lateral fluxes.101

4.1 Introduction . . . . . . . . . . . . . . . . . . . . 101

4.2 Approach . . . . . . . . . . . . . . . . . . . 103

4.3 Data $\ldots \ldots \ldots \ldots \ldots \ldots \ldots$

4.4 Results . . . . . . . . . . . . . . . . . . . . . . . . . 110

4.4 .1 Lateral flux estimations . . . . . . . . . . . . . . 110

4.4 .2 Uncertainties . . . . . . . . . . . . . . . . . . . . 114

4.5 Summary and discussion . . . . . . . . . . . . . . . 116

5 Conclusions $\quad 127$

5.1 Summarv of the results . . . . . . . . . . . . . . . . . . 127

5.2 Discussion . . . . . . . . . . . . . . . . . . . . . . . . . . . 132

5.3 Future work . . . . . . . . . . . . . . . . . . 135

\begin{tabular}{ll}
\hline & 137
\end{tabular}

\begin{tabular}{ll}
\hline B & 147
\end{tabular} 


\section{Chapter 1}

\section{Introduction}

Heat is transported from the equator to the poles by both ocean and atmosphere. In the ocean, the Meridional Overturning Circulation (MOC) is a major contributor to the meridional transport and storage of heat, fresh water, $\mathrm{CO}_{2}$ and other chemical and biological properties. The MOC consists of several components, the dynamics of which are crucial for the climate of the whole planet: 1) surface currents that bring warm water from the equator to the poles, 2) convective regions where the surface waters lose heat and become dense, 3) deep currents that transport dense water towards the equator and 4) upwelling that closes the circulation. The transport of heat by the ocean from low to high latitudes occurs via various pathways, but there are only a few regions in the World Ocean where the dense and intermediate waters are formed. One of these places is the Labrador Sea.

The circulation of the Labrador Sea consists of the weakly-stratified convective interior, the cyclonically flowing boundary current system and the various types of eddies that populate the Labrador Sea and connect the boundary current region with the interior. Deep convection occurs in the interior and results in the formation of Labrador Sea Water (LSW) - a significant contributor to the Deep Western Boundary Current (DWBC) that exports convected water from high latitudes equatorward. The convective processes play a major role in the ventilation of deep and intermediate layers of the North Atlantic, the redistribution of heat and fresh water throughout the water column, and the storage of greenhouse gases. LSW, as a part of North Atlantic Deep 
Water (NADW) spreads into the Southern Hemisphere and can be traced nearly everywhere in the World Ocean.

The Labrador Sea has been a focus of many studies during past decades. Much progress has been made towards understanding the convective process, its different stages and influencing factors. Many studies have focused on LSW, its formation rates and properties, as well as the major forcing mechanisms that contribute to the duration and depth of convective penetration (LabSea Group, 39]; Marshall and Schott, 50; Lazier et al., 45]). Another area of intense investigation is related to the spreading of newly formed LSW, its pathways and time scales as well as its modification as the water mass leaves the formation site (Rhein et al., 64]; Bower et al., [5]) and becomes a significant part of the DWBC. Very few studies, however, have focused on the waters entering the Labrador Sea that are the initial conditions for LSW production, and the waters that play the most important role for the post-convective restratification. Given the observed variability of the interior Labrador Sea properties, it is crucial to document and understand the variability of the inflowing waters, how they change on the time scales from months to decades and what influence they have on LSW formation. In particular, it is necessary to understand and quantify the role of the boundary current and its eddies in the water mass transformation as well as the heat and fresh water budgets of the Labrador Sea.

The main objectives of the thesis are to:

1) Describe the climatological hydrographic and velocity properties of the West Greenland Current system;

2) Understand the seasonal and interannual changes in the boundary current system at the entrance to the Labrador Sea and analyze the possible causes of the observed variability;

3) Study the evolution of the important class of eddies and its contribution to dense water formation;

4) Investigate the relation between the boundary current variability, and eddy production and their impact on the interior changes. 


\subsection{The circulation of the Labrador Sea: Mean state}

The Labrador Sea is a part of the Subpolar Gyre (SPG) that is located in the NorthWest corner of the North Atlantic Ocean between Greenland and the Labrador coast of Canada. To orient the reader I present a schematic of the region in Figure 1-1. Similarly to other high-latitude places, it is a region of severe meteorological conditions. It is characterized by the existence of the cold and dry Arctic air, frequent storms, Greenland icebergs, pack ice, and great air-sea buoyancy contrasts. It is a site where the cooling of the atmosphere induces a large buoyancy flux which together with a weak buoyancy stratification of the water results in deep convection. The depth of convection is determined by the strength and duration of the atmospheric forcing and the state of the ocean prior to the beginning of convection.

\subsubsection{Interior and convection}

Deep convection occurs in the interior of the basin during the winter. It is primarily driven by the large wintertime heat loss (Dickson et al., [18]) and tends to be confined to the western part of the central Labrador Sea (Lazier, [45] LabSea Group, [39]; Pickart et al., [58]). After being formed in the interior, the product of convection, LSW, spreads at intermediate depths southward and eastward and is found in the North Atlantic to the north of $40^{\circ} \mathrm{N}$ and along its western boundary to $18^{\circ} \mathrm{N}$ (Talley and McCartney, [43]). Its characteristics are easy to track since LSW is a low PV water mass with a pronounced salinity minimum $\left(\theta \sim 2.9{ }^{0} \mathrm{C}, \mathrm{S} \sim 34.84\right.$, Pickart et al., [59]).

There are three conditions that have to be satisfied in order for the convection to occur: i) the water must be weakly stratified; ii) the cyclonic circulation must be present around the convective area to bring the weakly-stratified water closer to the 
surface by doming of the isopycnals; and iii) the strong surface fluxes must act for prolonged times to extract enough buoyancy for the convection to occur. All these conditions are satisfied in the Labrador Sea. The dry and cold air blows over the relatively warm waters of the sea $\left(\sim 2^{0} \mathrm{C}\right)$ resulting in mean heat losses of the order of 200-300 W m² (LabSea Group, 39]; Marshall and Schott, 50], Pickart et al., [59]) resulting in LSW production rates of 4.5-10.8 Sv (Yashayaev, [82]; Rhein et al., 64]). After convection ceases, the second phase, called the restratification, begins to play a leading role in the water mass transformation (Straneo, [73]). Restratification is characterized by the removal of newly formed dense water away from the interior and the replacement by the warm and salty waters from the boundary current system that is achieved by means of the numerous eddies (Marshall and Schott, [50]; Katsman et al., [36]).

In addition to the convective site in the western part of the basin, there are a number of closed regions of cyclonic flow that form a weak anticyclonic gyre at mid-depth (roughly $700 \mathrm{~m}$ ) (Lavender at al., 42]). As Lavender et al., 42 have shown, these recirculation cells provide another pathway for the LSW flushing: it spreads eastward and can be found 1.6 to 2.6 years later in the Irminger basin and traced to the Iceland Sea as well.

\subsubsection{Boundary current system}

The central region of the Labrador Sea is encircled by a boundary current system, flowing around the basin's perimeter (Figure 1-11). The boundary current system of the Labrador Sea consists of several components located at different depths (see Figure 1-1 for the surface circulation). The upper layer of the current limited to about $1200 \mathrm{~m}$ consists of two branches (Cuny et al., [12]; Pickart et al., [58]). The surface (roughly 0-200 m) West Greenland Current (WGC) brings cold and fresh Arcticorigin waters. The Irminger Current (IC) is located underneath (200-1200 m) and offshore of the WGC and carries warm and salty subtropical waters from the North Atlantic Current. Below the IC, there is a layer of LSW at about 1000-1500 m that 
is characterized by nearly flat isopycnals and a minimum in the boundary current's velocity. The LSW layer in the boundary current is much thinner than in the interior. The deep layers are occupied by the waters originating from the Denmark Strait Overflow (DSOW) and the Nordic Seas - Iceland-Scotland Overflow Water (ISOW) (Pickart et al., [59]) that compose the DWBC. Their properties and variability are beyond the scope of this study and I will thus limit any further description of the boundary current system to the upper $1500 \mathrm{~m}$.

The boundary current system enters the Labrador Sea on the eastern boundary at Cape Farewell and stays inshore of the $3000 \mathrm{~m}$ isobath at the western side of Greenland (Cuny et al., [12]). At the place where the $3000 \mathrm{~m}$ isobath diverges from the shelf, the boundary current splits into two branches. One branch continues to flow northward along the coast into Davis Strait and the other branch makes a cyclonic loop around the interior of the Labrador Sea roughly following the $3000 \mathrm{~m}$ isobath (Cuny et al., [12]). It joins with the Labrador Current on the Canadian side of the Labrador Sea and leaves the region to the south. Since the goal of this work is to study the boundary current as it enters the basin, I limit myself to the portion of the boundary current located on the Greenland side of the basin, roughly southward of $62^{0} \mathrm{~N}$ where the major exchange with the interior by means of eddies takes place.

Both wind- and buoyancy-driven, the boundary current system follows the contours of constant $\mathrm{f} / \mathrm{H}$ as it enters the basin. However, where the topographic slope changes at roughly $61^{0} \mathrm{~N}, 52^{0} \mathrm{~W}$, the boundary current system adjusts to the widening and steepening shelf (Bracco and Pedlosky, [7]; Spall, [68]; Wolfe and Cenedese, [80]). As a result of such adjustment, the current becomes baroclinically unstable and produces one particular kind of eddies (Eden and Böning, 20], Katsman et al., [36]).

\subsubsection{Eddies}

The main role of the eddies is to exchange properties between the boundary current and interior regions (Lilly et al., [49]; Katsman et al., [36]; Straneo, [73]). 
The large wintertime heat loss to the atmosphere that occurs over the basin is balanced by the net inflow of warm subtropical waters transported by the boundary current. Over the mostly quiescent interior (Lavender et al., [40]), the surface heat loss is balanced by a net convergence of heat via lateral eddy fluxes (Lilly et al., 47]; Straneo, [74]). These fluxes are thought to result from two instability pathways: baroclinic instability distributed around the basin (Spall, 68]; Straneo, 74]), and localized topographic instability of the boundary current (Eden and Boning, 20]; Katsman et al., 36, Bracco et al., [8]). They drive the post-convection restratification of the interior, through the advection of fresh surface waters and warm, salty subsurface waters from the boundary current (Straneo, [73]; Lazier et al., 45]; Lilly et al., 49], hereafter L03), and remove the convective product from the interior (Katsman et al., 36]; Spall, 68]; Straneo, [74]).

One special type of eddy, the Irminger Current Anticyclone (ICA) or Irminger Ring, is thought to play a particularly important role in the advection of heat into the central region. These eddies contain a thick, subsurface layer of warm Irminger Water, modified subtropical water carried around the basin in the boundary current and its extension (e.g. Cuny et al., 12]), and are thought to contribute between 25 to $100 \%$ of the heat needed to balance the surface heat loss (L03; Katsman et al., [36]; Hatun et al., 33], hereafter H07). The region of their formation is characterized by a change in topographic slope and a large sea-surface height ( $\mathrm{SSH}$ ) variability associated with high eddy kinetic energy (Prater, 63]; L03; Lavender et al., 42]).

Another example of the possible importance of the Irminger Current eddies is the appearance of the fresh water cap at the surface of the Labrador Sea in early spring. Its origin is still not well understood (Straneo, [73]). Precipitation cannot account for such a significant fresh water layer; icebergs and melting of the sea ice are unlikely to supply it as well (Myers, [54]; Straneo, [73]). A primary contributor to this effect is possibly the cold, fresh West Greenland Current system which flows above and inshore of the Irminger Current and may influence the Labrador Sea by means of the 
Irminger Current eddies (H07). The authors of this recent study found that several of these eddies had a fresh surface layer and suggested that they may also play an important role in the freshwater cycle through the Labrador Sea's interior. The qualitative and quantitative impact of these eddies to the transformation of water masses during the restratification is still an open question. It is important to understand how exactly the eddies provide the observed fresh water for the interior: is their fresh cap being swept off by the wind or is it mixed down by convection?

The lateral fluxes associated with the eddies can be quantified in terms of the density gradient between the boundary current and interior, as demonstrated in the study by Spall, 68. Straneo, [74] complemented and deepened this study by parameterizing these fluxes and successfully reproducing the seasonal and interannual variability in the Labrador Sea's circulation (Straneo, [73]). It has been shown that these eddies play a crucial role in the dynamics of the Labrador Sea, in the water mass transformation, and heat and fresh water budgets (Straneo, [74]).

\subsection{Seasonal changes in the Labrador Sea}

As typical of high latitudes, the Labrador Sea undergoes considerable seasonal variability (Lilly et al., [47]; Straneo, 173]; Yashayaev, 82]). The cooling of the interior begins in the fall and continues during the winter eroding the seasonal thermocline over large regions by February. The maximum interior mixed layer depth is usually observed in March (LabSea Group, [39]; Marshall and Schott, [50]). Restratification of the surface water occurs very quickly and much of the upper column restores to its preconvection state by May (Pickart et al., [59]; Prater, 63]; Steffen and D'Asaro, [69]). The deepest convection and the greatest heat flux are observed seaward of the Labrador slope, where the continental winds are the driest and the coldest (LabSea Group, 39]; Pickart, [58]). Despite its location and severe atmospheric conditions, the interior of the Labrador Sea remains free of ice throughout the winter (Pickart, 
[58]; Pickart et al., [59]). The ice covers only regions adjacent to the land, especially on the Labrador side which makes ship observations challenging in winter (Pickart, [58]; Pickart et al., [59]).

An interesting feature of the Labrador Sea seasonal cycle is the appearance of a fresh layer at the surface immediately after the convection ceases (Pickart et al., [59]; Straneo, [73; Hatun et al., [32]). This layer, especially if it is warm as well, makes the water column very stable to convection and prevents vertical mixing with the layers below. The seasonal cycle is not fully resolved in the hydrographic data since the majority of the historical sections have been occupied in late spring - summer season. Moreover, restratification takes place in two phases (Straneo, [73]), the faster one happens in a very short period of time making it hard to observe. Thus, this process is still not fully resolved and understood.

While the wintertime convection and the ensuing restratification of the interior region was widely studied in the 1990s (LabSea Group, 39]; Marshall and Schott, [50]; Lilly et al., [47]), the eddies and, more importantly, their source, the boundary current, have received much less attention. Schmidt and Send, [6] describe a strong seasonality in the upper part of the boundary current system, the WGC, which carries the Arctic-origin water from the eastern side of Greenland. They observe the largest fresh water flow in the WGC between June and August and argue that it explains $60 \%$ of the seasonal freshening of the Labrador Sea. The seasonal variability of the intermediate portion of the boundary current that is responsible for the advection of heat, the Irminger Current, is largely unknown. The majority of the studies that focus on the boundary current properties and dynamics are based on summertime data (Stein, [70]; Myers et al., [54]). Overall, we know very little about the seasonality of the boundary current system: it appears to be unstable in the winter months as shown by the analysis of the eddy kinetic energy (EKE) field. The EKE maximum associated with the Irminger Ring production is observed in January-March and the minimum in the summer (Prater, 63]; and L03). Altimetry shows that the location 
of the EKE maximum undergoes a seasonal cycle as well: the EKE maximum reflected in the $\mathrm{SSH}$ is located at $61.5^{0} \mathrm{~N}, 52^{0} \mathrm{~W}$ (Prater, 63] L03), while the second largest maximum in $\mathrm{SSH}$ is situated in the central Labrador Sea at $58^{0} \mathrm{~N}, 52^{0} \mathrm{~W}$ and is observed later in the year.

It is unclear which changes in the current's structure or properties contribute to the seasonality in the eddy generation and, therefore, in the lateral fluxes. Investigating the seasonal changes in the upper components of the boundary current system, and their relation to eddy production and restratification, is one of the goals of this study.

\subsection{Interannual changes in the Labrador Sea}

Since the mid-1990s, the temperature and salinity of the entire Subpolar Gyre, which, besides the Labrador Sea, includes the circulation in the Irminger Sea and the Iceland basin, have increased (Hatun et al., [32]; Stein, [70]; Sarafanov et al., 65]; Yashayaev, [82]). This warming and salinification have been accompanied by a weakening of the circulation of the SPG observed both from altimetry and mooring data (Hakkinen and Rhines, 27. and Hakkinen and Rhines, [28]) and supported by model results (Böning et al., 44). Among the factors responsible for this variability are the changes in the wind strength, air-sea fluxes (Marshall and Schott, [50]), evaporation and precipitation, and variability in the boundary current system as well as in the lateral fluxes connecting it with the interior (L03; Katsman et al., [36]; Straneo, 73]). The contribution from the Arctic basin and melting of the Greenland icebergs and ice, variability of the North Atlantic Current and the "memory" of the sea also play a role in these changes (Marshall and Schott, [50]; Schmidt and Send, 66]). The variety of possible contributors to the observed interannual variability reflects the complexity of the system and the interplay between numerous processes. 
These changes can be partially explained by the transition of the North Atlantic Oscillation (NAO), one of the major modes of atmospheric variability in the Northern Hemisphere which influences the surface heat fluxes and the wind stress, from a positive phase to a mostly negative or non-persistent phase in the mid-1990s (Hurrell et al. 35]; Dickson et al., [18; Lazier et al., 45]). The positive NAO phase is associated with a larger heat loss from the ocean, which implies that more denser LSW is produced (Dickson et al., [18]). On top of the trend related to the NAO changes, the Labrador Sea (and SPG) seem to have undergone large changes in 1996/1997 and 2003 (Dickson et al., [18; L03; Brandt et al., 6]; Avsic et al., 2]; Hakkinen and Rhines, [28]). These years were characterized by large lateral heat fluxes (L03; Brandt et al., [6], Avsic et al., 2] ) that led to a rapid warming of the central Labrador Sea which, in turn, affected the amount and properties of LSW formed (Avsic et al., [2]; Bersch et al., [3]; Yashayaev et al., 82]). There is evidence, that in at least one of these years, these changes were associated with an increase in the number of eddies reaching the interior of the Labrador Sea (L03).

It has been documented that the eddy field changed from the early 1990s to the present time (L03). The decrease in convective intensity in the late 1990s (Yashayaev, [82] ) together with an inflow of fresh water at the surface and saline water at middepth made conditions for overturning less favorable. It lead to the increase in the eddies' duration since they were not destroyed by the surface fluxes (L03). There has been a documented increase in the eddy population in the southern Labrador Sea during the late 1990s (L03) that implied that eddies were able to drift in the interior for a long time so as to be able to reach the southern part of the Labrador Sea. As was reported by L03, based on mooring observations, the speed of the interior currents has increased during the years of relatively weak convection which could be a result of an enhanced eddy activity in the Labrador Sea. Altimetry measurements have shown that during the years of increased boundary current instability corresponding to the enhanced EKE maximum, lateral heat transport from the boundary region to the interior was greater than usual. This lead to a reduction of the convection depth 
due to significant lateral inflow of warm water from the intensified boundary current (L03; Eden and Böning, [20]). It is unclear, however, how the eddies' characteristics may change interannually and to what extent they contribute to the hydrographic variability observed in the Labrador Sea.

The role played by the boundary current in these changes is still largely unknown. Indeed, it has been found that only part of the Labrador Sea's large interannual variability can be attributed to the atmospheric forcing (Dickson et al., [17]; Pickart et al., [58]; L03) while the rest is attributed to changes in the lateral fluxes (L03 and Straneo, [73]). Several studies have documented a recent warming of the Irminger Current (Stein, 70] and Myers et al., [54]) and a corresponding decrease in transport (Myers et al., 55]) but their analysis was limited to summertime data. In addition, the boundary current changes were inferred by considering a single profile within the current that did not capture the changes across its entire width. It is still unclear, for example, if the interior changes are mainly the response to the variability in the surface fluxes or to the changing conditions at the inflow and hence, different rates of restratification (tightly linked to the amounts and properties of the eddies). Since the degree of restratification has an impact on convection in the years to follow, there is a growing interest in identifying and understanding the mechanisms which control it. Here we investigate systematically the changes that occur in the boundary current and the eddies and how they are related to the changes in the lateral fluxes and interior properties of the Labrador Sea.

\subsection{Implications}

This thesis work has many important implications but I will focus here on the three major contributions. First, the results described in the scientific chapters contribute to our understanding of the MOC variability on interannual to decadal time scales. Second, this work is important for the improvement of climate models. Finally, by 
advancing our understanding of the boundary current and eddy properties and their variability, I aim to explain the significant differences in the properties and transport estimations found in previous studies.

This work has been motivated by the growing interest in understanding our climate, the role of the ocean in the climate changes and the ability of numerical models to adequately represent these changes. The Meridional Overturning Circulation is the main carrier of heat, fresh water and other chemical and biological tracers that are brought from the equator towards the high latitudes. The MOC exhibits variability on different time scales, from seasonal to glacial-interglacial (Dong et al., [19]). The Atlantic MOC (AMOC) variability on interannual to decadal time scales has been related to the variability in high latitude processes (Deshayes et al., [16]), including LSW. Thus, in order to understand the variability of the AMOC, one should understand all the processes that are important for LSW formation as well as the connections and causalities among them. In particular, since the ultimate goal is to understand the variability of the AMOC, one should understand and be able to adequately represent the variability of the three major circulation components of the Labrador Sea, two of which, the boundary current and the eddies, are the focus of the current thesis.

The heat transport by the ocean as a part of the MOC has been shown to be sensitive to the changes in convection in the North Atlantic (Stouffer et al., [71]; Vellinga and Wood, [79]). But there is no simple relationship between the MOC strength and the production of LSW (Deshayes et al., [16]). Despite documented importance of LSW, there is little agreement between various climate models in the representation of its properties and formation rates as well as the MOC strength (Jong et al., [37]). The climate models do not resolve all the processes that are essential for LSW formation and moreover, the crucial processes, such as the eddy transfer of heat and fresh water from the boundary current to the interior are not fully represented. This work systematically documents the changes in the boundary current and interior in 
1990-2008, highlighting the important processes for LSW formation and variability, and points to the processes that should be present in the climate models in order to realistically represent LSW formation.

Another aspect that makes the Labrador Sea a crucially important place for the MOC owes to its geographical position, on the border between the Arctic and North Atlantic Oceans. It is a key location for the redistribution of the fresh water that arrives from the Arctic along the Greenland coast, and, as a result of the deep mixing, penetrates the intermediate/deep regions. Commonly, the models underestimate the salinity of the upper layers thus making the Labrador Sea more stable to convection and overestimate the salinities at the intermediate levels (Jong et al., [37]). As a result of this representation, the water column in the models appears to be much more stably stratified than it is in the real ocean and thus, the convection is limited to much shallower depths. The opposite scenario is when the models have high salinity at the surface that leads to persistent convection down to $2000 \mathrm{~m}$ that lasts decades (Msadek and Frankignoul, [52]). Low-resolution models tend to have problems with the restratification process due to the fact that the parametrization of the eddies responsible for that process does not fully capture their effect on it (Msadek and Frankignoul, [52]). Hence, the eddies' contribution to the properties and the dynamics of the Labrador Sea should be understood and realistically represented in the models.

This work will improve the representation of LSW production not only in the global climate models but can also be useful for the high-resolution models as well. The majority of the regional models have imperfections that prevent them from being able to reproduce the observed variability of the Labrador Sea system in a realistic way. For example, the location of convection and the deeper circulation is still represented unrealistically (Deshayes and Frankignoul, [15])

The amount of observational data collected does not allow us to study the interannual changes in the Labrador Sea for more than two decades. The interior monitoring on a regular basis only started at the beginning of 1990s with the annual occupation of the WOCE AR7W line. The results of the analysis of the available data in the 
Labrador Sea also vary significantly depending on the method the authors have used. For example, there is still little consensus about the extent of convection. The magnitudes of LSW formation vary in the range from 3 to $16 \mathrm{~Sv}$ (Rhein et al., 64]; Straneo, [73]) and the transport of the Irminger Water is a factor of four different from study to study (Myers et al., [53]; Pickart and Spall, 61]). All these uncertainties prevent us from a complete understanding the past and present state of the Labrador Sea and the Subpolar region in general. In this thesis I document the seasonal variability in the properties and velocity of the boundary current system and provide a possible explanation for differences in the previous estimates. The results of my analysis contribute to our understanding of the interannual variability in LSW properties and amounts that are tightly linked to the changes in the boundary current system.

Finally, the importance of the Labrador Sea's circulation has been recognized in interdisciplinary studies as well, including the biological productivity and ice sheet/ocean interaction. For example, the eddies shed by the boundary current system have been found to contribute to the increase in the nutrient supply of the upper ocean (Frajka-Williams and Rhines, 21]). Another example of the successful use of physical oceanographic data in other disciplines is the study of Greenland Ice Sheet (GIS) changes (Holland et al., [34]; Straneo et al., [75]). The melting of the GIS was found to dramatically increase in 1997 which corresponded to the warming of the Labrador Sea boundary current system (Holland et al., [34]).

This thesis would provide the first step in understanding the variability in these two major components of the Labrador Sea circulation, the boundary current system and the eddies, as well as its effect on the interior. The results of the analysis improve our understanding of the causes of the variability in the interior of the Labrador Sea and hence, in the properties of LSW found downstream. 


\subsection{Overview of the thesis}

Previous studies have focused on convective processes in the interior while it is recognized now that the boundary current's properties and dynamics at the entrance of the basin contribute significantly to LSW formation, together with the surface forcing. The main goal of this thesis is to improve our understanding of the complex Labrador Sea circulation, focusing on the boundary current components and the eddies that the boundary current sheds.

This thesis is structured in the following way:

Chapter 2 aims to improve our understanding of Irminger Current Anticyclones (ICAs) by analyzing a large hydrographic data set collected in the Labrador Sea from 1990 to 2004. By mapping seasonal and interannual changes in ICA's properties and locations we seek to quantify the anomalous heat and freshwater content of the eddies and understand how these vary through an eddy's life-cycle. One particular focus of this chapter is to document the transformation which the ICAs undergo in the winter, when the Labrador Sea is subject to a large surface buoyancy loss. Can the eddies survive these wintertime fluxes? If so, how are they transformed?

In Chapter 3 I obtain a robust climatological mean of the boundary current on the eastern side of the basin for 1992-2008 and examine both the surface and subsurface branches of the current. Utilizing the large hydrographic data base and the gridded satellite altimetry product, I study the seasonal and interannual variability in the properties and velocity of the boundary current system.

The net effect of the ICAs on the heat budget of the Labrador Sea is presented in Chapter 4 of the thesis. It is crucial to understand how exactly they provide the connection between regions, where they transfer heat to, at what time of the year this heat exchange is the most intense and other related issues. Understanding the dynamics and properties of the Irminger Current eddies will help to improve 
the estimates of their contribution to the Labrador Sea heat and fresh water balances.

The last chapter of this thesis, Chapter 5, provides the summary of the three science chapters and discusses the possible implications of this study and future work. 


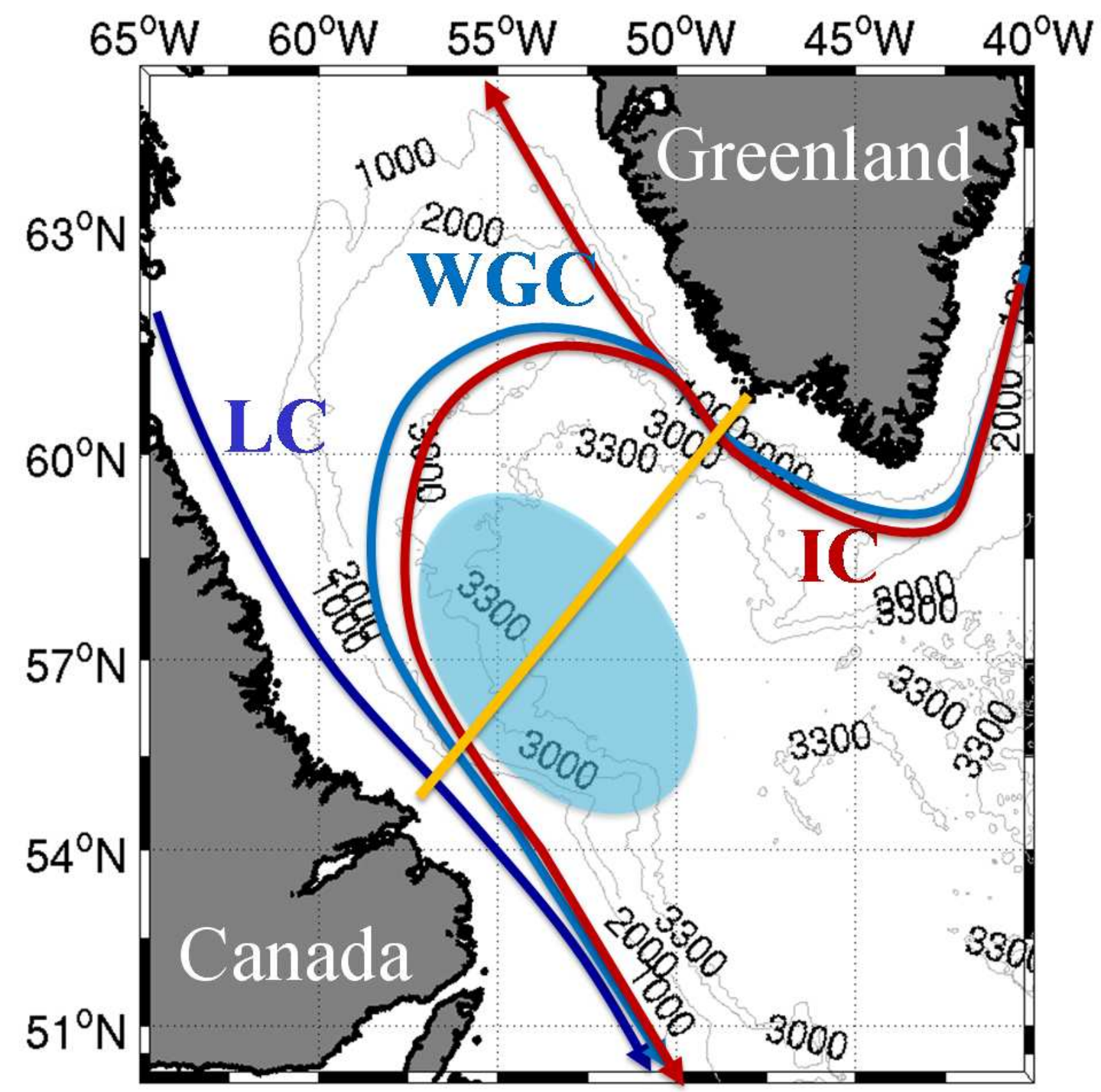

Figure 1-1: Schematic of the Labrador Sea with the surface currents (see details in the text) indicated. Light blue region represents interior, yellow line is AR7W, arrows represent the currents: WGC - West Greenland Current (blue), IC - Irminger Current (red); LC - Labrador Current (purple). Gray contours represent bathymetry: 1000, 2000, 3000 and $3300 \mathrm{~m}$ indicated. 


\section{Chapter 2}

\section{Irminger Current Anticyclones in the Hydrographic Record, 1990-2004}

\section{$2.1 \quad$ Introduction}

The goal of this chapter is to make the first step towards understanding of the restratification process in the Labrador Sea by analyzing the eddies' properties and their evolution on both seasonal and interannual time scales.

These eddies, predominantly anticyclones, are formed near the coast of Greenland and then propagate to the center of the basin. Originating from the boundary current system, they contain a fresh and cold layer at the surface that overlies a warm and salty layer at mid-depth which allows them to be effective carriers of both heat (in their subsurface layer) and fresh water (at the surface). Moving away from the source, they lose heat under the wintertime surface fluxes but little is unknown if they survive convection and how they are transformed as a result of such strong atmospheric forcing. In particular, it is unclear if their anomalous heat and freshwater content is released slowly via mixing and eddy decay or if, for example, they are rapidly destroyed by the strong wintertime air-sea fluxes which characterize this re- 
gion. The stages of their water mass transformation as well as the mechanisms of the heat and fresh water release to the interior are far from obvious. In order to achieve the understanding of the restratification processes, it is important to understand the changes in eddies' properties at each step in their lifetime, from origin to decay.

Even while recognized as important to the Labrador Sea's heat and freshwater cycles on the seasonal time scales, little is know about their ability to contribute the interannual changes in LSW production. Their quantities have been documented to change at mid-1990s (L03) while nothing is known about their hydrographic properties at the time of the most significant change for the whole Subpolar Gyre, in 1996/1997. Little is known about the changes in the structure of the eddies and more importantly, how these changes affect the restratification and LSW properties. Here I carefully examine the properties and distribution of the eddies found in 1990-2004 hydrographic record and try to relate the observed changes to the variability of their source and overall, of the Subpolar Gyre.

This chapter begins with a review of what is known about ICAs from previous studies. These studies provide us with a number of criteria for the detection of ICAs from hydrographic data. The general characteristics of the ICAs identified in this study are described in section 3, together with their classification within one of two groups: unconvected and convected ICAs. Property analysis and a one-dimensional mixing model are used in section 4 to argue that the latter group are indeed ICAs which have been transformed by the wintertime fluxes of the Labrador Sea. The interannual variations within the ICAs are described in section 5, including how changes in their properties compare with those of the Labrador Sea interior. A summary and discussion of the findings of this study are presented in section 6 . 


\subsection{Background: Characteristics of the eddies}

Previous studies have identified three kinds of eddies that populate the Labrador Sea: convectively formed anticyclones, Irminger Current Cyclones and Anticyclones (Lilly et al., 48]; L03; H07). This work focuses on the Irminger Current Anticyclones (ICAs), the most noticeable contributor to the Labrador Sea's heat and freshwater budgets. These have been studied from a variety of data sources which include moorings, floats, altimetry and gliders and their characteristics are described in Prater, [63], who identified one ICA from profiling RAFOS floats; L03, who examined thirteen ICAs from a 1994-1999 mooring record and sea surface height (SSH) anomalies in the satellite along track data altogether; and H07, who studied three ICAs using Seagliders and a variety of satellite products. The basic findings of these studies are briefly reviewed here.

ICAs are formed from an instability of the West Greenland/Irminger Current system off the west Greenland coast, at the location of the change in the topographic slope (Prater, 63] and L03; Fig. 2-1). This region, which is associated with a maximum in eddy kinetic energy (EKE), is important for the exchange of properties between the interior and the boundary current (Straneo et al., [72]). Tracking of individual, large-amplitude, isolated sea-surface height anomalies from the EKE maximum to a mooring in the central Labrador Sea - where these anomalies were found to be associated with subsurface $\theta / S$ properties typical of ICAs - allowed L03 to identify this region as the ICA generation region. Eddy generation is thought to peak in winter (December to March) when both sea-surface height variance (Prater, [63]) and eddy kinetic energy (L03) peak.

ICAs are characterized by a thicker and more pronounced layer of warm, salty Irminger Water than the Labrador Sea's interior (Prater, 63] and L03) or than the neighboring water masses in the current (H07). This is consistent with the general notion that at formation these eddies trap warm and salty Irminger Water (IW) 
from the boundary current and preserve its properties by inhibiting lateral mixing. Properties of the eddies - warm and salty cores are observed to vary: potential temperature $\theta=4.9^{\circ} C$ in Prater's eddy, $\theta \sim 3-4.15^{\circ} C$ and $\mathrm{S} \sim 34.85$ in L03's eddies, while $\theta=4.6-5.2^{0} C$ and $\mathrm{S}=34.9$ in H07's eddies. It is unclear if this variability reflects differences at formation or transformation following formation. The eddies' core radii have been estimated to be $25 \mathrm{~km}$ (Prater, 63]), 15-30 km (L03) and 30-35 km (H07). Their anticyclonic circulation is supported both by the trajectories of Prater's RAFOS floats, by their positive SSH anomaly and agreement of the moored current meter record with a model eddy, and finally by the direct velocity measurements by the glider. The estimated azimuthal velocities are 20-40 $\mathrm{cm} \mathrm{s}^{-1}$ (Prater, 63]), 30-80 $\mathrm{cm} s^{-1}$ (L03) and 50-70 $\mathrm{cm} s^{-1}(\mathrm{H} 07)$.

One important additional feature described by H07 is that the ICAs have a fresh and cold surface layer of approximately $200 \mathrm{~m}\left(\theta \sim 2.5^{0} \mathrm{C}\right.$ and $\left.\mathrm{S} \sim 34.3\right)$. This is consistent with the boundary current structure to the west of Greenland where cold, fresh waters of Arctic origin are found to lay above, and onshore of, the warm, salty Irminger Water (see for example Lazier et al., 45]). At present, it is unclear whether the fresh surface cap was only a feature of the H07 eddies or if such a cap might also have been present in the eddies observed by Prater, [63, and L03 who 1) perhaps documented eddies already modified by the surface fluxes at the time of the observation implying that the freshwater cap had been removed if it existed and 2) were unable to fully resolve the upper part of the water column and would not have been able to detect it in all their measurements.

Two different pathways for eddy propagation from their formation region have been identified: 1) slow southwest drift towards the central Labrador Sea (L03); 2) relatively fast advection within the branch of the Irminger Current which veers off the Greenland slope following the $3000 \mathrm{~m}$ isobath (Prater, 63]; H07, Fig. 2-1). Eddies following the first pathway reach the central Labrador Sea in approximately 2 months, at an average translation speed of $5 \mathrm{~cm} \mathrm{~s}^{-1}$ - consistent with the expansion of the 
EKE maximum towards this region (L03 and Prater, 63]). The second pathway was confirmed by the glider observations that detected three eddies trapped within the westward flowing Irminger Current branch. It is unclear from that study, however, where and if the ICAs leave the boundary current to drift into the basin's interior.

\subsection{ICAs in the hydrographic data}

\subsubsection{Data}

This study utilizes hydrographic data collected in the Labrador Sea from 1990 to 2004. It contains data along the AR7W World Ocean Circulation Experiment (WOCE) line (mostly occupied by the Bedford Institute of Oceanography but also by other groups). Additionally we included a 1998 section collected by E. D'Asaro during the Labrador Sea Deep Convection Experiment (LabSea Group, [39]). Most of the 33 sections in this data set were sampled along the AR7W line but several sections included data collected along slightly different lines (Fig. 2-1). These data, or portions thereof, have been used and described in a number of studies including Lazier et al., 45]; L03; Pickart and Spall, 61]; Rhein et al., 64]; and Yashayaev et al., [82], 83. Most of the sections were occupied in the late spring or summer with the exception of the wintertime sections of 1997 and 1998 and the fall sections of 1996 and 2002.

\subsubsection{Criteria for finding the ICAs}

In this study, ICAs are identified from hydrographic data based on the characteristics described above. Specifically, we rely on the fact that at formation the eddy's properties are similar to those of the Irminger Water found in the current along west Greenland and that they retain this subsurface warm, salty anomaly as they drift into the Labrador Sea's interior (Fig. 2.6). Thus, we identify ICAs by seeking warm, salty and buoyant anomalies in the 200 - $1000 \mathrm{~m}$ depth range, the Irminger Water 
depth range, in hydrographic stations outside of the boundary currents. We require at least one profile separating the boundary current from the prospective eddy profile to avoid describing meanders. Because the properties of both the boundary current and the interior vary considerably both seasonally and interannually (Yashayaev et al., 82]), it does not make sense to look for absolute properties in the Irminger Water density/depth range. Instead, we look for warm $\left(\theta^{\prime} \geq 0.1{ }^{0} C\right)$ and salty $\left(S^{\prime} \geq 0.01\right)$ anomalies that space at least $100 \mathrm{~m}$ in the 200-1000 $\mathrm{m}$ depth range in the individual hydrographic profiles (after a $50 \mathrm{~m}$ low pass filter) with respect to a mean interior profile. The mean interior profile is defined as the spatial average of the temperature and salinity profiles within the $3300 \mathrm{~m}$ isobath (the same definition of interior used by L03, Yashayaev et al., [81] and Straneo, 73]). Note that potential eddy profiles are subjectively omitted when estimating the mean interior conditions. Potential eddies are further visually inspected to ensure that their structure indeed resembles what we expect ICAs to look like, based on earlier studies.

It is noted that these criteria are quite stringent and thus, as shown below, there is little doubt that the anomalies identified are indeed ICAs. More likely, the stringency of the criteria eliminated potential ICAs which were sampled at their edge or were weak enough (for example due to erosion) that their characteristics were no longer truly distinguishable from filaments or decaying coherent eddies. Finally, we note that from the hydrographic data alone it is impossible to establish if an eddy was sampled near its center or on its flank. The studies of H07 and L03, however, show that properties within the eddy are fairly homogeneous over the roughly $30 \mathrm{~km}$ core of the eddy and that the gradients are confined to the narrow eddy boundary of about $7 \mathrm{~km}$. Thus, their findings support the notion that ICAs have a relatively homogeneous core which can be captured by one or two profiles. 


\subsubsection{Eddy Characteristics}

Using the criteria described above, we found 29 ICAs in the hydrographic data whose basic characteristics (including location and time/date when observed) are listed in Table 1. The second column represents the type of eddy as described further in the text: uICA is "unconvected" and cICA is "convected" anticyclones. The core potential temperature and salinity are defined as the properties associated with the subsurface salinity maximum in the IW range in the eddy profile. (Note that the subsurface temperature and salinity maxima are slightly offset both in eddies and in the boundary current with the temperature maximum typically being slightly closer to the surface than the salinity one).

Overall, the eddies were distributed throughout much of the area occupied by the hydrographic sections (Fig. 2-1). Their temperature and salinity anomalies with respect to the interior's mean are shown in Figure 2.6. As evident from these figures, these features are characterized by sizable anomalies in the Irminger Water depth range. The $\theta / S$ characteristics of these ICAs fall between those of the interior of the Labrador Sea and those of the boundary current on the Greenland side (Fig. 2-3). One apparent characteristic of the ICAs is that they are associated with a temperature maximum and a salinity maximum resulting in an "elbow" in $\theta / S$ space (Fig. 2-3) in the Irminger Water range, $\sigma=27.65-27.72 \mathrm{~kg} \mathrm{~m}^{-3}$ range (Pickart et al., [63]). All the ICAs identified in this study exhibited the characteristic "elbow".

The ICAs identified fall naturally into two groups which we refer to as unconvected and convected for reasons that will appear clear shortly. Of the 29 ICAs, 18 were of the unconvected kind while 11 of the convected kind. The properties of the unconvected eddies (uICAs) are quite similar to those of the boundary current, with a fresh (and sometimes cold) layer at the surface and a warm and salty layer at mid-depth. An example of an uICA is shown in Figure 2-4. All the panels display the hydrographic properties of the eddy compared to the properties of the boundary 
current and mean section profiles. The seasonal distribution is such that no uICAs were found in the winter sections.

Convected eddies (cICAs, Fig. 2-5) are defined as those containing at least one mixed layer whose thickness exceeds $100 \mathrm{~m}$ and within which temperature and salinity are homogeneous. The mixed layers observed were up to $800 \mathrm{~m}$ thick and not necessarily located at the surface. This is consistent with what was first documented by L03 who argue that these deep mixed layers have convective origin and speculated that they had subducted underneath the lighter waters leading to vertical stacking of mixed layers. One important finding of this study, whose possible causes and implications are discussed later, is that none of the cICAs have a fresh surface layer. Also, while cICAs were observed in all seasons, they were only found after the winter of 1996-1997.

It is reasonable to assume that the vertical mixed layer is evidence that the convected ICAs have endured at least one winter since formation and that the large wintertime surface buoyancy loss has resulted in a partial homogenization of properties within the eddy followed, in some cases, by surface restratification. This is supported both by the fact that the cICAs contain at least one vertically mixed layer and, in general, that their stratification, in the surface and intermediate depth water masses $\left(\sigma=27.64-27.73 \mathrm{~kg} \mathrm{~m}^{-3}\right)$ is lower than that observed in the uICAs (Fig. 2-6) . The weak stratification is consistent with the fact that the water column is vertically mixed from the surface down during convection. Similarly, the absence of a fresh surface cap, in the cICAs, is also consistent with wintertime convection since this would rapidly lead to the mixing of salty water into the surface mixed layer (as happens in the central Labrador Sea, Straneo, [73]). Further evidence that this class of ICAs has undergone wintertime transformation is provided by the fact that all of the (seven) ICAs observed in winter were cICAs (i.e. contain mixed layers and had no freshwater cap). Likely these eddies were still undergoing transformation while observed. Both eddies observed in the late fall contain a shallow mixed layer (they are also labeled as 
cICAs); likely they have just started experiencing convection. Finally, the two mixed layers observed in one summer ICA may indicate an eddy which may have survived two winters or, perhaps, merging of two convectively modified eddies (as proposed by L03). A more in depth analysis of convection in ICAs is given in the next section.

\subsubsection{Spatial distribution}

The uICAs are found mostly clustered in the proximity of the boundary currents on both the Greenland and Labrador sides of the basin, and only a few are found in the interior, while cICAs are typically found only in the central Labrador Sea (Fig. 2-1). The cluster off the Greenland coast is consistent with the interior eddy pathway 1) described above. These eddies were all observed in the late spring/summer and assuming a drift speed of roughly $5 \mathrm{~cm} \mathrm{~s}^{-1}$ (L03), it would have taken them about 30 to 70 days to reach the locations where they are found. This finding is consistent with their formation during winter (the peak formation period) and their subsequent drifting towards the central Labrador Sea.

Regarding the uICAs observed in the cluster off the Labrador coast (see Fig. 2-1), if they had reached their location by traversing the central Labrador Sea it would have taken them roughly four months, assuming the inferred mean interior drift speed of $5 \mathrm{~cm} \mathrm{~s}^{-1}$. If, on the other hand, these eddies had taken the "rapid route" around the Labrador Sea, pathway 2) described above, in the westward extension of the current which follows the $3000 \mathrm{~m}$ isobath, then their travel time is likely to have been only on the order of two months, assuming speeds in the range of 12-20 $\mathrm{cm} \mathrm{s}^{-1}$ (Lavender et al., [40] and Cuny et al., [12]). Since these eddies were observed in June, it seems unlikely that they could have been formed four months earlier without showing any indication of convective modification. Indeed they contain the freshest surface waters and warmest Irminger Water observed in any ICAs $(\mathrm{S} \sim 33.6-33.9$ at the surface; $\theta \sim 3.96-4.21^{0} \mathrm{C}$ in the IW range) suggesting, if anything, that they have undergone little modification since formation. This finding supports the existence of a second 
pathway for ICAs to propagate into the Labrador Sea's interior. This pathway may provide a rapid, and sizable, input of both heat and fresh water from the west Greenland side to the Labrador Sea's western interior through eddy advection within the current and, eventually, eddy drift into the interior.

\subsection{Wintertime modification of an ICA}

We have identified two types of eddies in the Labrador Sea which we claim to be convected and unconvected ICAs. Here we present evidence that supports the conclusion that cICAs are simply uICAs which have experienced at least one Labrador Sea winter and have undergone convective modification. We show this both qualitatively as well as quantitatively by predicting the evolution of the mixed layer properties in an uICA when subjected to a realistic surface buoyancy loss.

The first circumstantial evidence that cICAs are convectively transformed uICAs is shown in Figure 2-7, where an unconvected eddy observed in October 1996 is compared to a convected eddy from February 1997. Note that these eddies are sampled at different locations so these profiles could belong to the same eddy that moved south between October 1996 and February 1997, or to different eddies. The density profile of the winter eddy is consistent with convective mixing to about $500 \mathrm{~m}$, beyond which the properties of the two eddies are very similar.

We use a mixed layer model to show that the properties of the mixed layers within the cICAs are what one would expect to observe if uICAs were subjected to a realistic surface buoyancy loss. In using a one-dimensional model we are assuming that the large wintertime buoyancy loss drives mostly vertical mixing (as in the Labrador Sea's interior, Harcourt et al., [31]). In addition, it is likely that the coherent nature of the eddies impedes strong lateral mixing during restratification - again supporting the vertical mixing assumption. To investigate the evolution of uICAs during the 
winter of the Labrador Sea we use the one-dimensional model described in Lilly et al., 47] and L03. This model takes an initial profile, a given surface buoyancy flux, and predicts the evolution of both the mixed layer depth and its properties. Model assumptions are that 1) the mixed layer is vertically homogeneous, 2) properties below the mixed layer depth are unchanged with respect to the initial profile and 3) density at the base of the mixed layer is continuous, i.e. the model represents nonpenetrative convective mixing (though both potential temperature and salinity can be discontinuous at the base). The thermal expansion and haline contraction coefficients are allowed to vary as functions of potential temperature and pressure. The surface buoyancy loss over the Labrador Sea, in the winter, is due both to cooling and evaporation. In analyzing the relative importance of either term, from wintertime ship-based observations from the Labrador Sea, L03 found, however, that their ratio is approximately constant. Thus, if one knows the buoyancy and the ratio one approximately also knows how much freshwater was evaporated and how much heat was removed (see L03, Appendix B for a more in depth discussion of the model and its assumptions for the Labrador Sea). Using the uICA as the initial (pre-convection) profiles and $\gamma$, the ratio of the evaporation to the heat flux, one can then estimate the time-varying evolution of the mixed layer and its properties.

The mixed layer evolution for all the sampled uICAs are plotted in $\theta / S$ space in Figure 2-8, together with those of two boundary current profiles from the west Greenland side taken during the fall. We stress that the trajectories represent the progressive change in mixed layer properties as the mixed layer deepens and should not to be confused with the typical $\theta / S$ curves associated with a single hydrographic profile. The initial point of the mixed layer trajectory (indicated by a square) corresponds to the surface properties of the initial profile.

The overall similar shape of the trajectories is due to the fact that the water mass structure in the profiles is qualitatively the same. The different slopes of the curves can be understood by considering that the surface layer of the uICAs is fresh 
and typically warm. Initially, evaporation and heat loss will result in a rapid cooling and, also, in an increase in salinity. As the buoyancy loss continues the mixed layer deepens into the warm, salty subsurface Irminger Water and the mixed layer becomes progressively warmer and saltier (even though the water column has undergone a net heat loss). As the mixed layer deepens beyond the Irminger Water, the mixed layer properties rapidly become colder again - due to the presence of the colder LSW beneath (Fig. 2-8). As evident from these curves, the trajectories associated with the pre-1997 uICAs and the post-1997 uICAs are quite different. After 1997, the mixed layer properties are systematically saltier and warmer.

Each point on the uICAs mixed layer properties trajectories corresponds to a given buoyancy loss. On these curves we next provide a more quantitative estimate of the mixed layer properties one would expect given a realistic buoyancy loss. This buoyancy loss is estimated using the climatological (annual) buoyancy loss curve derived by Straneo, [73] from National Centers for Environmental Prediction (NCEP) reanalysis data. Explicitly, if the uICA is observed in October, for example, we calculate the net buoyancy loss it would experience from October to April (the end of winter) from the climatological flux curve and identify the mixed layer properties associated with this buoyancy loss. The mixed layer properties thus estimated are superimposed on the trajectories for each uICAs (and for two boundary current profiles), Figure [2-8. From the pre/post 1997 division it is apparent that mixed layer properties prior to 1997 are associated with larger densities $\left(\sigma_{\theta}>27.73 \mathrm{~kg} \mathrm{~m}^{-3}\right)$ than those after 1997. The fact that these densities are greater than those of the Irminger Water suggests that convection would have penetrated beyond the Irminger Water layer in these eddies. By erasing the Irminger Water anomaly within the eddy, convection would effectively tend to erode the bulk of the eddy. While we can only speculate at this point - we note that this is consistent with our not finding any cICAs prior to 1997 and suggests that convection may have resulted in their destruction.

The estimated mixed layer properties for the uICAs are next compared to those 
actually observed in the cICAs (in the case of the multiple mixed layers we show the upper one). The observed mixed layer properties fall into two clusters: cluster 1, centered on $\sigma_{\theta}=27.65 \mathrm{~kg} \mathrm{~m}^{-3}\left(\theta \sim 4^{0} C\right)$ and relatively warmer and saltier than cluster 2 centered on $\sigma_{\theta}=27.7 \mathrm{~kg} \mathrm{~m}^{-3}\left(\theta \sim 3^{0} C\right)$, Figure 2-8. Of the two, mixed layers in cluster 2 roughly coincide with those estimated for the end of winter post1997 uICAs. This supports the idea that cICAs from cluster 2 represent convectively modified uICAs formed after 1997. Mixed layers in cICAs from cluster 1, on the other hand, roughly fall in-between the mixed layer trajectories derived for the post 1997 uICAs and the boundary current's mixed layer trajectories. This suggests that, prior to undergoing convection, these eddies' properties were closer to those of the boundary current than the observed uICAs. While we have no direct evidence of it, we can think of several (related) scenarios in which this may happen:

1) The uICA profiles (post-1997) used to initialize the model were mostly observed in late/spring summer and, since they are unconvected, they are all likely to have formed towards the end of the winter/early spring. It is conceivable, therefore, that ICAs formed at a later time may have slightly different properties which, due to our biased sampling, we did not observe.

2) Mixed layer deepening may, in part, have occurred within the boundary current, prior to eddy formation, thus trapping some modified boundary current water.

In summary, this analysis supports the notion that

i) cICAs are effectively ICAs which have undergone wintertime convection and, therefore, that ICAs can indeed survive convection driven by the Labrador Sea's wintertime fluxes.

ii) The fresh cap at the surface of the ICAs is eroded through vertical mixing with the deeper, saltier IW, within the ICA itself.

iii) Wintertime convection can, and indeed often does, reach the Irminger Water layer and thus directly extract heat from this anomalously warm layer within the eddy.

iv) Convection in uICAs prior to 1997 would have likely led to the complete erosion of the Irminger Water anomaly which perhaps explains the absence of the cICAs before 
1997. (We note, however, that our criteria for eddy identification rely on the existence of the IW core, hence we have no way of identifying ICAs in which convection has eroded or greatly modified this layer. The extent to which such eddies can survive convection beyond the IW layer thus remains an open question.)

We stress that we have no evidence that any of the uICA or cICA profiles belong to the same eddy. Indeed, we believe this is overall quite unlikely. Our assumption here, however, is that ICAs form with relatively similar conditions within a specific season of a specific year. Still caution must be taken in interpreting these results since the seasonality of either the boundary current or the ICAs properties is presently unknown. Another uncertainty of these experiments lies in the parameter $\gamma$ used in the model to define the ratio of the water column evaporation-precipitation fluxes to the heat fluxes. We found that our results are not very sensitive to its changes; however, if the mixed layer develops to significant depths, the slope of the evolution curve is different with variations of $\gamma$. Finally, the heat fluxes from NCEP obtained from Straneo, [73, used in the experiments were reconstructed for the central Labrador Sea. To keep the calculations as simple as possible we have ignored the large interannual and spatial variability over the region (Straneo, [73]).

\subsection{Interannual variations of the ICAs}

The central Labrador Sea exhibits a large degree of interannual variability which, in turn, is associated with varying amounts and properties of LSW formed (Yashayaev, [83]). While much of this variability has been attributed to the surface fluxes (Dickson et al., [18] - these alone cannot explain all of the observed variability (L03; Straneo, [73]). A second possible source of variability involves the exchange of heat and freshwater with the boundary current - an exchange primarily carried out by mesoscale eddies. Changes in the lateral fluxes may result from upstream changes in the boundary current's properties, such as the warming and increase in salinity reported by 
Myers et al., 54, and/or from changes in the processes that induce boundary current instabilities (for example changes in the local or remote wind-stress) as manifested by the changes in the eddy kinetic energy off the west Greenland coast reported by Brandt et al., 6]. In both cases, such changes will likely be associated with changes in the number and characteristics of eddies and ICAs, in particular.

The connection between changes in ICAs and changes in the Labrador Sea's interior has been proposed by several investigators to explain the warming observed in 1997. This warming is attributed to an increase in the lateral heat fluxes (Straneo, [73 ) and coincides with an increase in the number of eddies observed as well as changes in their properties (L03). The mechanisms behind this change are unclear but it is known that 1997 was a transition year for the Labrador Sea region. Specifically, the North Atlantic Oscillation (NAO), the dominant mode of interannual variability over the North Atlantic, switched from a positive to a negative phase (Hurrell et al., [35]) which set an end to the extreme surface buoyancy loss (and convective activity) in the Labrador Sea that had persisted from the late 1980s to the early 1990s (Pickart et al., 58; ; Lazier et al., 45]).

Here we investigate the potential role that ICAs play in influencing the Labrador Sea's properties by mapping changes in the ICAs characteristics and properties (both in the absolute sense and relative to the Labrador Sea's interior) over the period 19902004. It is noted that to quantify the lateral heat flux associated with the ICAs one would need to know both the number of eddies formed each year as well as their heat anomaly with respect to the interior. Since neither the satellite nor the hydrographic data can provide us with this information, we instead confine our analysis to a more qualitative discussion of the heat and freshwater content variability observed in the eddies. 


\subsubsection{Water mass property variability}

As described above, 1997 was a year of transition for the Labrador Sea and the subpolar region, in general. Given that ICAs link the boundary current and the interior region, it is not surprising that they too exhibited a marked transition at this time. In this analysis, no convected ICAs were observed prior to 1997. While data coverage does not allow us to conclude that cICAs were not present prior to 1997, it is reasonable to speculate that during the strongly forced earlier period these eddies may have been destroyed by convection during the winter. Indeed, the one-dimensional mixing model presented earlier suggests that convection would have penetrated beyond the Irminger Water layer in the pre-1997 uICAs.

Within uICAs, the layer from 200 to $1500 \mathrm{~m}$ is warmer, saltier and lighter following 1997 (Figs 2-9] and 2-10). Note that this change is not restricted to the Irminger layer alone. It also appears that the post-1997 eddies are warmer in the upper 200 $\mathrm{m}$ however, considering the large seasonal variability in this upper layer, it is difficult to assess if this is a true interannual signal or a result of limited data points.

The shift from strong to weak convection that occurred in 1997 in the Labrador Sea was associated with the formation of lighter vintage of Labrador Sea Water $\left(L S W_{2000}\right)$ than had been formed in earlier years ( $L S W_{1994}$; Yashayaev, [82]; Lazier et al., [45]). Following this change, the deep, older LSW layer progressively shrunk while the lighter, newer LSW layer thickened. Here, we show that a similar transition was going on at depth even within the eddies. The mean thickness of each relevant density class in the unconvected pre-1997 and post-1997 eddies is shown in Figure 2-11. Thickness is defined as the vertical spacing between the isopycnals corresponding to each of the water masses: $\sigma_{\theta}>27.76 \mathrm{~kg} \mathrm{~m}^{-3}$ and down to $2000 \mathrm{~m}$ for $L S W_{1994}$; $27.76 \mathrm{~kg} \mathrm{~m}^{-3}>\sigma_{\theta}>27.72 \mathrm{~kg} \mathrm{~m}^{-3}$ for $L S W_{2000} ; 27.6 \mathrm{~kg} \mathrm{~m}^{-3}<\sigma_{\theta}<27.72 \mathrm{~kg} \mathrm{~m}^{-3}$ for IW; from the surface to $\sigma_{\theta}<27.6 \mathrm{~kg} \mathrm{~m}^{-3}$ for the WGC. Similarly to the interior, the

total LSW layer has decreased in thickness (from $88 \%$ to $74 \%$ ), with a decrease in 
the denser LSW and an increase in the lighter, while the IW layer has grown (from $11 \%$ to $25 \%$ ) at the expense of LSW.

In summary, we have observed that ICAs changed significantly around 1997 and, specifically, that they have become warmer and more buoyant as the Irminger Water layer has thickened at the expense of the LSW layer. In addition, the amount of $L S W_{1994}$ has decreased yielding to the newly formed LSW. These changes are in line with those observed for the interior but had not, to our knowledge, been documented in detail for the eddies. In particular our analysis shows that the anomalies previously reported for 1997 appear to be associated with a shift in eddy properties which persisted past 1997. This finding is in agreement with the trends observed in the Irminger Current along the west Greenland coast, Myers et al., [54].

\subsubsection{Heat and freshwater anomaly variability}

ICAs are warmer, saltier and more buoyant than the interior of the Labrador Sea and as such provide a net heat (and salt) flux to the interior (L03; H07; Straneo, 73]). The magnitude of this flux, amongst other things, is proportional to the heat and freshwater anomaly contained within the eddy with respect to the interior. Here we estimate the interior-eddy heat and freshwater anomaly of uICAs (since no cICAs are observed prior to 1997) during the period 1990-2004.

For heat, we compare the heat contained in the upper $2000 \mathrm{~m}$ of an 'interior water column' with an eddy water column' as follows. The heat content, HC, of a generic water column is defined as:

$$
H C=\rho_{0} c_{p} \int_{-2000}^{0} \theta(z) d z
$$

where $\rho_{0}$ is the reference density $\left(\rho_{0}=1027 \mathrm{~kg} \mathrm{~m}^{-3}\right) ; c_{p}$ is the heat capacity of water at constant pressure $\left(c_{p}=4200 \mathrm{~J} / \mathrm{kg}^{0} \mathrm{C}\right)$. For the interior, the heat content is 
calculated using the horizontally averaged interior profile (eddies removed). Winter sections are omitted, for the sake of a better comparison with the uICAs since these are never observed in winter. For the eddies - we simply calculate the heat content of the eddy profile. As expected, the heat content of the eddies is always larger than that of the interior (Fig. 2-12). Both the interior and the eddy heat content increase from 1990 to 2004 - with the largest increase concentrated around 1997 (Fig. 2-12). While there is considerable scatter, the warming trend in both the ICAs and the interior is comparable, i.e. the heat content anomaly remains relatively constant in time. Thus, in an absolute sense, the net advection of heat into the interior due to a single eddy is relatively uniform in time. It is important to note, however, that the warming of the interior and of the eddy is occurring in different layers. The eddies are primarily warming in the upper layers while the interior is primarily warming in the deeper layers.

Finally, we investigate changes in the freshwater content of both the eddies and the Labrador Sea's interior. We define the freshwater content as:

$$
\Delta F W=h\left(\frac{S_{0}}{S_{n}}-1\right)
$$

where $\triangle F W$ is the amount of freshwater which must be added to an eddy (interior) profile from 1990 (the starting year) to match the vertically averaged salinity (again over $2000 \mathrm{~m}$ ) observed in the eddy (interior) for a given year; $h$ is a thickness of the layer considered; $S_{0}$ is the vertically averaged salinity of the 1990 eddy (mean); $S_{n}$ is the vertically averaged salinity of the given eddy (mean) profile. I find that both the interior and the eddies are becoming saltier (not shown). The observed increase in salinity of the interior is consistent with that described in Straneo, 73], and Yashayaev, 82]. The eddies, which are becoming saltier at a faster rate than the interior, owe their salinity increase primarily to the 200-800 m layer, i.e. the Irminger Water layer. 


\subsection{Summary and discussion}

The annual cycle of convection and restratification of the Labrador Sea involves a vigorous exchange between the interior deep convective region and boundary currents which encircle the basin. This exchange, primarily achieved through mesoscale eddies that form as a result of boundary current instabilities, is a dominant player in the advection of heat into the interior necessary to balance the annual loss to the atmosphere. Also, it acts to modulate convection by controlling the degree of restratification that sets the stage for the following winter's convection. Of the many eddy-types present in the Labrador, one particular kind - the Irminger Current Anticyclones - is thought to dominate the interior/boundary current exchange. Indeed, previous studies suggest that these eddies alone supply up to $90 \%$ of the heat and $50 \%$ of the surface freshwater that seasonally re-stratifies the basin. These eddies are formed by a topography-induced instability of the boundary current system off of the west Greenland coast. They effectively trap and carry warm, salty water of subtropical origin, Irminger Water, into the Labrador Sea and also the fresh surface waters of polar origin.

Notwithstanding their importance for the annual budgets, little is known about how, where and when these eddies release their anomalous heat and salt contents into the Labrador Sea's interior. This is an important question as we try to understand how this convective basin seasonally re-stratifies and what processes govern its interannual variability. In particular, can these eddies survive the large winter heat loss of the Labrador Sea? What controls their variability (in number and properties) and how does it relate to that observed in the Labrador Sea?

In this study we compiled a database of in situ eddy observations by identifying 29 ICAs over 15 years of hydrographic data (from 1990-2004). We found that the ICAs naturally fall into two categories, based on their water mass properties and vertical structure: unconvected eddies and convected eddies. The former have a fresh 
surface layer above the subsurface warm Irminger Water - resembling the stacking of water masses in the boundary current. While two ICAs with a fresh cap had been previously reported, these were located in the boundary current itself; here we document eddies with a fresh cap in basin's interior as well. The convected eddies have at least one mixed layer, whose thickness range from 100 to $800 \mathrm{~m}$. These do not have a fresh surface layer and contain a colder, fresher modified Irminger Water layer.

Generally speaking, unconvected eddies were observed in the proximity of the boundary currents along the Greenland and the Labrador coasts. This is consistent with the existence of two distinct eddy pathways: one from the region of formation (along the Greenland coast) straight into the Labrador Sea's interior and the second around the boundary current, to the Labrador coast, and only then into the Labrador Sea's interior. Eddies associated with the latter pathway appear to have the freshest surface cap which may indicate that they are the youngest ICAs observed. This finding suggests that eddies are an efficient way of preserving and carrying fresh surface and subsurface warm/salty anomalies from the coast of Greenland into the Labrador Sea's interior through multiple pathways.

Through the analysis of the water properties and using a one-dimensional mixing model, it is argued that convected eddies are eddies that have undergone vertical convective mixing during the Labrador Sea's intense winter. This suggests that 1) these eddies can survive, and remain coherent, while undergoing strong water mass transformation and 2) that their exchange with the surrounding water is limited. This is consistent with the numerical simulations of Legg and McWilliams, 46] who found that when a large surface buoyancy loss is applied to a field of baroclinic cyclones and anticyclones, the latter tend to survive while the former tend to be destroyed. The survival of the buoyant anticyclones to the wintertime surface buoyancy loss, in turn, has several important implications for when and where the anomalous heat and salt of the eddy are released. 
First, winter convection mixes the surface fresh layer into the underlying Irminger Water thus partially neutralizing the eddy's salinity anomaly with respect to the surroundings. Thus, it seems unlikely that these eddies may contribute to the seasonal freshwater restratification of the surface layer, known to occur in the spring, if their fresh layer is effectively removed in the winter. Second, the eddy's anomalous heat content can be directly removed by the atmospheric heat loss without being first mixed into the surrounding interior waters.

A clear change in eddy properties occurred following the winter of 1996-1997 when the Labrador Sea switched from a strongly convecting decade to a weakly convecting decade. Specifically, no convected eddies were found prior to 1997, and post-1997 unconvected eddies contain a thicker, warmer, more buoyant layer of Irminger Water. The heat content increase observed in the eddies is occurring at the same rate as that observed in the Labrador Sea's interior. It is speculated here that changes in the eddies are indicative of changes that are occurring over the larger scale of the subpolar gyre. In particular, it is likely that no convected eddies were observed during the strong convection period since they may have been destroyed by the large surface fluxes. Furthermore, the changes in the eddies are consistent with those reported in the boundary currents around the basin. 


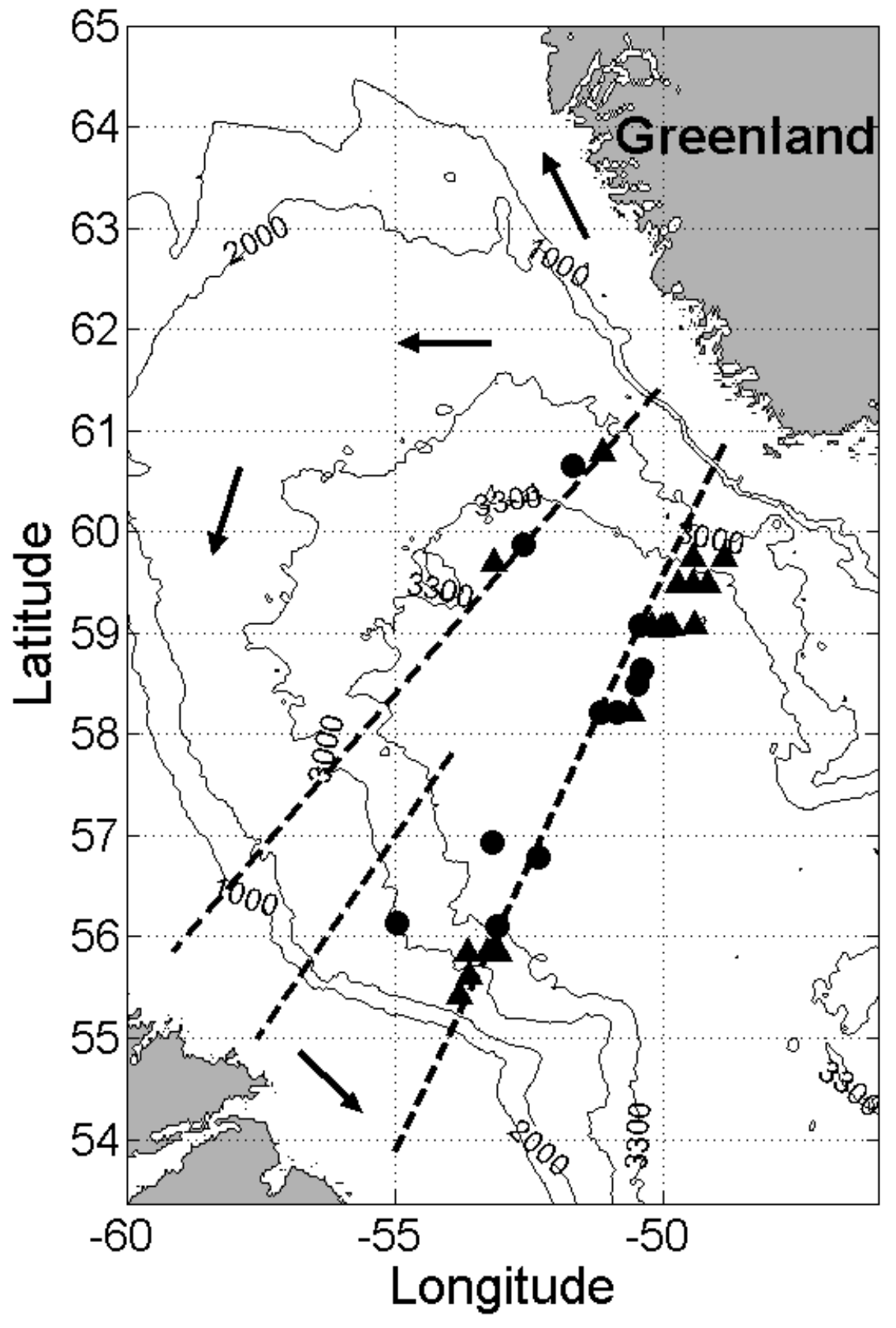

Figure 2-1: Schematic circulation of the Labrador Sea overlaid on the bathymetry (thin black lines with numbers indicating the depths of 1000, 2000, 3000 and 3300 $\mathrm{m})$. The southernmost section (AR7W) and the other two sections occupied are shown by the thin dashed lines. The West Greenland Current (WGC) is shown by a solid line, the Irminger Current (IC) by a thick dotted line, and the Labrador Current is shown by a thick dashed line. Arrows represent the direction of the flow. The star marks the approximate location of eddy formation. Symbols indicate the locations where the ICAs were found. Convected ICAs are identified by circles and unconvected ICAs by triangles. 

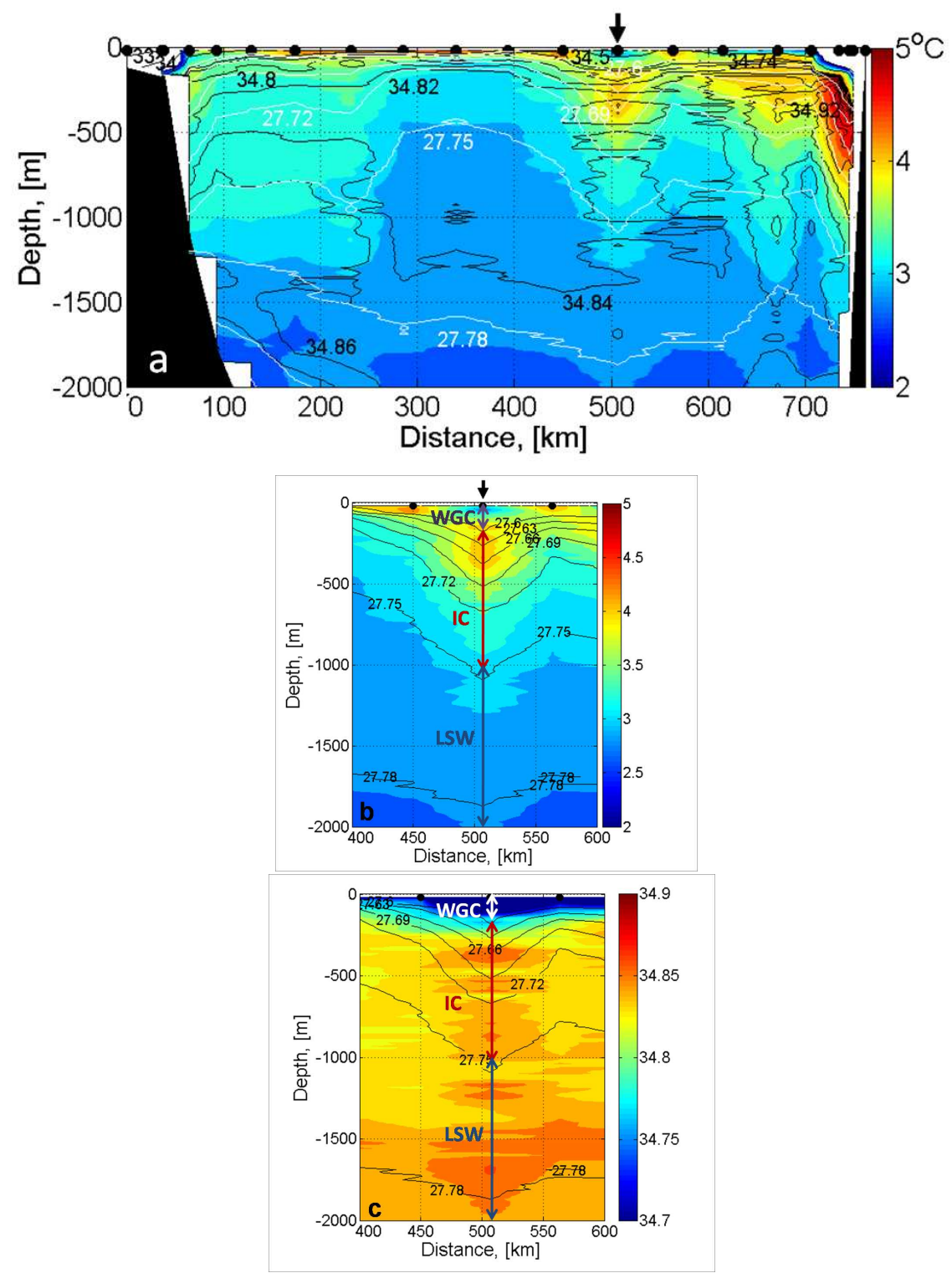

Figure 2-2: a) A hydrographic section of potential temperature $\theta$ (color), salinity (black contours) and potential density (white contours) across the Labrador Sea sampled in May 1997. The arrow marks the location of an ICA. b) Potential temperature and c) salinity in the ICA (May 1997) with arrows indicating different water masses and black dots representing positions of the hydrographic stations. 

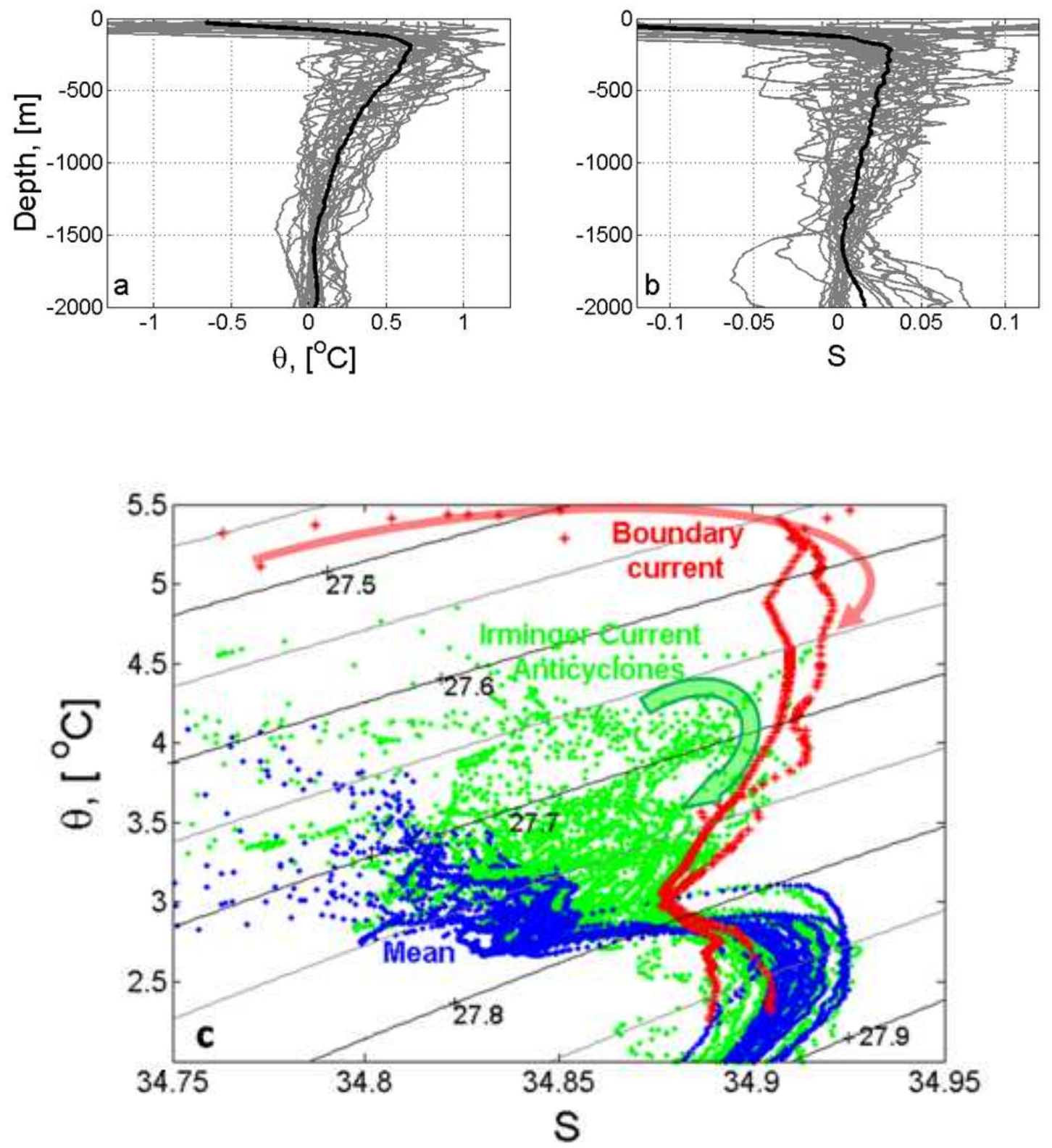

Figure 2-3: Characteristics of the ICAs: a) potential temperature and b) salinity anomalies (gray) for all ICAs relative to the interior (see text); the average anomaly is shown in black; c) $\theta / \mathrm{S}$ diagram for ICAs (green), Labrador Sea interior (blue) and two typical profiles from the West Greenland Current (red). The arrow indicates schematically the elbow in $\theta / \mathrm{S}$ space associated with the ICAs. 

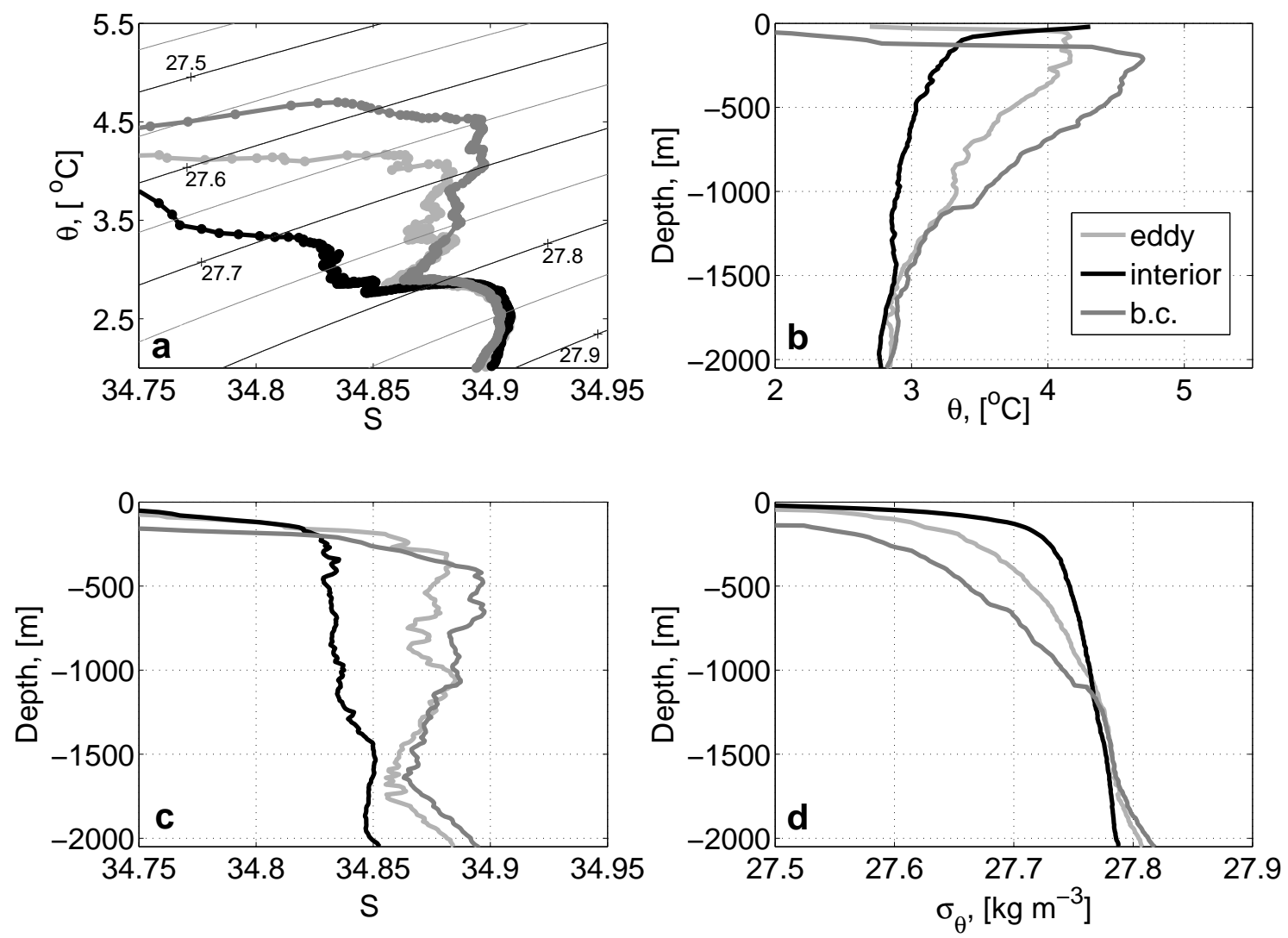

Figure 2-4: a) $\theta$ /S diagram; b) potential temperature; c) salinity; and d) potential density for the unconvected eddy observed in spring of 1997 (gray), the interior (black), and the boundary current (dark gray). 

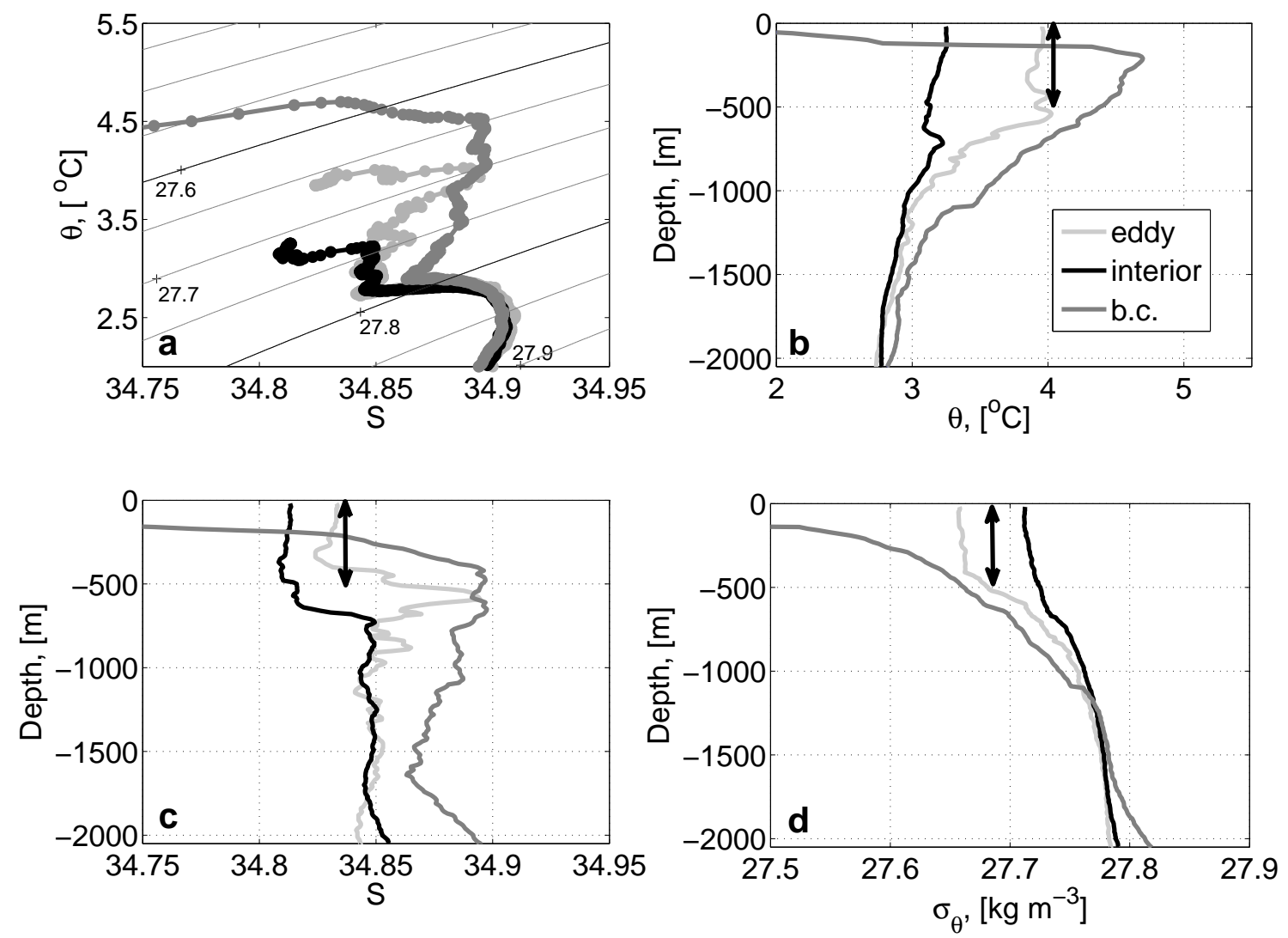

Figure 2-5: A convected eddy observed in winter of 1997. a) $\theta$ /S diagram; b) potential temperature; c) salinity; d) potential density in the eddy (gray), interior (black) and boundary current (b. c., dark gray). The mixed layer in the eddy is indicated with an arrow. 


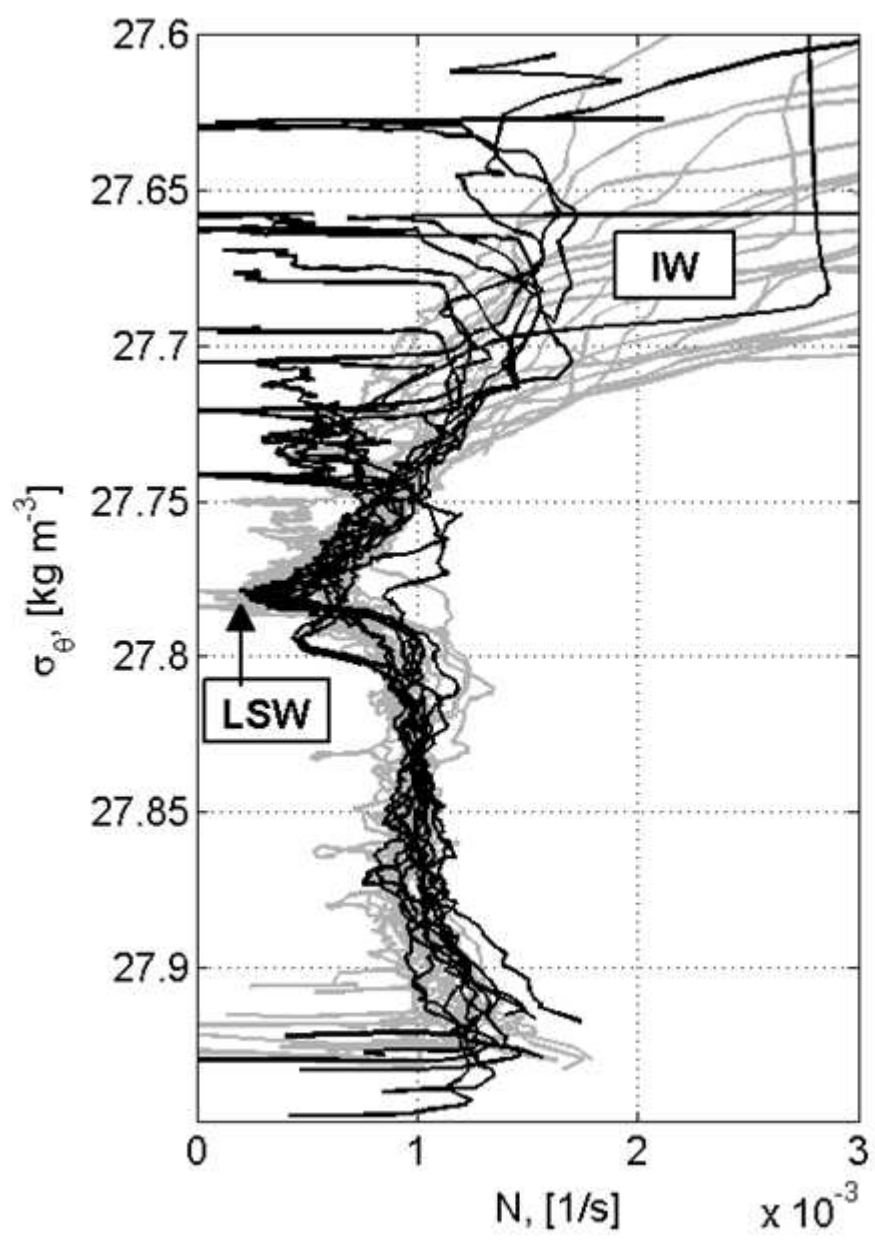

Figure 2-6: Buoyancy period in convected (black) and unconvected (gray) ICAs as a function of potential density. Boxes indicate approximate location of Irminger Water (IW) and Labrador Sea Water (LSW) in the ICAs (see text for the definition). 


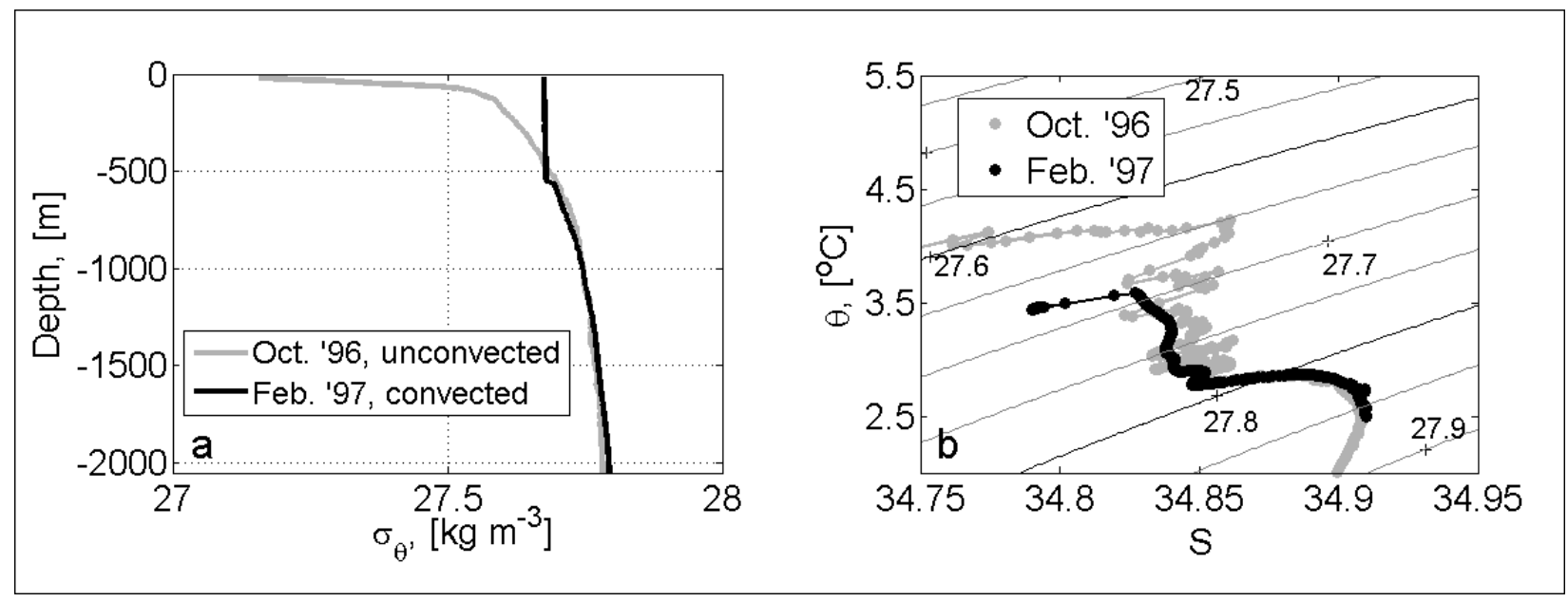

Figure 2-7: a) Potential density (left) and $\theta$ /S diagram (right) of a convected (Feb. 1997) and an unconvected (Oct. 1996) ICA. 


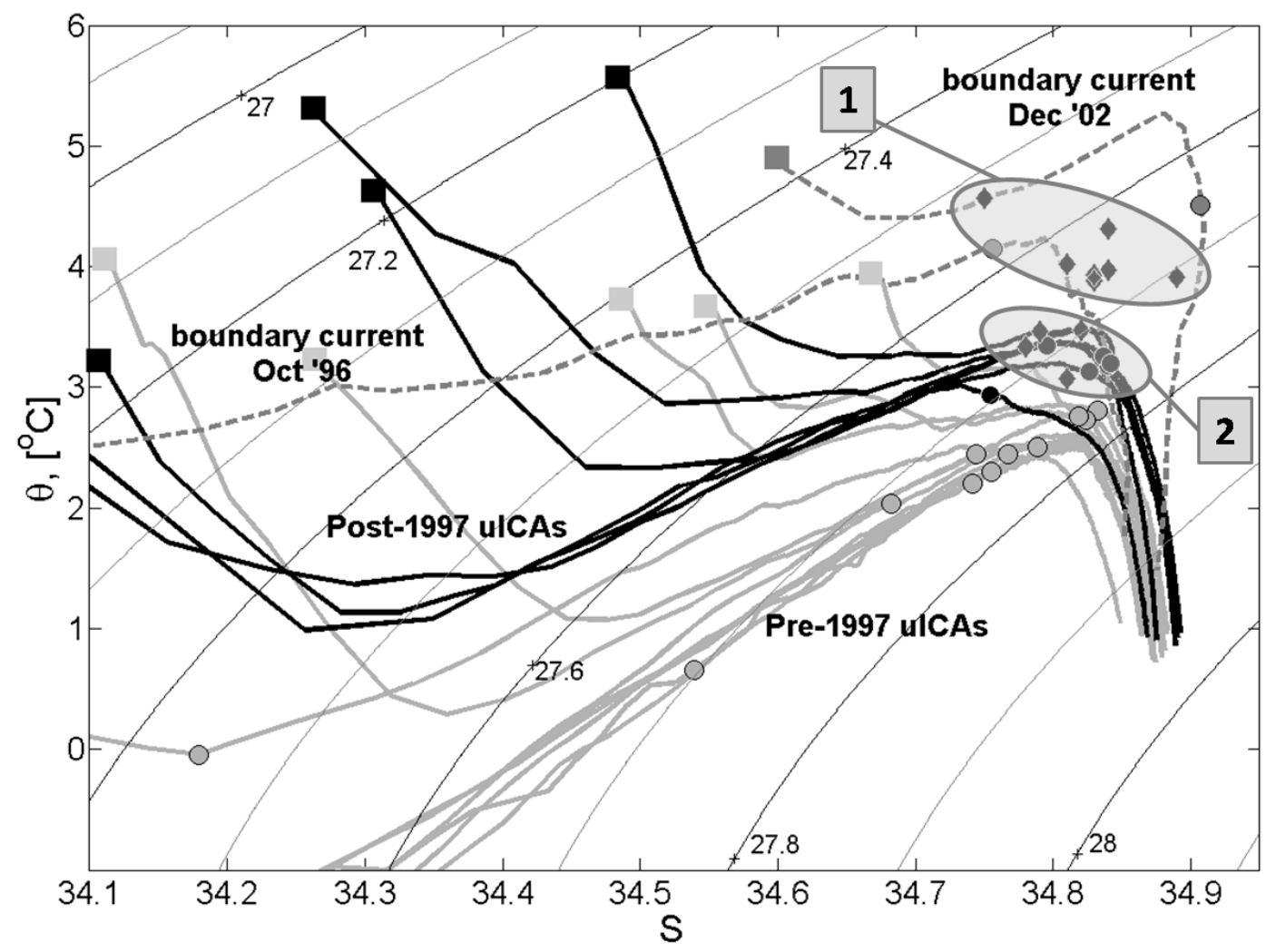

Figure 2-8: Unconvected pre-97 (light gray), post-97 (black) ICA and boundary current (dark gray dashed) mixed layer evolution trajectories. Diamonds show the properties of observed mixed layers in cICAs while the circles on each trajectory indicated the estimated mixed layer properties given a realistic buoyancy loss (see text). The squares mark the surface initial conditions for each profile. The shaded ellipses indicated the two clusters of cICAs described in the text. 


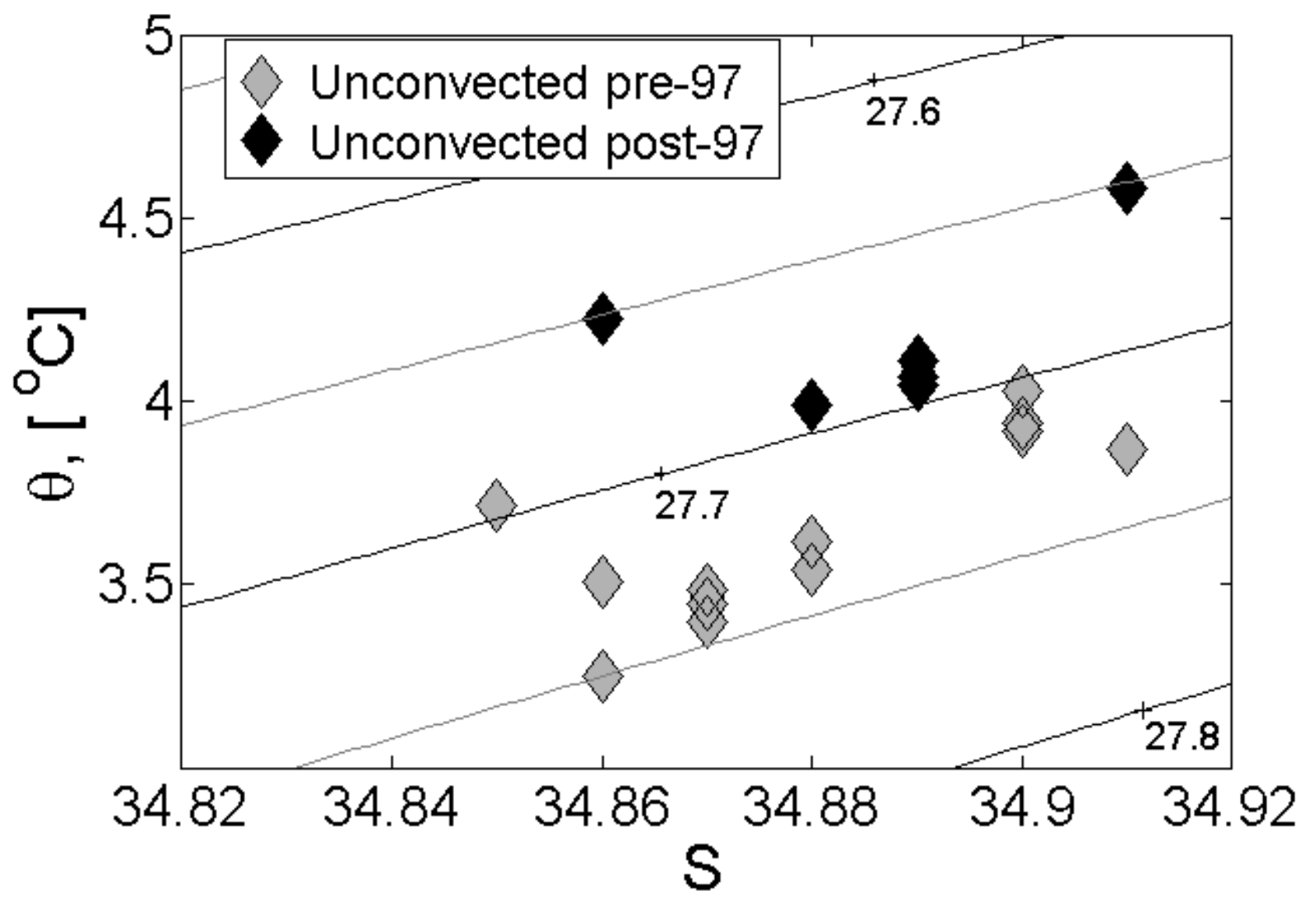

Figure 2-9: $\theta$ /S diagram showing the core properties of the unconvected ICAs. Color shows the time of observation: pre-1997 (gray) and in 1997 and after (black). 

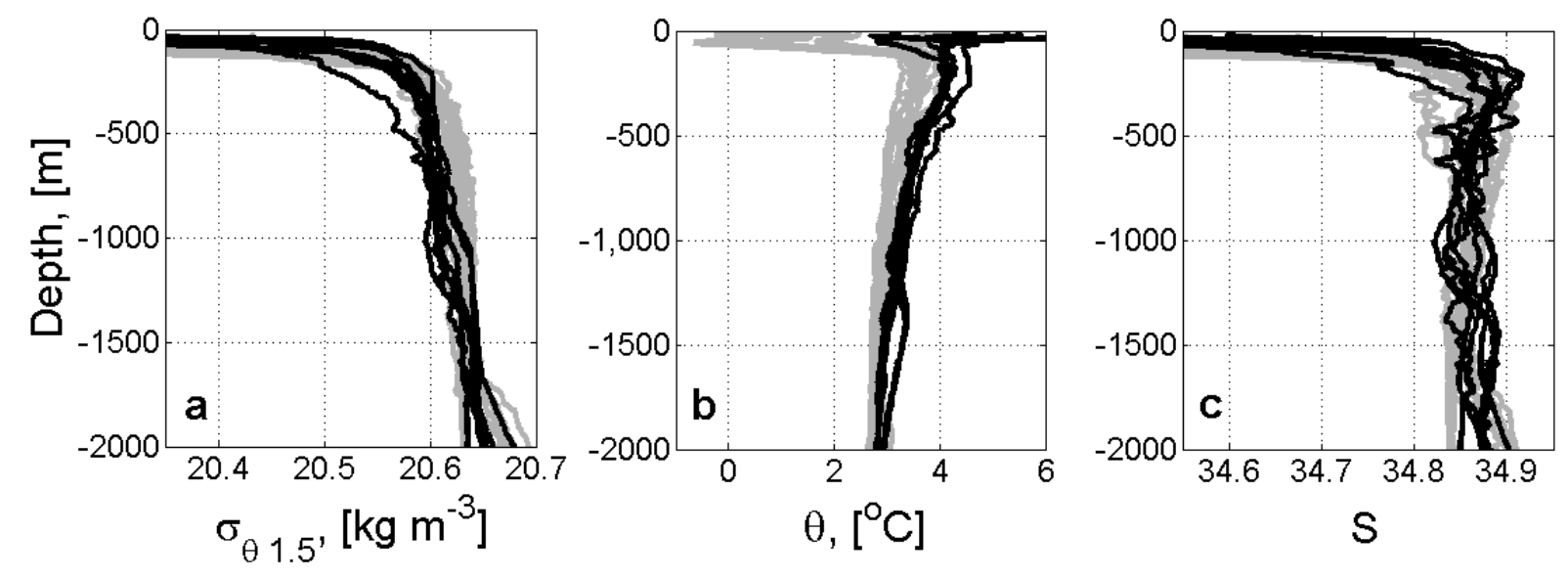

Figure 2-10: Unconvected ICAs observed pre-1997 (gray) and post-1997 (black): a) potential density referenced to $1500 \mathrm{~m}$; b) potential temperature; c) salinity. 


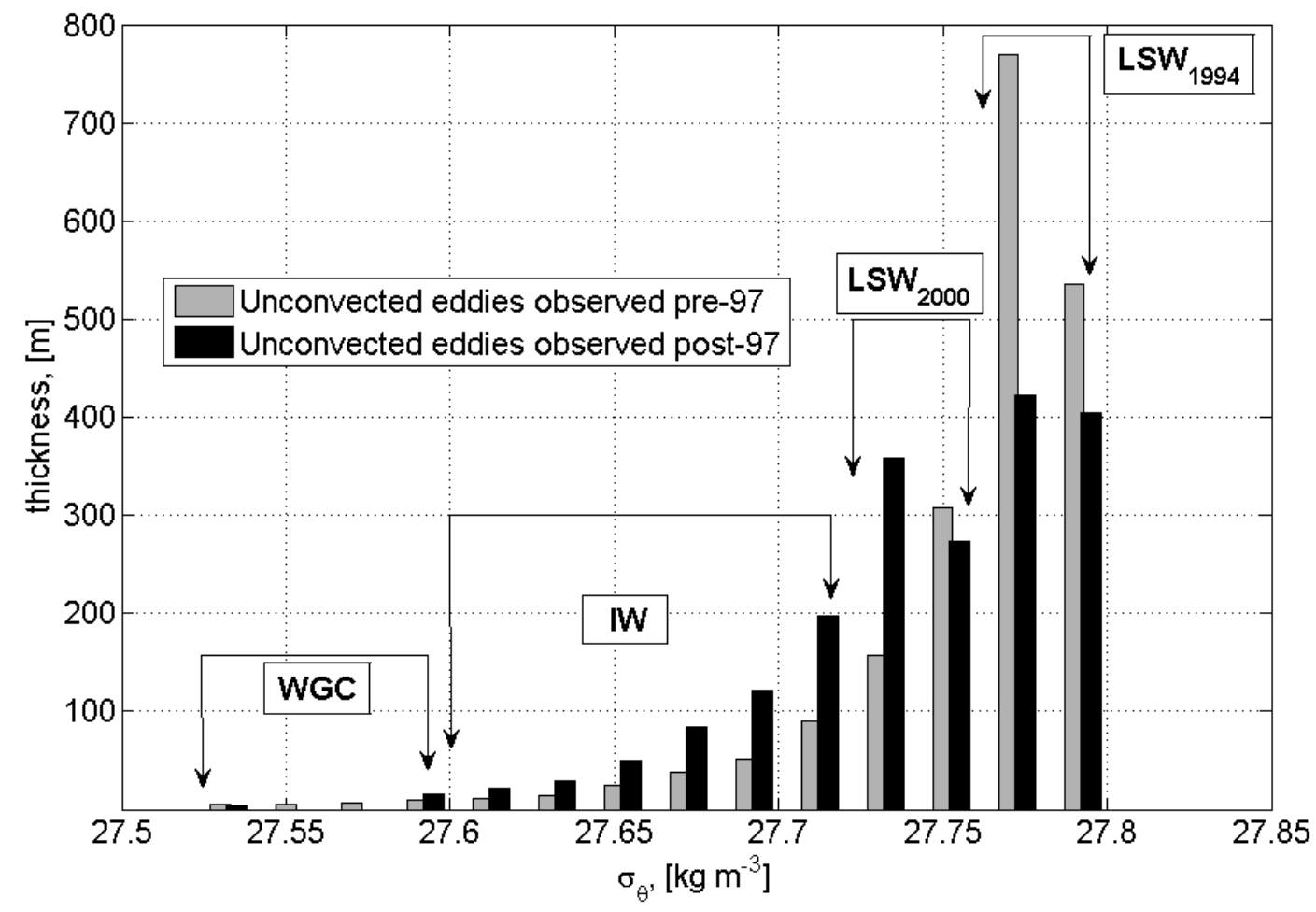

Figure 2-11: Layers' thickness in the unconvected ICAs (gray: pre-1997 and black: post-1997). The principal water masses and their density ranges are labeled. 


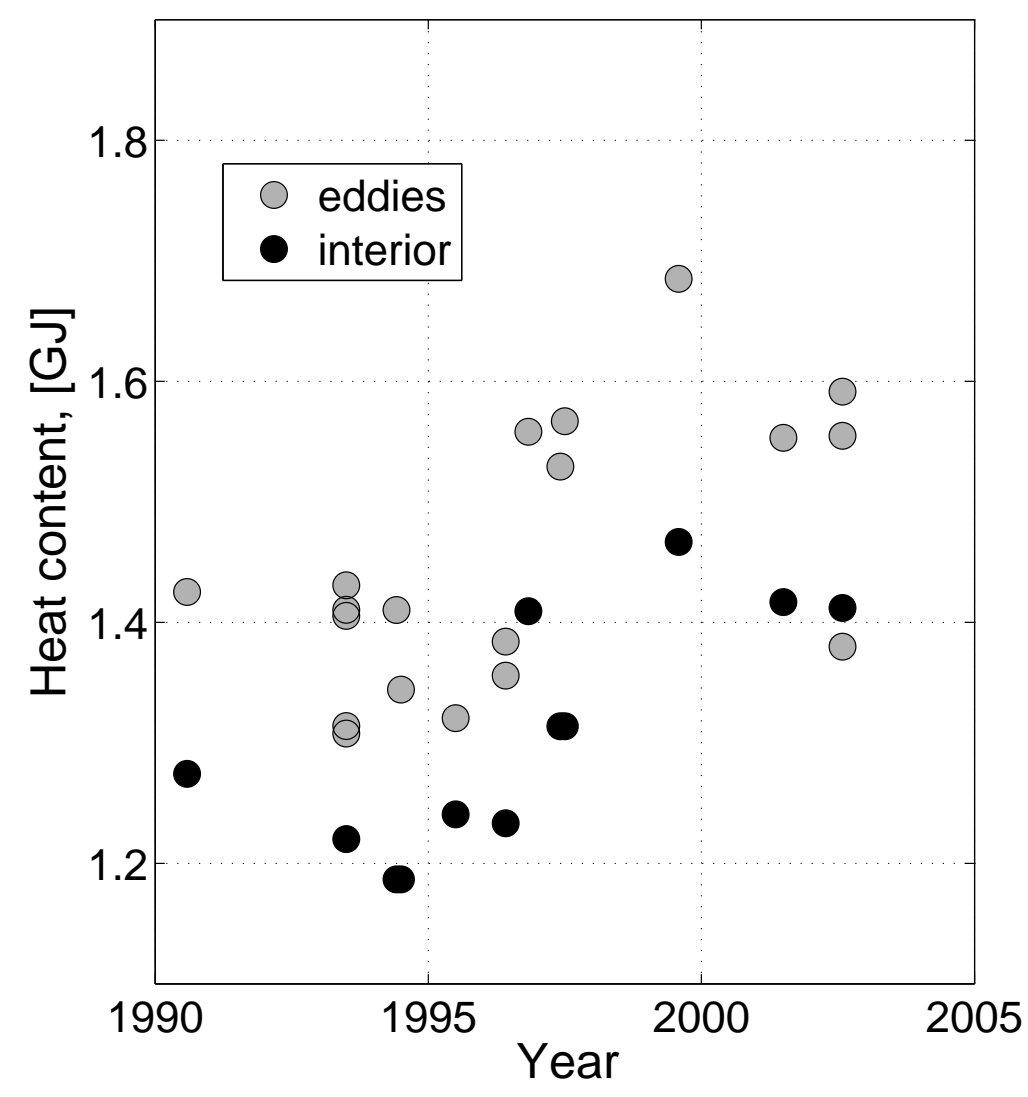

Figure 2-12: Heat content as a function of time in the interior and in the ICAs. 
Table 1. Properties of the unconvected (uICAs) and convected (cICAs) eddies. The cICAs belonging to different clusters are indicated by I and II (see text for clarifications).

\begin{tabular}{|c|c|c|c|c|c|c|c|}
\hline Number & $\begin{array}{l}\text { Type } \\
\text { of ICA }\end{array}$ & Longitude & Latitude & Year & Month & Eddy Core $S$ & Eddy Core $\theta$ \\
\hline 1 & uICA & -49.44 & 59.49 & 1990 & 7 & 34.90 & 3.96 \\
\hline 2 & uICA & -53.37 & 55.78 & 1993 & 6 & 34.91 & 4.21 \\
\hline 3 & uICA & -53.11 & 55.97 & 1993 & 6 & 34.90 & 4.28 \\
\hline 4 & uICA & -49.94 & 59.06 & 1993 & 6 & 34.87 & 3.62 \\
\hline 5 & uICA & -53.39 & 55.84 & 1993 & 6 & 34.90 & 4.21 \\
\hline 6 & uICA & -49.47 & 59.45 & 1993 & 6 & 34.87 & 3.61 \\
\hline 7 & uICA & -49.16 & 59.75 & 1994 & 5 & 34.88 & 3.80 \\
\hline 8 & uICA & -53.82 & 55.42 & 1994 & 6 & 34.88 & 3.70 \\
\hline 9 & uICA & -49.95 & 59.06 & 1995 & 6 & 34.86 & 3.51 \\
\hline 10 & uICA & -50.88 & 58.22 & 1996 & 5 & 34.86 & 3.32 \\
\hline 11 & uICA & -49.95 & 59.06 & 1996 & 5 & 34.85 & 3.21 \\
\hline 12 & uICA & -53.63 & 55.61 & 1996 & 10 & 34.87 & 3.44 \\
\hline 13 & cICA (I) & -52.34 & 56.78 & 1996 & 11 & 34.85 & 4.49 \\
\hline 14 & cICA (I) & -52.61 & 59.88 & 1997 & 2 & 34.89 & 4.02 \\
\hline 15 & cICA (I) & -51.70 & 60.65 & 1997 & 2 & 34.90 & 4.31 \\
\hline 16 & cICA (II) & -54.97 & 56.13 & 1997 & 2 & 34.86 & 3.35 \\
\hline 17 & cICA (II) & -50.87 & 58.22 & 1997 & 3 & 34.83 & 3.38 \\
\hline 18 & uICA & -53.17 & 60.78 & 1997 & 5 & 34.86 & 4.23 \\
\hline 19 & uICA & -51.15 & 59.75 & 1997 & 6 & 34.88 & 4.15 \\
\hline 20 & cICA (II) & -53.11 & 56.11 & 1998 & 2 & 34.84 & 3.65 \\
\hline 21 & cICA (II) & -53.20 & 56.94 & 1998 & 2 & 34.84 & 3.59 \\
\hline 22 & $\operatorname{cICA}(\mathrm{I})$ & -50.88 & 58.22 & 1998 & 2 & 34.88 & 4.05 \\
\hline 23 & cICA (I) & -50.41 & 58.64 & 1998 & 7 & 34.85 & 4.31 \\
\hline 24 & uICA & -49.17 & 59.75 & 1999 & 7 & 34.91 & 4.58 \\
\hline 25 & uICA & -49.47 & 59.49 & 2001 & 6 & 34.89 & 4.13 \\
\hline 26 & uICA & -49.93 & 59.07 & 2002 & 7 & 34.89 & 4.12 \\
\hline 27 & uICA & -49.47 & 59.84 & 2002 & 7 & 34.89 & 4.13 \\
\hline 28 & cICA (I) & -49.94 & 59.07 & 2002 & 12 & 34.87 & 4.85 \\
\hline 29 & $\operatorname{cICA}(\mathrm{I})$ & -50.51 & 58.50 & 2004 & 5 & 34.89 & 4.31 \\
\hline
\end{tabular}




\section{Chapter 3}

\section{West Greenland Current system: seasonal and interannual variability}

\subsection{Introduction}

The primary aim of this chapter is to understand the changes that occur in the boundary current system, the main contributor of heat and fresh water for the whole Labrador Sea, on both seasonal and interannual time scales. The importance of the boundary current system for the restratification and ultimately, the properties of LSW, has been recognized for some time but the detailed systematic study of both components and the changes that they undergo has been missing up to the present study.

Here I document structural and property changes in the boundary current using a larger data set than used in any of the previous studies which gives me a better temporal and spatial coverage. My goal is to understand how the changes in the boundary current on different time scales influence the interior of the Labrador Sea and therefore what role they play in modulating convection.

In this chapter, I present the first seasonally weighted climatology and study the seasonal and interannual variability of the West Greenland Current boundary current 
system at the entrance into the Labrador Sea using a combination of hydrography and satellite altimetry measurements. In section 2, I discuss the data products used to compute the absolute velocities. In section 3, I describe the mean climatological sections as well as the seasonal and interannual variability of the boundary current system. Each of these three subsections of the chapter are organized in a similar way: they start with the analysis of the satellite altimetry product which is then complemented by the analysis of the hydrographic data. Section 4 focuses on the uncertainties and major sources of errors that originate both from the hydrographic data and gridded satellite altimetry product. A summary of this section together with some possible explanations for the observed variability is offered in section 5 .

\subsection{Data}

Two complementary data sets are utilized in this study: hydrography and satellite altimetry.

\subsubsection{Hydrographic data}

Hydrographic data used for the analysis is a combination of three data sets covering different time periods: 1) Bedford Institute of Oceanography, from 1990 to 2004 (described in Chapter 2); 2) HYDROBASE, from 1987 to 2007 (HYDROBASE website: http://www.whoi.edu/science/PO/hydrobase/, maintained by R. Curry); and 3) International Council for the Exploration of the Sea (ICES) data base from 1963 to 1997. Each of three data sets was quality controlled and the spurious measurements were removed. Then all the data were interpolated onto a regular grid with the vertical resolution of $10 \mathrm{db}$. From all the data sets I have extracted sections that cross the boundary current within a $100 \mathrm{~km}$ distance of the WOCE AR7W line (defined in Chapter 2) and extend from about $30 \mathrm{~km}$ offshore to about $200 \mathrm{~km}$ into the interior of the Labrador Sea (see schematic in Figure 1-1). Of all 67 available sections, I use a subset of 18 sections starting from 1992 for which reliable altimeter data is avail- 
able (Figure 3-1). The spatial resolution of each hydrographic section is different and varies from the coast to the interior with generally higher resolution in the boundary current and lower resolution towards the interior. The methodology used to project the hydrographic sections on the regular grid is described in Appendix A.

In this study, as opposed to most previous studies, which were mainly based on the hydrographic data from spring and summer seasons (Stein, [70]; Myers et al., [54]), I also use data from the fall and winter. The monthly and yearly distribution of the sections is shown in Table 1.

\subsubsection{Satellite altimetry data product}

Satellite altimetry data are used in this study to obtain surface velocity fields across the boundary current. The data product used is the gridded absolute surface geostrophic velocity product from Archiving, Validation, and Interpretation of Satellite Oceanographic (AVISO) website, http://www.aviso.oceanobs.com/. The satellite altimetry measurements cover the time period from October 1992 to January 2008 and consist of the data products from TOPEX-Poseidon, ERS-1, ERS-2, Jason-1 and ENVISAT missions combined together and interpolated onto a regular $1 / 3^{\circ}$ grid. From the variety of AVISO products I have chosen to use the delayed mode gridded absolute geostrophic velocities that are referenced to the mean state of the current for 19922007. This choice was motivated by the limited availability of the along-track product at the location of AR7W at the times of the hydrographic measurements. The maps of the absolute surface velocity gridded product are available every 7 days.

Besides the difference in the temporal resolution between the along-track and gridded products, the spatial coverage of the gridded one has larger uncertainties. For example, depending on the location of the chosen area of study and the algorithm used for the objective mapping of the data product, one can get very different values of SSH between the along tracks. I compared the gridded product with the along-track data 
before the beginning of the analysis (without knowing what algorithm has been used in the gridding process) in order to roughly estimate how different these products are in this geographical region. First, since the altimeter product is generally inaccurate along the tracks propagating from land to the ocean on the scales on the order of 100 km (personal communication, Le Traon, 2008), I made sure that all tracks, sampling the boundary current, ascend from the Labrador Sea interior towards Greenland. Then, to evaluate the accuracy of the gridded data product, I compare the gridded SSH with the along-track SSH data product for several arbitrarily chosen dates and find that they do not differ by more than $10 \%$. The largest differences occur at the position of the boundary current front and are due to the fact that the gridded data product is much smoother than the along-track one. Note that I compare the originally downloaded SSH products first instead of comparing the absolute velocity fields due to the fact that there is no along-track absolute velocity product provided by the AVISO team. Further, I compute the absolute velocity myself to verify the agreement between the gridded and along-track products.

I compute velocity from the along-track SSH data and compare it to the absolute surface velocity from the gridded data product for several arbitrarily chosen times. The example shown in Figure 3-2 provides a picture of the typical comparison and shows that the along-track velocity has more variability on small scales. It also shows that the along-track data has higher velocity values at the location of the boundary current front. This example, however, is based on a single satellite data product, and thus, provides less accurate result than the combination of several satellites generally used in the gridded data product (Ablain et al., [1]).

There are several sources of errors in the absolute velocity estimated from satellite altimetry. They originate from the uncertainties in the satellite performance such as the measurement noise, the wave height contribution, the tidal and orbit errors $(\mathrm{Fu}$ et al., 24]; Fu and Cazenave, 25]). Another significant error especially in the coastal areas (closer than $100 \mathrm{~km}$ from the shore) originates from the atmospheric forcing. Most of these errors are substantially reduced as a result of the data processing by 
the AVISO team who compute the atmospheric corrections, minimize the errors via various fitting and filtering (M.-I. Pujol, personal communication, 2010, and AVISO product documentation). The pressure and tidal effects are also taken into account (thanks to the fact that there are two tidal gauges on the Greenland coast on both sides from AR7W) during the data processing stage and the error maps are provided for each of the gridded fields. The merging of the along-track data from different satellites and its gridding is based on the objective analysis that allows producing not only the gridded fields themselves but also the corresponding mapping error fields. The errors originating from the approximations due to the geostrophic balance assumption in calculations of the velocity fields are added to the uncertainties mentioned above. The maps of these errors are produced for each gridding and are represented in percent of the signal variance that allows us to estimate the relative error as a result of the mapping process.

The limitations of the absolute velocity gridded product for the region of the boundary current system in the Labrador Sea include: i) the limited accuracy near the shore (in the boundary current region the product is reliable until about $30 \mathrm{~km}$ from the coast, which in the geographical area of study means the depth on the order of $200 \mathrm{~m})$; ii) the spatial limitations due to the horizontal resolution of $1 / 3^{0}$ that does not allow us to resolve the exact position and width of the front; iii) the weekly availability of the gridded product and thus, rare coincidence in time with the instantaneous hydrographic measurement.

The reader is referred to the section 4 of this chapter for the discussion of the AVISO limitations as well as the other uncertainties of the present study. Here I attempted to prepare the reader for the analysis by outlining some of the uncertainties that the original data have. For now, we assume that the signal that exists in the satellite data product is real and we can use AVISO in the analysis. 


\subsection{Results}

Combining AVISO and the hydrographic data sets, I investigate the seasonal and interannual variability of the boundary current system. First, I compute the climatological mean for 1992-2008, and then document the seasonal and interannual changes in both hydrographic properties and velocity field. Finally, I discuss the possible implications of these findings for the lateral fluxes and interior of the Labrador Sea.

\subsubsection{Climatology}

AVISO

High accuracy satellite altimetry which became available continuously since 1992 provides a unique tool for studying the seasonal and interannual variability of the ocean circulation. In the Labrador Sea, where shipboard data are sparse and difficult to obtain in the winter, satellite altimetry is especially valuable. In this study I examine both seasonal and interannual variability of the Labrador Sea boundary current using satellite data over the period from 1992 to 2008.

The absolute velocity obtained from the satellite altimetry product and interpolated onto the AR7W line is shown in Figure 3-3 (the method is described in Appendix A). The mean distribution of the surface velocity is defined as

$$
\bar{u}(r)=\frac{1}{T} \int_{0}^{T} u(t, r) d t
$$

where $\mathrm{u}$ is the velocity component across the AR7W line, $\mathrm{r}$ is the distance from the coast along the AR7W line, $\mathrm{t}$ is time, $\mathrm{T}$ is the period of time from October 1992 to January 2008 (Figure 3-3). The mean current has an offshore maximum of $30 \pm$ $4 \mathrm{~cm} \mathrm{~s}^{-1}$ centered around $50 \mathrm{~km}$ from the shore. Velocity decreases rapidly towards the land and somewhat less rapidly towards the interior. The maximum velocity of the individual profiles can reach $60 \mathrm{~cm} \mathrm{~s}^{-1}$. The width of the current, defined as the 
distance from the coast to where the mean northward flow becomes zero, is $150 \mathrm{~km}$. This value is in the agreement with the description of the current based on surface drifters (Cuny et al., [12]).

\section{Hydrography}

The surface velocity structure provides an incomplete picture of the full velocity field and contains little information about the properties of the boundary current. Despite obvious advantages of AVISO such as its high temporal resolution it cannot replace the hydrographic data that provide invaluable two-dimensional picture of the boundary current. Here I analyze historical hydrographic data to put the observed surface changes into a systematic context.

In order to justify that the hydrographic climatology based on 18 sections is representative of the mean state of the current, I compare the climatology of the surface current based on all the available surface velocity profiles to the one obtained from the 18 profiles that correspond in time to the hydrographic measurements (Figure 3-4).

The satellite altimetry data product shows that the subset of the measurements is able to reasonably reproduce the mean state and seasonal variability (not shown) of the current. Based on the satellite data product I assume that available hydrographic sections spanning from 1992 to 2008 and covering spring and fall (spring includes the months from April to September and fall includes the months from October to March of the following year) are representative of the mean boundary current state. As the results below show, AVISO supports the representativeness of the available hydrographic data for the 1992-2008 climatological mean.

\section{Properties}


We start our analysis by presenting a 15-year climatological mean to introduce the general features of the boundary current system. In order to eliminate the seasonal bias, we compute the climatological mean by calculating the spring and fall seasonal means first, and then averaging the two together. The season definition is based on the availability of the hydrographic data and supported by the seasonality of the surface current observed from the satellite data product. There are two major differences between the climatology presented here and the climatologies from the previous studies (Stein, [70]; Pickart and Spall, 61]; Myers et al., [54], 55]). The first is the addition of the winter and fall data that turned out to significantly change the average. The second important difference is the method of the absolute velocity field computation. In the present work the relative geostrophic velocity for each of the sections is referenced to the absolute velocity at the surface obtained from AVISO product (see Appendix A for detail). Previous studies referenced velocity to the model outputs (Myers et al., [54, 55]), to the mean velocity from the float data for 1994-1999 (Pickart and Spall, 61]) and Acoustic Doppler Current Profiler (ADCP) data (Hall and Torres, 29]).

There are several water masses that one can identify in the hydrographic section of the boundary current (Figure [3-5). The cold and fresh surface water belongs to the West Greenland Current that carries Polar Water (PW) from the Arctic (Lazier et al., 45], Cuny et al., [12; Stein, 70]) that lies above and onshore of the warm and salty Irminger Water (IW) (Cuny et al., [12] Stein, [70]) originating from the Subtropical Gyre. The interior portion of the section contains Labrador Sea Water (LSW) at roughly 500 - $1500 \mathrm{~m}$ (Yashayaev, 82 ). The bottom part of the section is occupied by the North Atlantic Deep Water including the water masses from the Nordic Seas (not shown). Both in the mean and in the majority of the individual sections one sees a local surface offshore temperature maximum that is separated from the boundary current (at about 180-200 km offshore). The absolute velocity section (Figure 3-5) shows that the West Greenland and Irminger Currents are indistinguishable in velocity (in the data I am using) but can be separated by their hydrographic 
properties. Velocity is on the order of $30-35 \mathrm{~cm} \mathrm{~s}^{-1}$ and decays with depth. At the depth of the Irminger Current, velocity is $10-20 \mathrm{~cm} \mathrm{~s}^{-1}$ consistent with the previous estimates based on float data (Lavender et al., [41]). The offshore portion of the current is remarkably barotropic, similar in values to the one described by Pickart and Spall, 61]; and to the individual sections of Hall and Torres, 29].

The climatological Irminger Current over 1992-2007 (Figure 3-5) is warmer, saltier and lighter than the average section computed from the springtime data alone. This is explained later by comparing the spring and fall sections. The standard deviation of the mean (Figure [3-6) is the largest at the surface where the seasonal cycle is the strongest.

The large seasonal and interannual variabilities of the Irminger Current properties make it difficult to define its core. If the definition is based on the fixed values of temperature and salinity (e.g. Myers et al., 54 who defined the Irminger Current as the water with $\theta>3.5^{\circ} \mathrm{C}$ and $\mathrm{S}>34.88$ ) then it includes some Labrador Sea Water in case of the warmer average conditions. If the definition is too stringent, for example, $\theta \sim 4.5^{0} \mathrm{C}$ (Cuny et al., [12]), then the deeper portion of the Irminger Current is not included in the mean. In an effort to build a robust definition I tried to use various combinations of temperature and salinity gradients, velocity, and potential vorticity. I individually analyzed all the hydrographic sections taking into account the seasonality and interannual changes as well as the difference between the depths of the temperature and salinity cores. In the end, after a careful analysis, I decided that the most appropriate definition for Irminger Current is the water mass bounded by the West Greenland Current's lower isohaline of 34.4 at the top, the depth of $1000 \mathrm{~m}$ at the bottom, and the location of the $3000 \mathrm{~m}$-isobath on the offshore flank (Figure [3-7). This part of the boundary current will be further referred as the "Full IC". The discussion of this choice as well as the Irminger Current transport estimation compared to the other studies is discussed in detail in Appendix B. The values of the Irminger Current's volume and temperature transport heavily depend on the 
definition of the Full IC used for the calculation (Appendix B).

Since the boundary current system is spread horizontally and its properties vary with depth and across the current, I introduce the definition of the Irminger Current core, further in the text referred to as the "inshore box". The inshore box bounds the region centered at $500 \mathrm{~m}$ deep and $75 \mathrm{~km}$ offshore and extends for $400 \mathrm{~m}$ vertically and $20 \mathrm{~km}$ horizontally (Figure 3-7). It represents only the core of the Irminger Current, i.e. the warmest and saltiest part of the current. The upper boundary is set to $300 \mathrm{~m}$ to limit the possibility of capturing the West Greenland Current's fresh signal. The lower boundary is set to $700 \mathrm{~m}$ to account for seasonally and interannually varying core temperatures and slightly offset deeper salinities. The core properties of the Irminger Current are characterized by potential temperature of $4.63 \pm 0.2^{0} C$, salinity of $34.91 \pm 0.02$, potential density of $27.64 \pm 0.02 \mathrm{~kg} \mathrm{~m}^{-3}$ and velocity of $13 \pm 8 \mathrm{~cm} \mathrm{~s}^{-1}$.

\subsubsection{Seasonal variability}

AVISO

One of the goals of this work is to study the seasonal variability of the boundary current system. I start by looking at the surface velocity from the satellite altimetry data shown in Figure 3-8. Since this analysis is not restricted by the availability of the hydrographic data and is based purely on the satellite data product, I am able to look at the complete annual cycle and resolve the monthly variations. To limit myself to the seasonal description, I define the seasons in a conventional way: January through March are called "winter", April-June - "spring", July-September - "summer", and October-December - "fall". Two properties of the current vary seasonally: the am-

plitude of the maximum velocity and the location of the velocity maximum. The largest velocities occur in the fall when the current is the widest and the maximum is located approximately $50 \mathrm{~km}$ offshore. In the spring and summer the maximum moves onshore and the velocities are weaker. Overall, the current is the widest and 
the fastest in the fall.

A similar result is obtained by considering the horizontal mean velocity defined as

$$
\bar{u}(t)=\frac{1}{R} \int_{0}^{R} u(t, r) d r
$$

where $\mathrm{R}$ is the width of the current, equal to $150 \mathrm{~km}$. The current is the fastest in November and the slowest in April and May (Figure 3-9). One can see a local maximum in June that reflects the inshore acceleration of the current (consistently with the inflow of the freshwater into the region). Unfortunately, it is difficult to distinguish the two currents - the West Greenland Current and the Irminger Current - in the altimetric data due to its coarse spatial resolution.

My six-months definition of the season definition introduced earlier in the text is consistent with the boundary current velocities from Figure 3-9. This seasonal distribution will be used from this point and throughout the study. The months from October to March of the following year and the spring as the months from April to September (even though the hydrographic data for the spring would be limited to May-July), taking into account the limited annual distribution of the hydrographic data.

\section{Hydrography}

The analysis of the climatological mean section and the results from the AVISO data in the previous part point out to the need of differentiating between the seasons. The combination of AVISO and hydrographic data allows us to investigate the link between changes in surface velocity with changes in the current's structure on seasonal timescales. Also, this analysis will help interpret results from previous analyses when only spring data were used. 


\section{Properties}

The springtime climatological mean, calculated as an average of 13 spring sections, is shown in Figure 3-10 (a-d). One can identify the same water masses that are described for the mean section: the cold and fresh PW in the top right corner of the section; warmer and saltier IW below; LSW in the central part of the section and NADW at depths. As expected from the altimetry results and evident from the hydrographic sections, the velocities throughout the water column in the springtime average section are smaller than the ones of the mean.

There are only 5 occupations of the AR7W section during the fall that cover both the early 1990s and the 2000s. All the water masses identified in Figures [3-5] and 3-10 can be seen here. However, it is possible to see several pronounced changes with respect to the spring/summer section: i) PW layer is thinner during the fall; ii) IW layer is warmer, saltier, thicker and deeper during the fall; iii) both velocity structure and properties of the boundary current are more spread in the horizontal direction in the fall (Figure 3-10).

The core properties of Irminger Water for the two seasons are listed in the Table 2. To be quantitative, the core of the Irminger Current is warmer by about $0.6^{0} C$, saltier by 0.01 and faster by $3 \mathrm{~cm} \mathrm{~s}^{-1}$ in the fall.

\section{Velocity}

It is an important question to ask whether the fall acceleration of the current is due to changes in the density structure of the current or to an acceleration of the entire current by decomposing the velocity field into a baroclinic and a barotropic component. I define the baroclinic component as the geostrophic velocity relative to $1000 \mathrm{~m}$. This depth is not chosen arbitrarily. After a careful analysis of the individual 
hydrographic sections and reviewing of the previous results (Pickart and Spall, 61]; Yashayaev, [82]), I conclude that the the horizontal density gradients are the smallest at this depth which coincides with the depth of LSW in the boundary current. Since the horizontal density gradients are small, it implies that the vertical shear in the mean flow is small as well, making this depth a good choice for a reference level. Barotropic velocity can be defined in a variety of ways but in order to achieve the goal of understanding of the circulation variability on seasonal and interannual time scales, we define the barotropic velocity in this study to be the absolute velocity at the reference level, i.e. at $1000 \mathrm{~m}$ depth.

The baroclinic component, Figure [3-11, is greater in the fall than in the spring by roughly $6 \mathrm{~cm} \mathrm{~s}^{-1}$ above $1000 \mathrm{~m}$. The width of the fall baroclinic current is greater throughout the water column as well.

By definition, the barotropic velocity is equal to the absolute velocity at 1000 $\mathrm{m}$. The $1000 \mathrm{~m}$ isobath crosses the section at roughly $65 \mathrm{~km}$ offshore and thus, the inshore portion of the boundary current is not resolved (Figure 3-12). Over the portion that is resolved, however, this analysis shows that the seasonal changes in the barotropic component are relatively small.

To conclude, this analysis shows that the seasonal differences in the velocity are primarily due to the enhancement of the baroclinic component in the fall, while the seasonal changes in the barotropic component are small.

\section{Transports}

The boundary current's hydrographic properties and velocity structure significantly differ between the two seasons giving rise to changes in the amounts of heat and fresh water that are transported into the region.

As seen from Table 3, the West Greenland Current (bounded by the 34.4 isohaline and $150 \mathrm{~km}$ from the shore) transport is larger by $16 \%$ in the spring. This fact is 
consistent with the enhancement of the inshore surface velocity and is likely to be a result of the Greenland ice melt and increased inflow from the Arctic. The Irminger Current (bounded by the 34.4 isohaline on top, $3000 \mathrm{~m}$ isobath from the interior and $1000 \mathrm{~m}$ depth) transport decreases by roughly $16 \%$ in the spring consistent with the overall smaller velocities and the area of IW.

The larger fall volume transport that is correlated with the higher Irminger Water temperatures and salinities results in a greater temperature flux during the fall (159.4 $\pm 53.1 \mathrm{TW}$. While in the fall the volume transport increases only by $17 \%$ compared to the one for the spring, the temperature transport increases by the order of $30 \%$. Therefore, the temperature transport is equally determined by changes in the temperature and velocity of the boundary current. The fresh water is carried by the West Greenland Current and is mainly brought into the region in spring. The springtime transport estimate is $60.1 \pm 15.8 \mathrm{mSv}$, consistent with earlier studies by Myers et al., [54.

The total volume transport of the full section that horizontally spans from 0 to $150 \mathrm{~km}$ and extends from the surface to the bottom does not significantly change with season. During the fall, when the upper part of the boundary current (0 - 2000 m) accelerates and can potentially contribute to the increased total transport across the whole section, the deeper part of the current (2000 m - bottom) decelerates. It is important to keep in mind that the contribution from the upper part of the current is smaller than the uncertainties in the total transport.

\subsubsection{Interannual variability}

The analysis of the Labrador Sea interior variability (discussed in detail in Chapter 1) points to the need for understanding of the boundary current variability to fill in the gap in out understanding of the interior interannual variability that is not fully explained by the atmospheric variability. The changes in the boundary current that 
occur on the interannual time scales affect the magnitudes and duration of the lateral fluxes which are the primary mechanisms of the post-convective restratification.

There is little information from previous studies on the changes in the boundary current system as it enters the Labrador Sea. There are some indications that the boundary current system has become warmer and saltier and its volume transport has decreased over the last forty years (Stein, [70; Myers et al., [54]). These studies, however, have a number of limitations that make it difficult to investigate the interannual changes. For example, they utilize only the springtime measurements confined within the upper $700 \mathrm{~m}$ and present interannual changes of a horizontally averaged boundary current profile, therefore, without taking into account changes in width or considering the gradient between the current and the interior region. In the present work I systematically study the interannual changes in the boundary current system and their relation to changes in the interior.

Within the warming trend from the mid 1990s to present, described above, the years of 1997 and 2003 stand out as being associated with an abrupt interior warming (Avsic et al., [2]; Lazier et al., 45]) and enhanced EKE (Brandt et al., 6]) that cannot be solely explained by the changes in the atmospheric forcing (Lilly et al., [49]; Straneo, 73]). Similar changes occurred in the number and properties of the Irminger Rings as documented by Lilly et al., 49], Brandt et al., 6] and Chapter 2 which, during these years, were observed in larger numbers and with a warmer, saltier, thicker IW core.

Here I attempt to connect the changes in the boundary current with the observed eddy and interior changes. In particular, I emphasize the link between the current and the interior changes. Finally, I provide the discussion of the possible impacts of the observed variability on the lateral fluxes.

AVISO 
I investigate the interannual changes by computing the monthly mean horizontal velocity, $\bar{u}(t)$ from AVISO, defined above, Figure 3-13, Both spring and fall velocities show a decreasing trend with magnitudes of more than $2 \mathrm{~cm} \mathrm{~s}^{-1} \pm 2 \mathrm{~cm} \mathrm{~s}^{-1}$ over the 16-year record. The reader should keep in mind that the interannual decrease in the velocity is much smaller than the characteristic amplitude of the seasonal variability $\left(4-8 \mathrm{~cm} \mathrm{~s}^{-1}\right)$. Overall, the significance of this trend is unclear due to the poorly understood possibilities of the trend-like behavior of many of the corrections to the satellite altimetry data product. There is a significant interannual variability superimposed on this trend, and, in particular, 1997 and 2003 are characterized by a large positive anomaly (while 1996 and 2000 are the years with a negative anomaly). The trend may have reversed after 2004 .

Similar results are obtained if we consider an annual mean (from April of one year to March of the next year following the definition of Straneo, [73]), Figure 3-14, We note that this result is robust and independent of whether we consider the velocity maximum or the mean across the current, similarly, it is insensitive to the definition of the year.

\section{Hydrography}

To investigate how the interannual changes observed at the surface are related to changes in the properties and structure of the boundary current I consider the property gradient across the Irminger Current portion of the boundary current system.

Consider the two boxes located within the boundary current: the "inshore box" defined above as the box that represents the core of the IC and the "offshore box" defined by a rectangle centered at $500 \mathrm{~m}$ depth and $150 \mathrm{~km}$ offshore (Figure 3-7) with the vertical extent of $400 \mathrm{~m}$ and horizontal - $20 \mathrm{~km}$. The offshore box is located on the edge and reflects the properties of the interior. The inshore/offshore gradient 
provides a measure of the property gradient across the boundary current.

Figure 3-15 (a-c) shows that Irminger Water has become warmer, saltier, and lighter since the beginning of the 1990s. These trends occur in both the inshore and offshore boxes at comparable rates, implying that overall, the interior and the boundary current are changing at the same rate and that the gradient remains approximately constant. Little variability in the density gradient across the boundary current implies little variability for the magnitudes of the lateral fluxes (which will be discussed in detail in Chapter 4). The years of 1997 and 2003, however, stand out as characterized by significant anomalies in the inshore part of the boundary current which are absent in the interior record. Hence, during these years the interior/boundary current temperature and density gradients were much greater.

Following the peaks in the core of the Irminger Current this change spread to the interior with a two-year lag. The peaks in the offshore temperature of the current in 1999 and 2005 are consistent with the changes observed by Avsic et al., 2], who documented the increase in the interior temperatures and salinities in 1997-1999 and 2003-2005. Salinity changes occur with a larger degree of variability and generally are noisier (Figure 3-15). The two years (1996 and 2003) are characterized by a reversal in the salinity gradient between the inshore and offshore boxes, which is an indication of an increased fresh water inflow in the upper part of the boundary current system, the WGC. The layer of the cold and fresh water extends down to 300-500 m during the summers of these years, penetrating into the boxes that in the rest of the record contain only the warm and salty Irminger Current.

The potential density in both boxes shows the lightening of the water column that occurs at comparable rates, dominated by the changes in temperature (Figure [3-15). The fact that the quiescent interior and the fast boundary current are lightening at the same rate suggests that the similarity in their evolution is likely explained by the lateral fluxes and not by the local forcing. 
The lack of a trend in the horizontal density gradient across the Irminger Current on the interannual time scales suggests that the baroclinic component of the flow is mostly constant during this period (except for 1997 and 2003 which are discussed in the next chapter). This, in turn, suggests that the decrease in surface velocity shown in Figure 3-14 must be due to the barotropic component. Such a result is confirmed through the direct computation of the flow at $1000 \mathrm{~m}$ (the barotropic component) averaged over the width of the inshore box shown in Figure 3-16, I therefore conclude that the slow-down trend from 1995 to 2004 is primarily due to the changes in the barotropic flow around the SPG and Labrador Sea.

The abrupt changes of 1997 and 2003, on the other hand, are associated with large changes in the current with respect to the interior. In particular, the increase in the density gradient implies a speed up of the baroclinic component of the current (Figure 3-16).

\subsection{Uncertainties}

There are a number of error sources which influence the results that originate from both hydrographic data and satellite altimetry data product. The uncertainties due to the hydrographic data are better understood and can be estimated in most of the cases. There are many gaps in our understanding of the uncertainties originating from the satellite products. They are due to a large number of manipulations and techniques that the satellite product undergoes before it reaches the user from the moment of the data collection.

The hydrographic data uncertainties come from projecting, gridding and from the unresolved parts of the water column that result from the extrapolation of the property fields. Another uncertainty in the results could be coming from the possible sampling of the eddies in the hydrographic sections but given the careful analysis of 
the eddy field performed in Chapter 2, the likehood of missing an ICA in the section is very small. The projection and gridding errors do not affect the result much due to the fact that the original sections were only rotated by small (less than $5^{\circ}$ ) angles. The gridding/extrapolation technique described in detail in Appendix A has been shown to produce the meaningful fields and used in a number of studies before (Sutherland and Pickart, [76], Fratantoni and Pickart, [23], Våge et al., 78]). The uncertainty that originates from the lack of data in the bottom triangle between the adjacent to the coast profiles results in the problems with measuring of the density gradients below the deepest common level of neighboring hydrographic stations. The rough estimate of this error is less than $1 \mathrm{~cm} \mathrm{~s}^{-1}$ in the velocity field at the depths shallower than $1500 \mathrm{~m}$. This uncertainty may be larger at the depths of the DWBC but they are beyond the scope of this study. In general, the uncertainties related to the imperfections in the hydrographic analysis are smaller than the uncertainties caused by the use of the satellite product.

The satellite altimetry product in general, and in the geographical region used in the analysis, in particular, has a lot of uncertainties. The altimetry products are known to have problems in the coastal areas (closer than $30-100 \mathrm{~km}$ from the land depending on the region of study) due to the unresolved high-frequency SSH changes that result from highly variable atmospheric forcing, the instability of the water vapor radiometer near the shores, tidal effects and other corrections. The temporal resolution of the along-track data product cannot exceed 20 days (as a result of the 10-day repeat orbit) and the 7-day gridding interval has definitely a higher frequency than what the satellites are actually capturing. The gridded product is certainly not representing the short-scale motions but keeping in mind the width of the current of $150 \mathrm{~km}$ and the fact that the elevations in the surface height are likely to be good within several centimeters per path (M.-I. Pujol, personal communication, 2009) this should not significantly affect the observed velocities of the order of $30 \mathrm{~cm} \mathrm{~s}^{-1}$. The errors originating from the uncertainty of the geoid can have large consequences for the altimetry-derived surface velocities, especially in the vicinity of the coast and on 
the spatial scales of 150-200 typical for this study. The estimation of the geoid corrections is not possible given the available tools. However, the comparison of satellite velocity data to the ADCP-based velocity shows that satellite altimetry provides a realistic estimation along AR7E section (Våge et al., [78 ] ). Unfortunately, the ADCP data that are analyzed for the AR7W section is limited to only a few years and thus, a similar to AR7E comparison cannot be repeated.

Finally, the comparison of the absolute geostrophic velocity field obtained by referencing the geostrophic velocity from the hydrographic section to the absolute surface velocity from the satellite altimeter product (described in detail in Appendix B) to the independent data sets (the mean over 1990-1997 from Pickart and Spall, [61] and individual ADCP velocity sections provided by Hall and Torres, [29]) are surprisingly good given all the uncertainties that the data have. It is possible, the errors listed above for both AVISO product and hydrographic data cancel each other by accidental coincidence or maybe our knowledge about the error budget is still not perfect.

\subsection{Summary}

Having analyzed the satellite altimetry and hydrographic data from 1992 to 2008, we obtained the seasonally weighted climatological mean and studied the seasonal and interannual variability of the boundary current.

The mean maximum surface current's velocity, $\left\langle u>_{\max }\right.$, centered roughly at $50 \mathrm{~km}$ offshore is $30 \pm 4 \mathrm{~cm} \mathrm{~s}^{-1}$, is consistent with the previous estimates from the drifters by Niiler and Maximenko, [56] and Fratantoni, 22]. The barotropic velocity of the climatological section defined at the depth of the minimum vertical shear as the absolute velocity at $1000 \mathrm{~m}$ is on the order of $10-12 \mathrm{~cm} \mathrm{~s}^{-1}$ consistent with Pickart and Spall, 61, while Myers, [54, documents only 5-7 $\mathrm{cm} \mathrm{s}^{-1}$ at $700 \mathrm{~m}$. 
It is shown for the first time that both surface and subsurface parts of the boundary current exhibit a strong seasonal cycle. The acceleration of the inshore portion of the current and the increase in thickness of the fresh West Greenland Current typical in the spring is consistent with the timing of the largest fresh water inflow into the Labrador Sea observed by Schmidt and Send, [66]). The analysis of the Irminger Current shows that it is the warmest, saltiest, thickest and fastest in the fall. The property gradients across the current are also the largest in the fall, implying the largest gradients between the boundary current and interior. These increased gradients, that coincide in time with the maximum heat flux and wind stress curl, likely contribute to making the current more unstable and could, therefore, explain why the EKE peaks in early winter - in agreement with the modeling studies arguing that the Irminger Rings are formed as a result of a mixed barotropic and baroclinic instability (Eden and Boning, 20]; Katsman et al., [36]; Bracco et al., 8]). Also, our results are consistent with model results of Brandt et al., [6] ) who document an increased eddy activity in the winter months when the current is faster and more energetic. The enhancement of the Irminger Current velocity is attributed to a large extent to the baroclinic component of the velocity that explains about $70 \%$ of the seasonal velocity changes based on the amplitudes of different velocity components. The differences in the barotropic components of the spring and fall mean sections are negligible. While on average, the boundary current's seasonal cycle is very pronounced, there are years (1996/1997 and 1999-2001) when the seasonal cycle is not well pronounced. When the density gradients are small, the current is more stable and the amount of eddies produced is small. If the density gradient is small throughout the year (as opposed to a typical year when it increases in the fall), the number of eddies produced remains constant and is not increasing in the fall. This is consistent with the observed continuous eddy production during these years in the numerical model by Brandt et al., 6], who suggest that during these years the seasonal cycle in the eddy production is absent and link it to the diminished seasonal cycle in the boundary current.

The interannual changes are pronounced in both the surface and the subsurface 
parts of the boundary current. Satellite altimetry over the AR7W section across the boundary current shows changes similar to the large scale changes in the SPG described by Hakkinen and Rhines, 27] and [28]: the boundary current's velocity is decreasing owing to the decrease in the barotropic, wind-driven, component of the flow. In addition to the interannual variability, the higher spatial and temporal resolution allowed us to study the seasonal variability of the boundary current system, which was filtered out in Hakkinen and Rhines, [27.

The subsurface part of the boundary current, the Irminger Current, has become warmer, saltier and lighter from 1992 to 2008 as seen both in the inshore and offshore (interior) boxes. The changes occur at comparable rates, thus, nearly preserving the horizontal density gradient and therefore, the baroclinic component of the velocity over the 16-year record. The fact that the changes occur at comparable rates is consistent with the theoretical model of the Labrador Sea provided by Spall, 68 and Straneo 74 that explains the connection between the interior and the boundary current region by the existence of the eddy fluxes. It is also consistent with the heat content increase in both Irminger Current Anticyclones and interior (discussed in Chapter 2) which occurs at comparable rates.

There are two outstanding years over this 16-year period of study. The years 1997 and 2003 are marked by the largest temperature/density differences between the interior and the boundary current that result from the anomalous values in the core of the Irminger Current. The increase in the horizontal density gradient implies the increase in the baroclinic component of the flow. The enhancement in the baroclinic component, in turn, can possibly lead to its instability that explains the observed high EKE values during these years (Avsic et al., [2]; Lilly et al., 49]). 


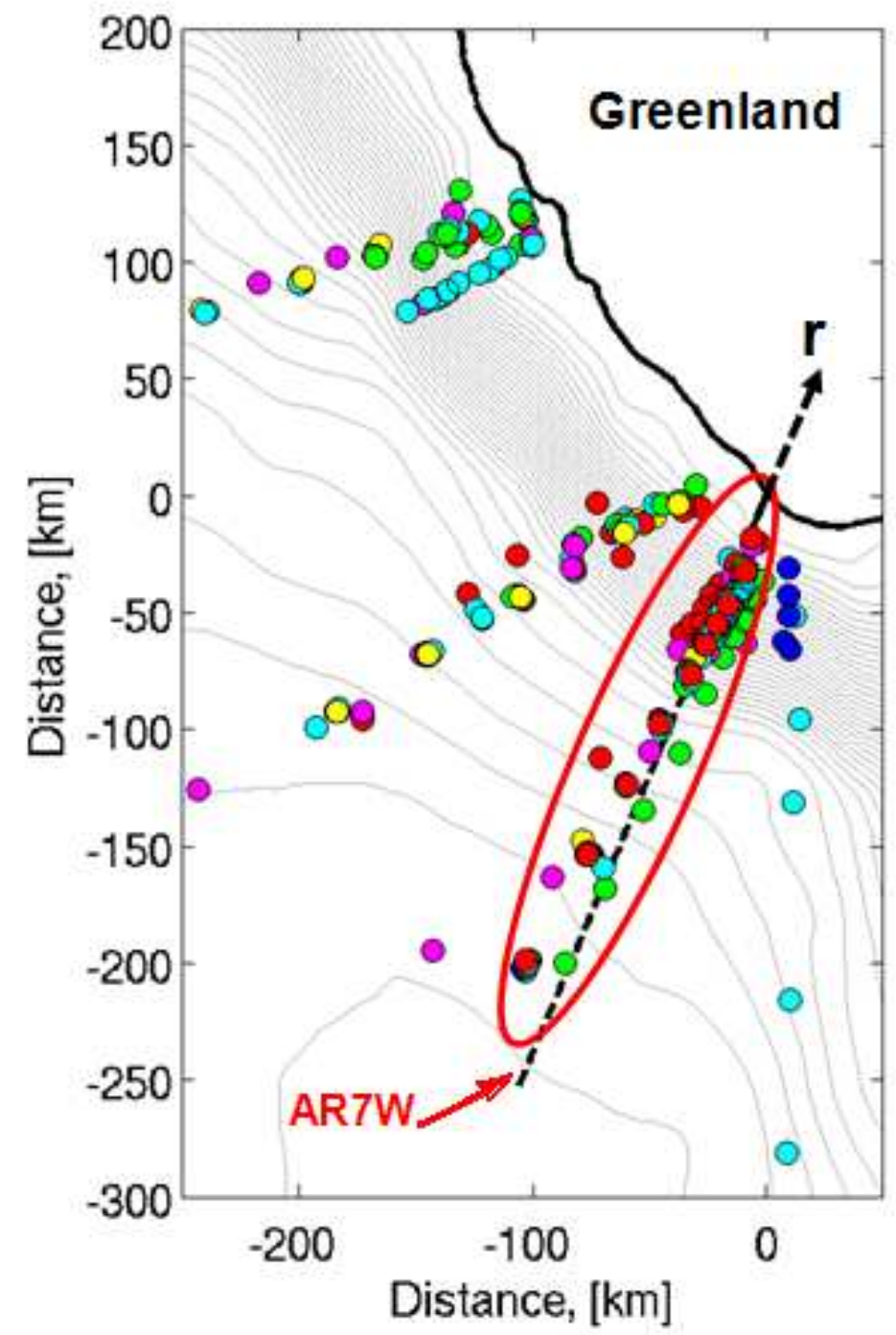

Figure 3-1: The location of the original hydrographic stations of the three data sets. The black dashed line indicates the location of AR7W line. Gray contours mark the bathymetry lines obtained by smoothing of the Smith and Sandwell ([67]) topography. Different colors represent occupations of the sections at different times and locations. Red oval marks the sections used in this chapter. 


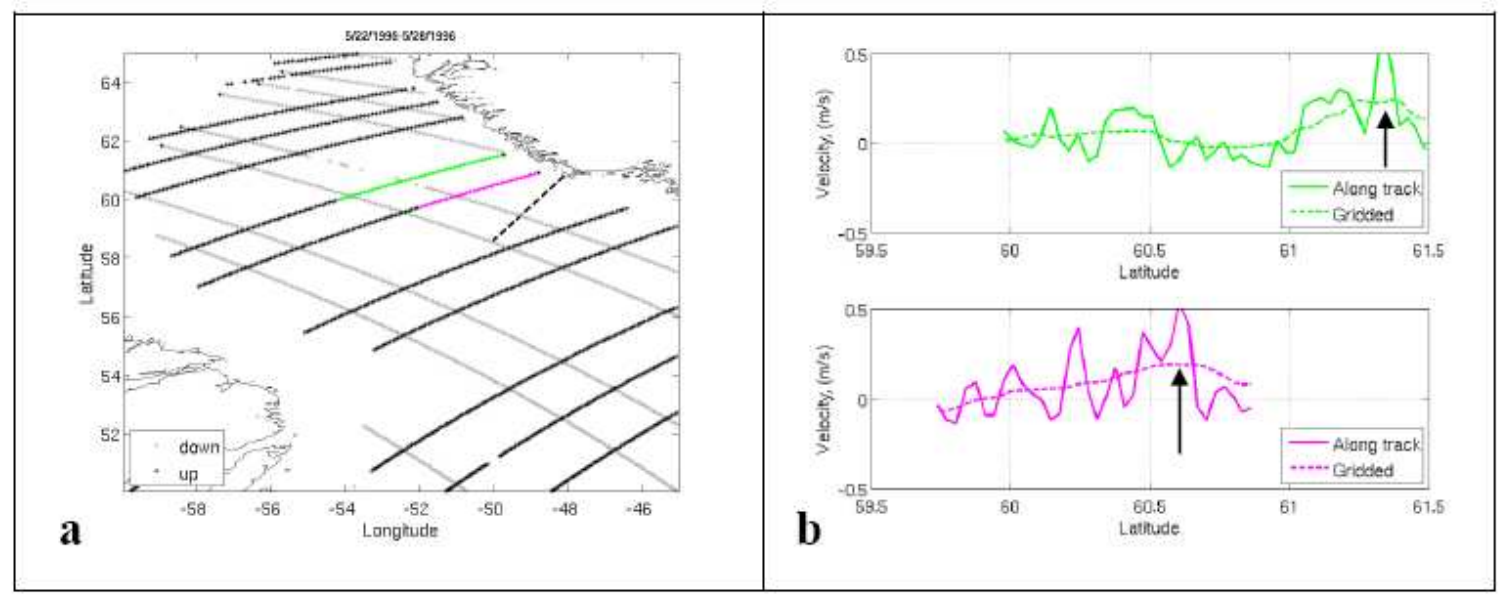

Figure 3-2: a) Tracks of the TOPEX-Poseidon satellite over the Labrador Sea with the ascending (black) and descending (gray) tracks. Ascending (green) and descending (magenta) tracks are the chosen for the comparison in panel (b). The location of the AR7W section is shown by a black dashed line. The numbers indicate the day within a 10-day period of the satellite orbit. b) Comparison of the along-track SSH data with a gridded AVISO product as a function of latitude for the ascending (green) and descending (magenta) tracks. 


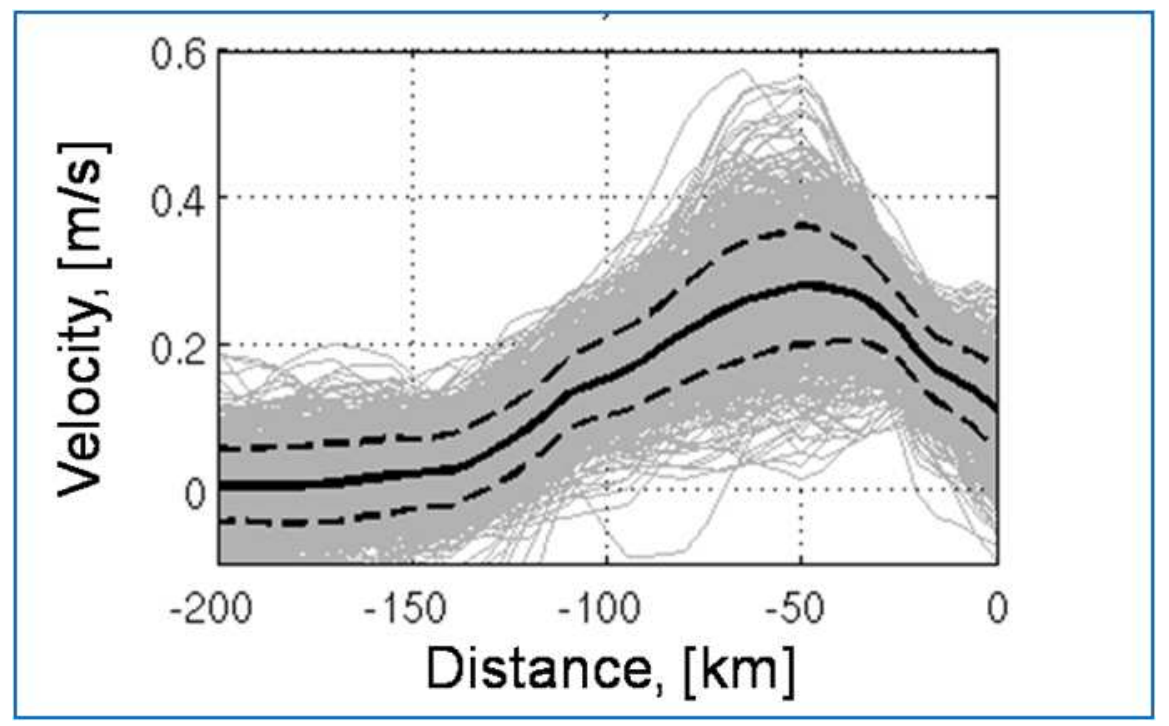

Figure 3-3: The surface velocity from AVISO product for the period of 1992-2008 (gray), climatological mean (solid black), and normalized standard deviation (dashed black) overlaid. 


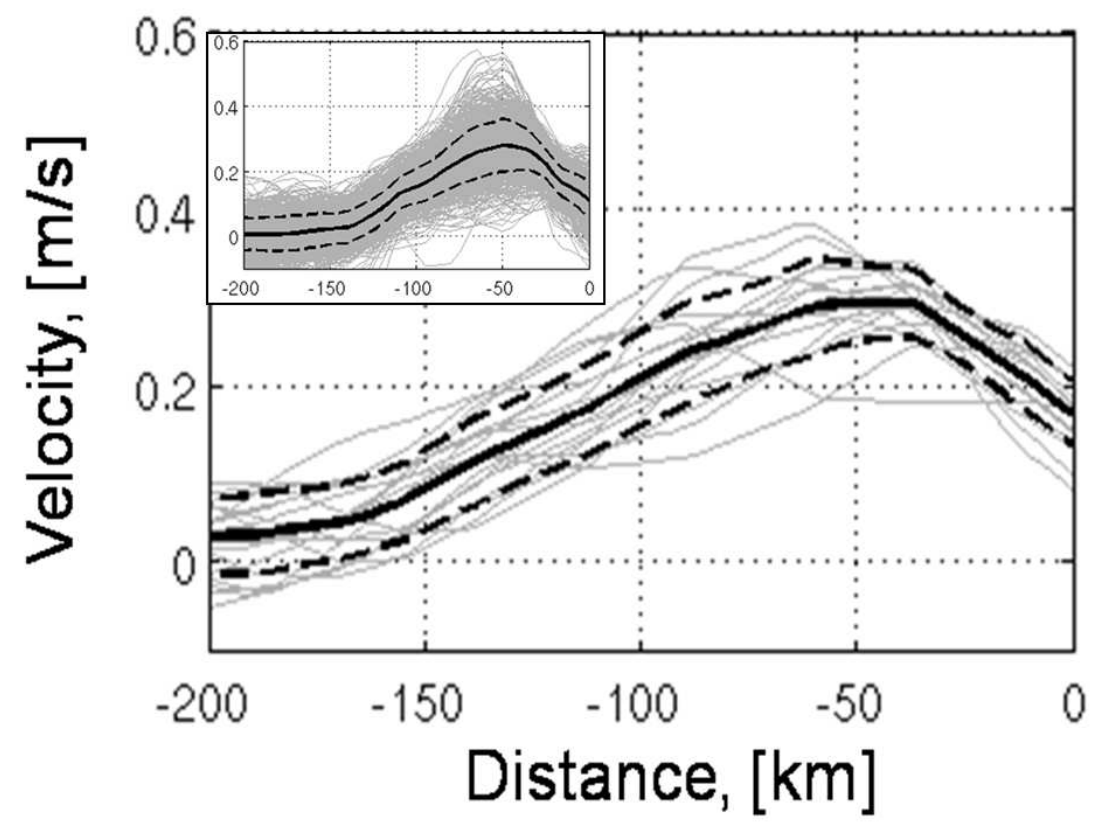

Figure 3-4: Surface velocity as a function of distance for a subset of profiles corresponding to the dates of hydrographic measurements. Individual profiles (gray), mean (solid black) and standard deviation (dashed). The inset shows the full AVISO data set from 1992 to 2008 (shown in Figure 3-3). 


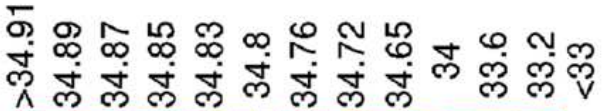
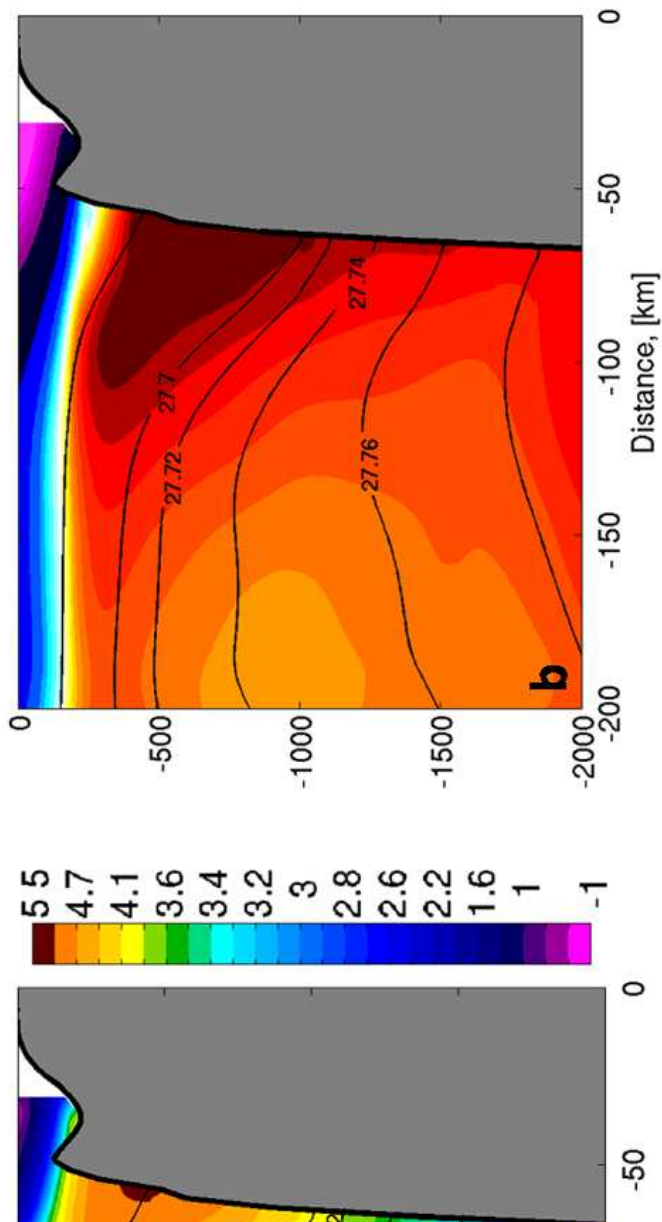

芯

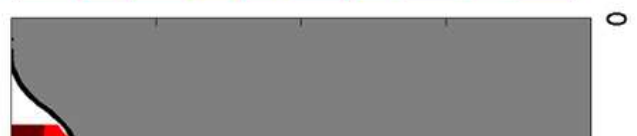

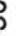
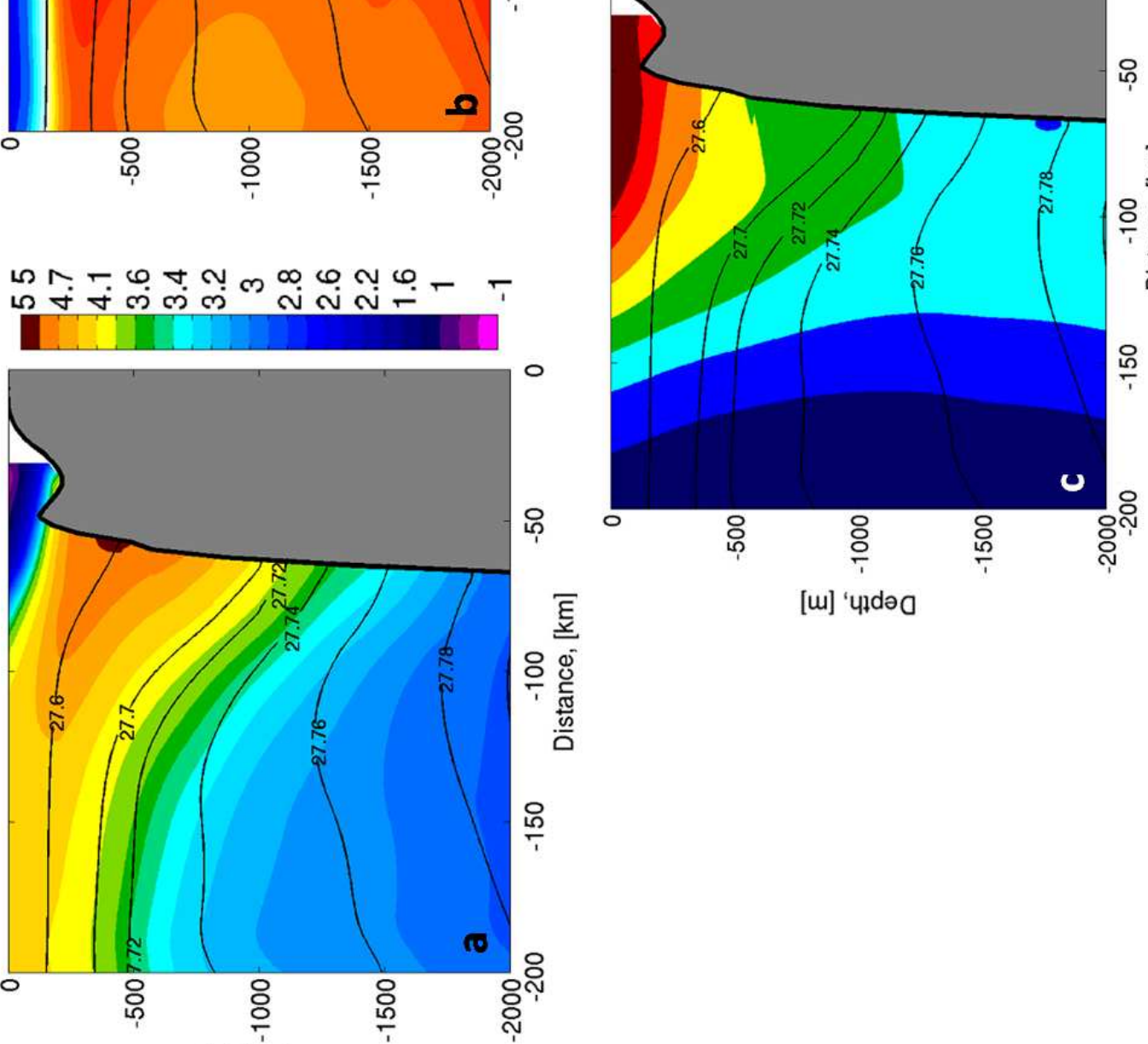

[u] 'بldəa

Figure 3-5: Climatology of the boundary current for 1992-2007: (a) potential temperature; (b) salinity; and (c) absolute geostrophic velocity with potential density contours overlaid. 

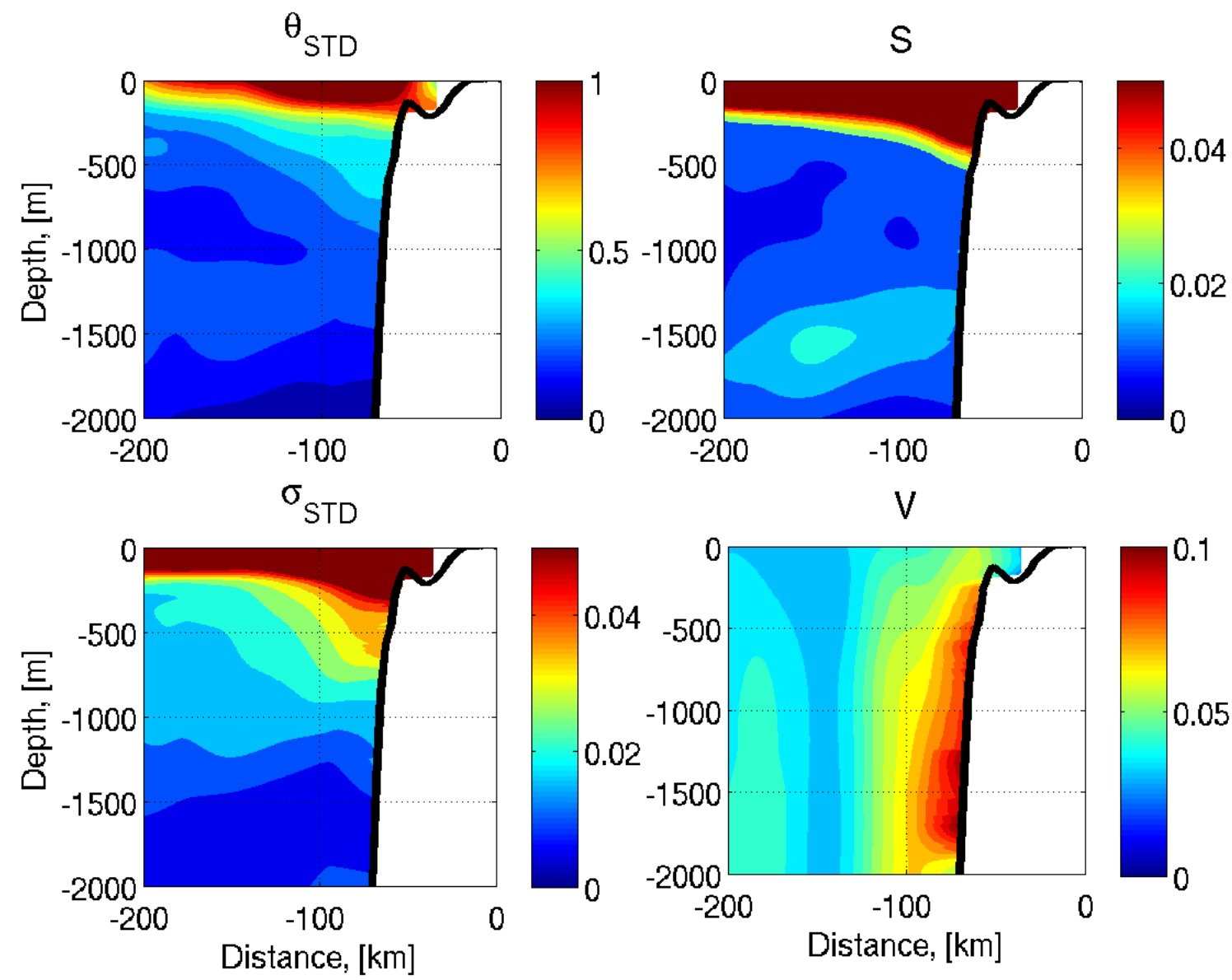

Figure 3-6: The standard deviation of the 15-year mean for a) potential temperature; b) salinity; c) potential density; and d) velocity. 


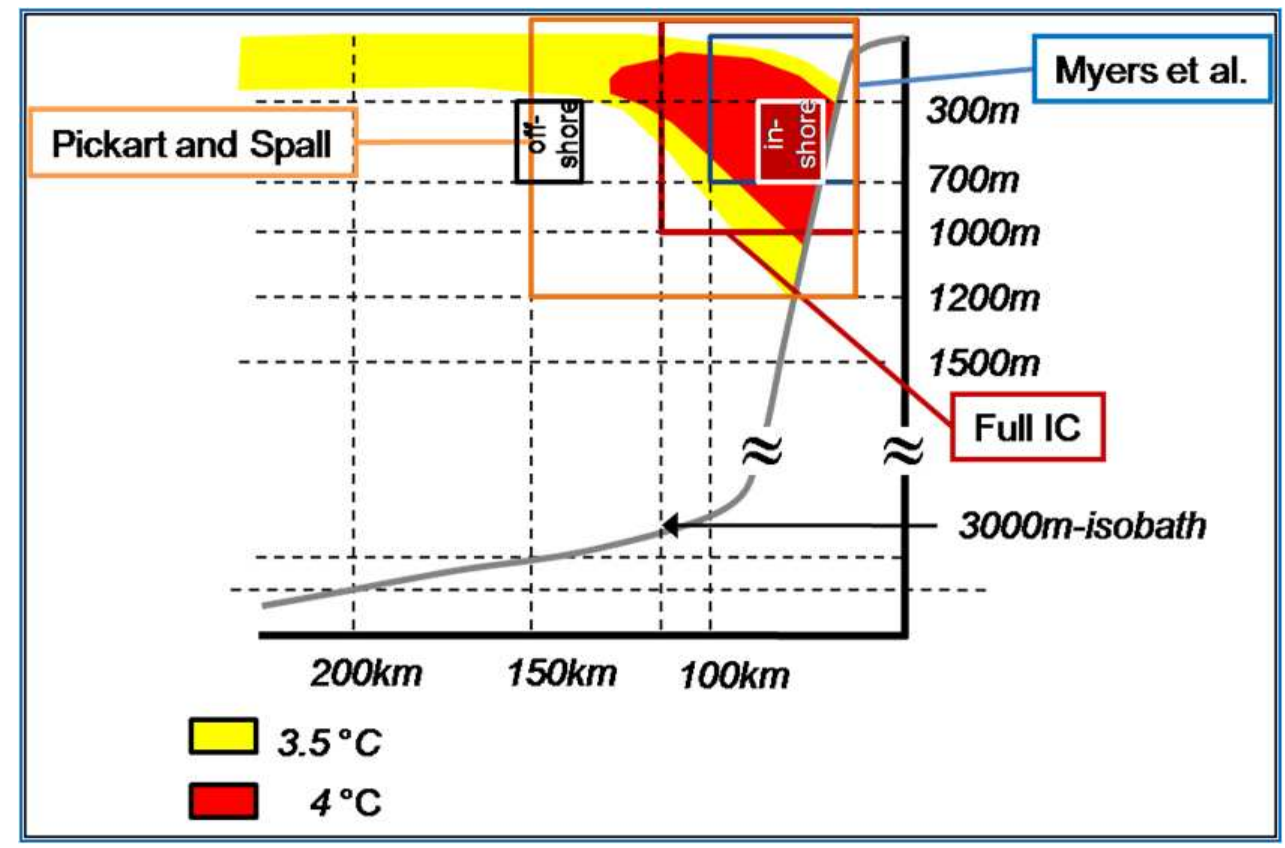

Figure 3-7: The schematic of the Irminger Current (yellow, $\theta>3.5^{0} \mathrm{C}$ and red, $\theta$ $>4^{0} \mathrm{C}$ ). Blue box shows the definition of the IC used in Myers et al., 54; orange box - used by Pickart and Spall, 61]; maroon box - my definition of the Irminger current used in the transport calculations. The white box indicates the core of the boundary current, referred to in the text as "inshore" box. The black box is includes the offshore flank of the boundary current and is referred to in the text as "offshore" box. 


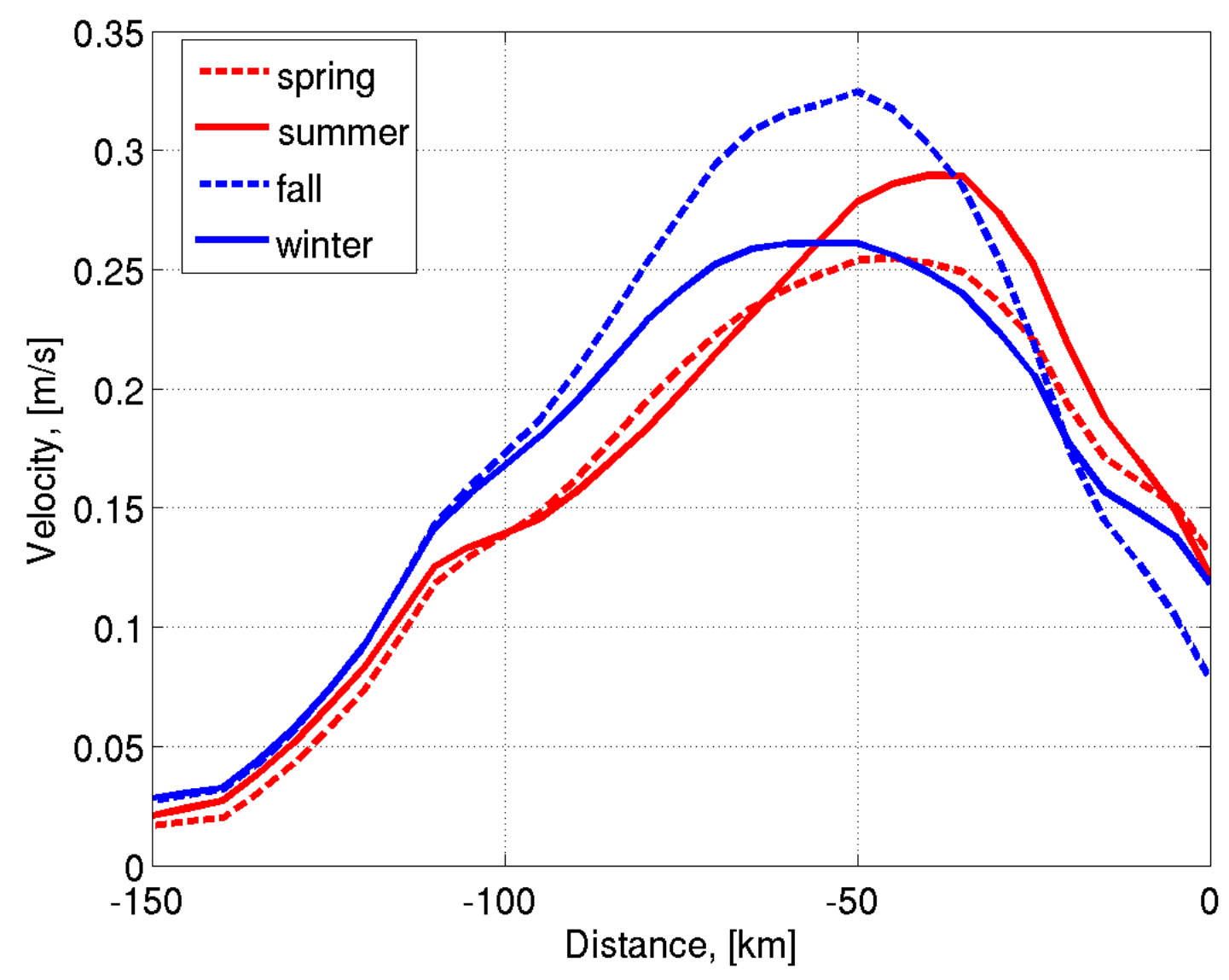

Figure 3-8: Mean seasonal distribution of the surface velocity obtained from the gridded AVISO data set for 1992-2008. See text for the definition of the seasons. 


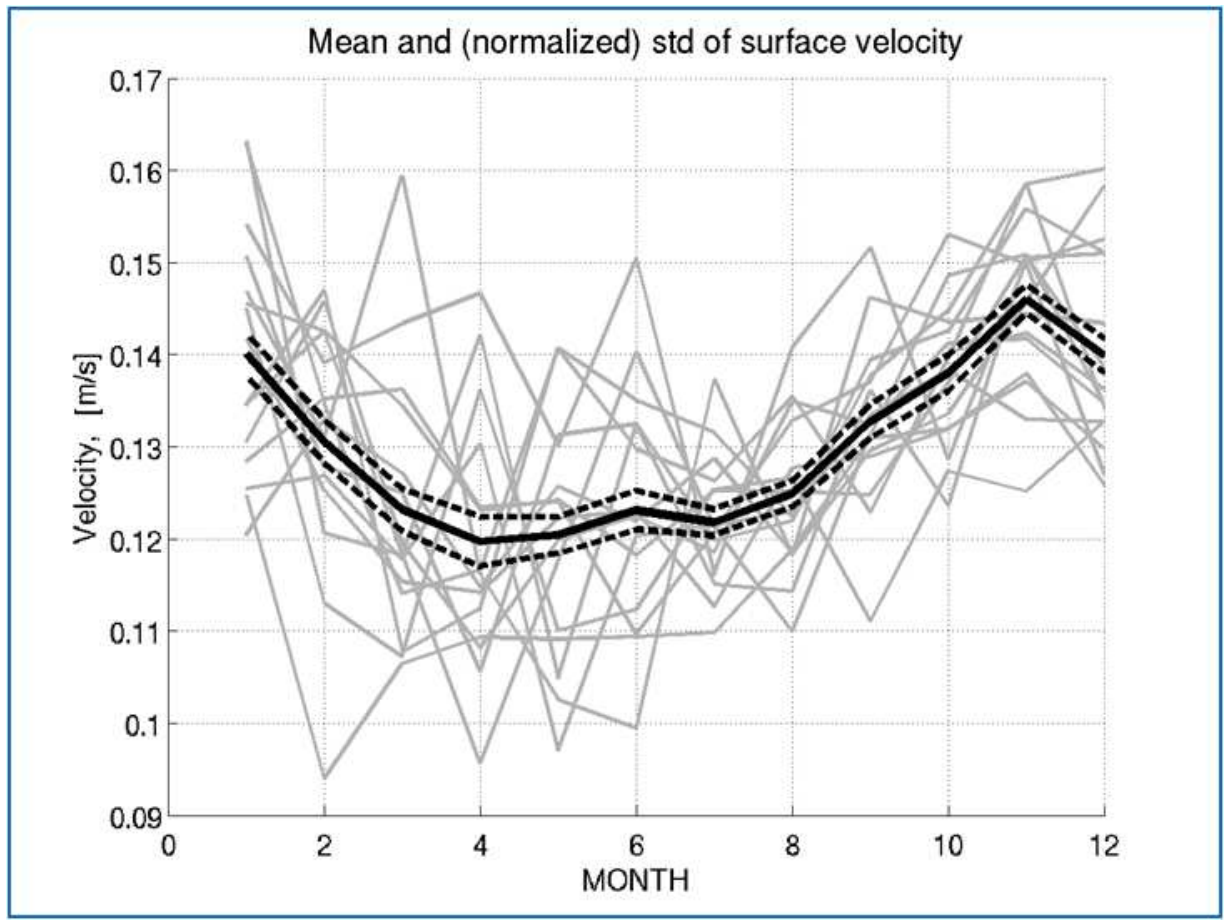

Figure 3-9: Monthly climatology of the surface current (black solid line) and the standard deviation of the mean (dashed lines) overlaid on the monthly means for each year (gray). 

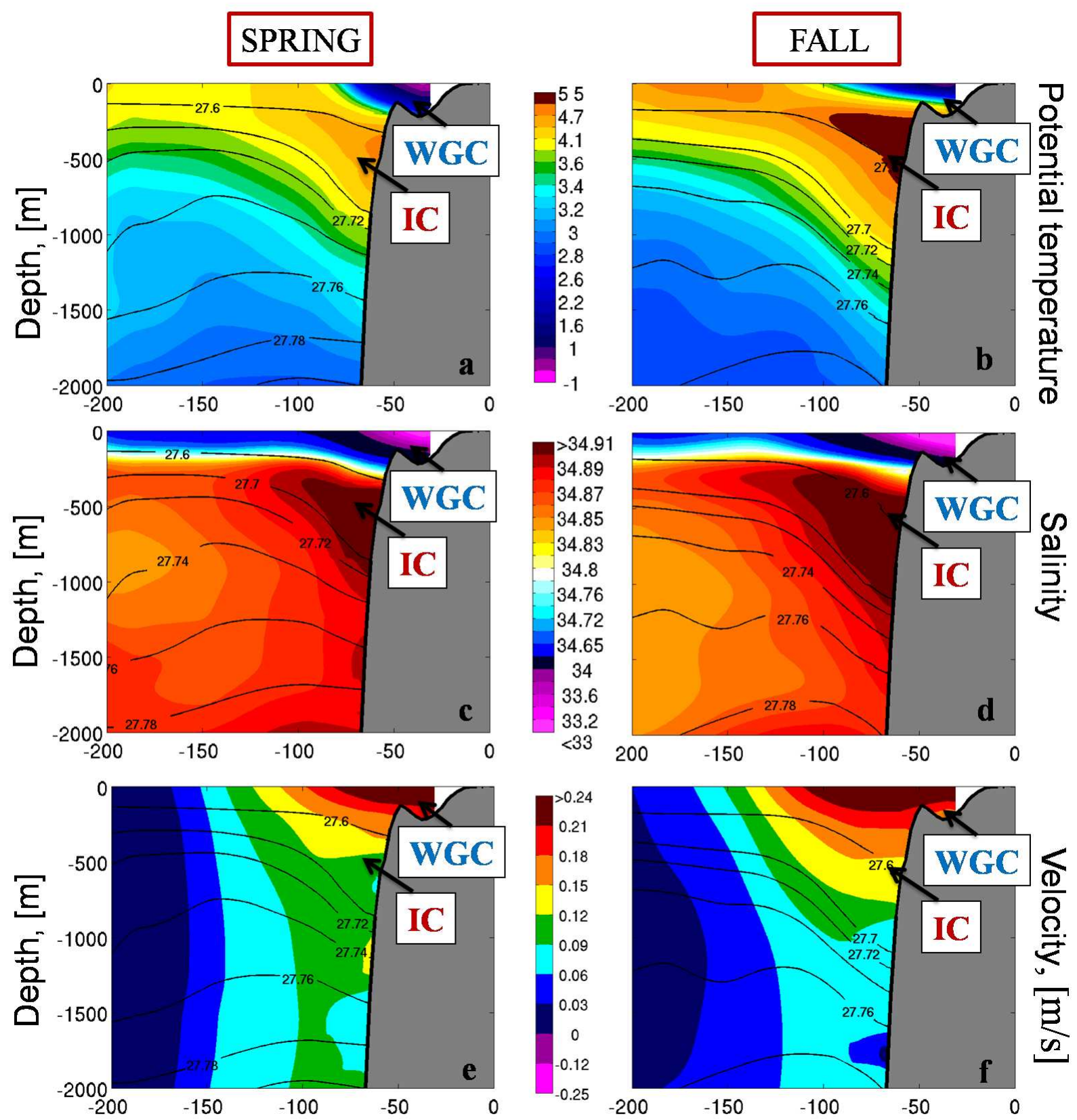

Figure 3-10: Spring (a,c,e) and fall (b,d,f) climatology of the boundary current: (a, b) potential temperature; (c,d) salinity with potential density overlaid; and (e, f) absolute geostrophic velocity. 

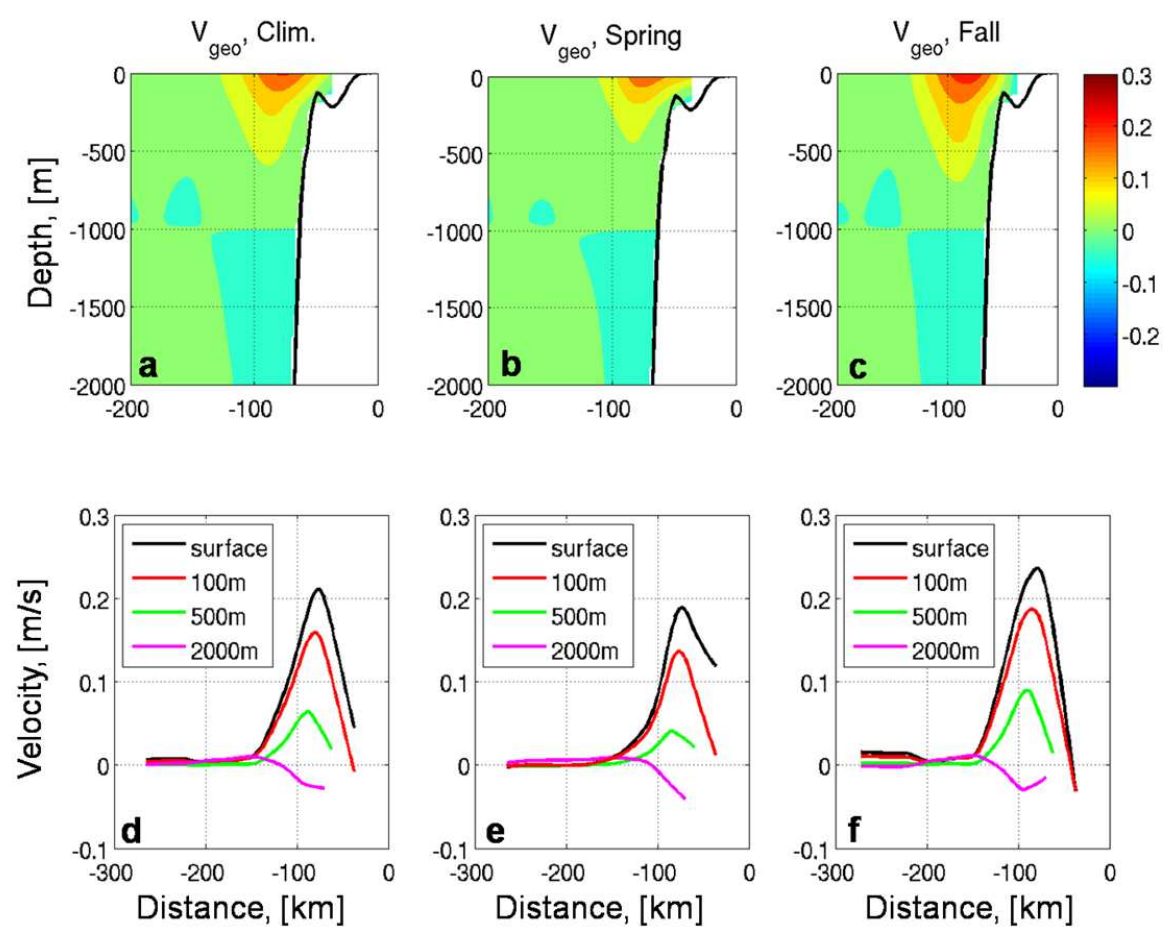

Figure 3-11: Baroclinic component of the boundary current referenced to zero at 1000 $\mathrm{m}$ for a) climatological mean section; b) spring mean; c) fall mean; and baroclinic component of the velocity at different depths for d) climatology; e) spring mean and f) fall mean. 


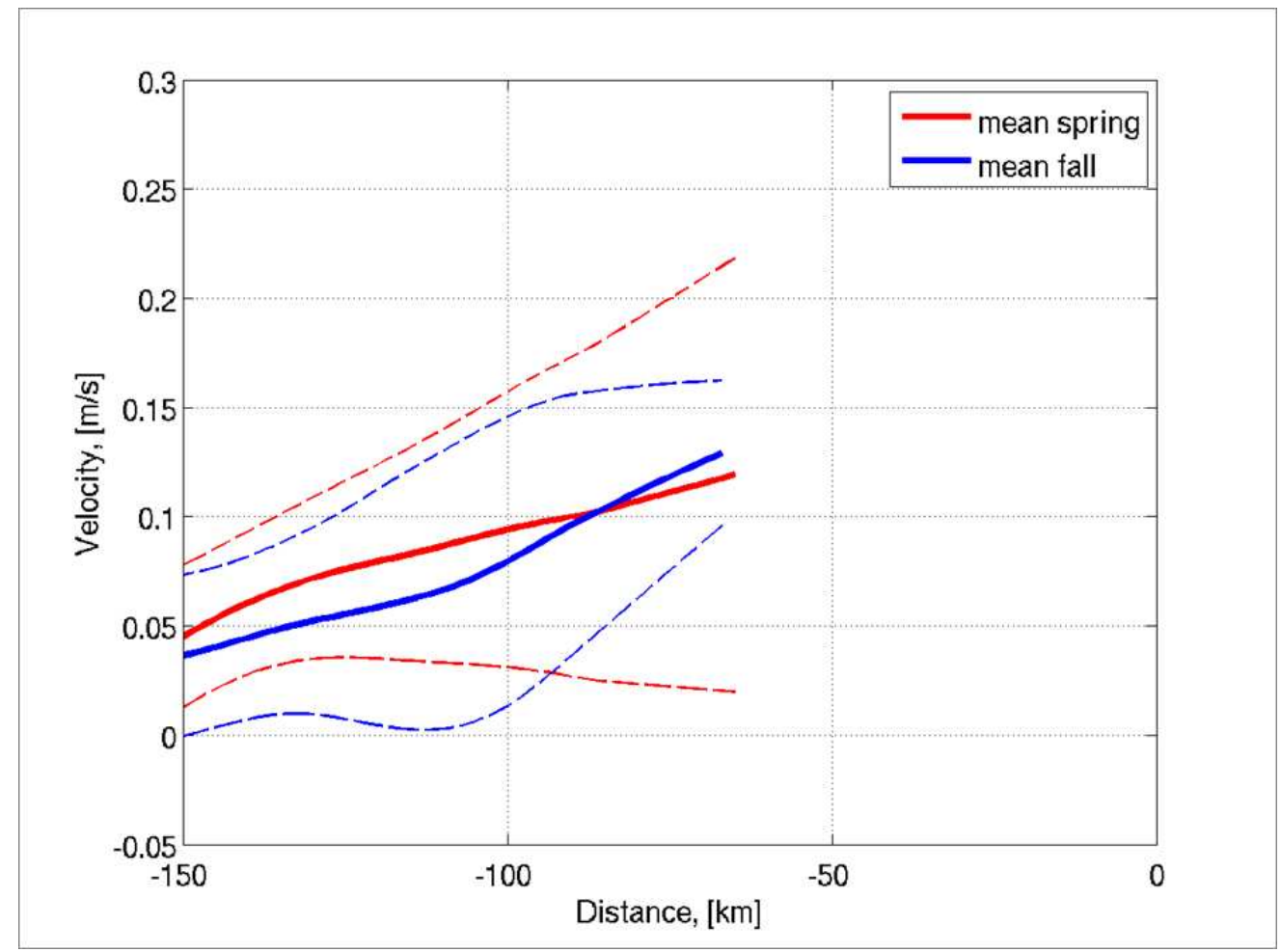

Figure 3-12: Barotropic component of the boundary current (see text for the definition) for the mean fall (solid blue) and spring (solid red) section. The standard deviations from the mean spring and fall profiles are shown in dashed red and blue lines respectively. 


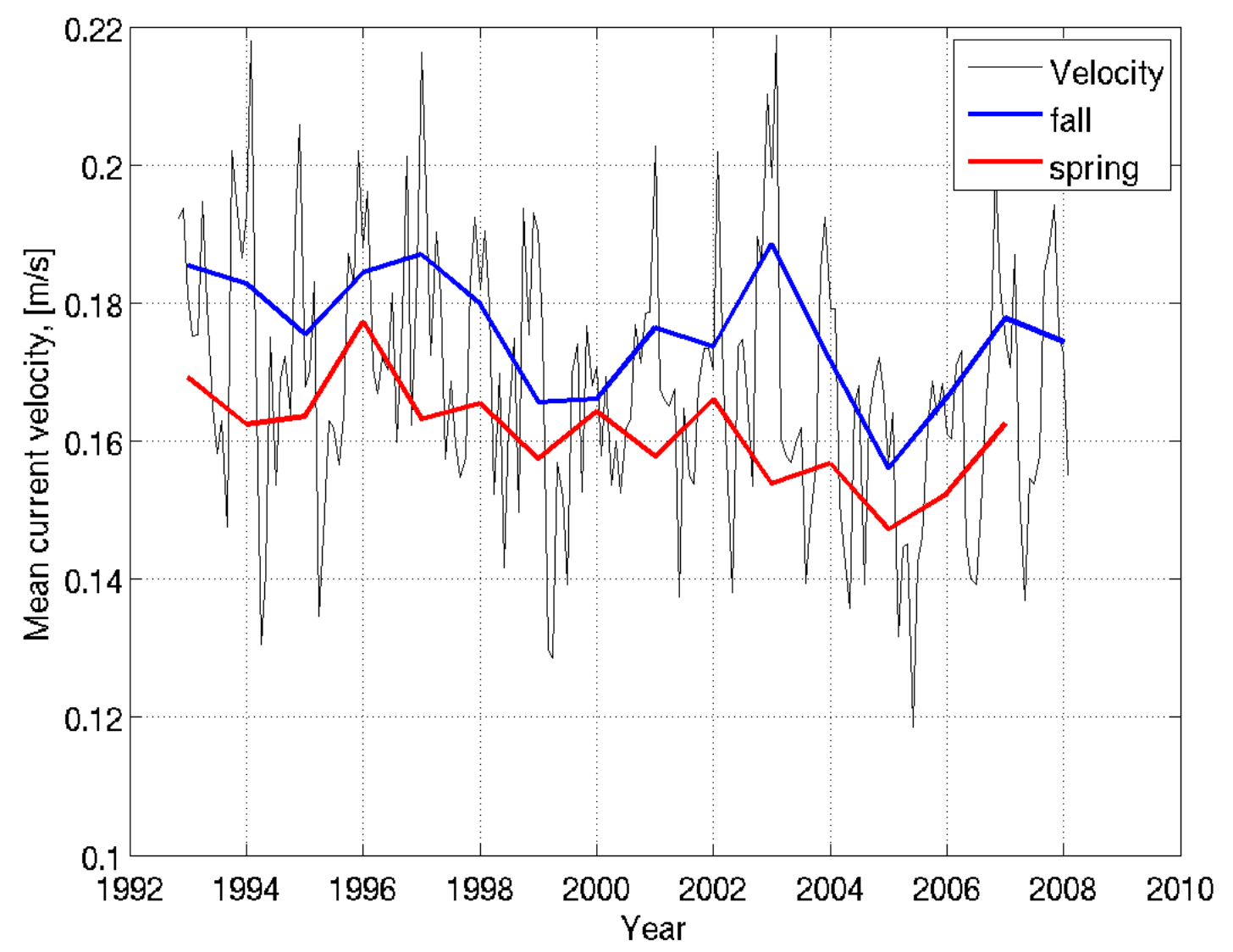

Figure 3-13: Monthly mean surface current velocity averaged over $150 \mathrm{~km}$ (black). Months with maximum (blue) mean velocity (as seen from Figure [3-9 November through January) and months with minimum (red) mean velocity (March through May) are averaged and plotted as function of year. 


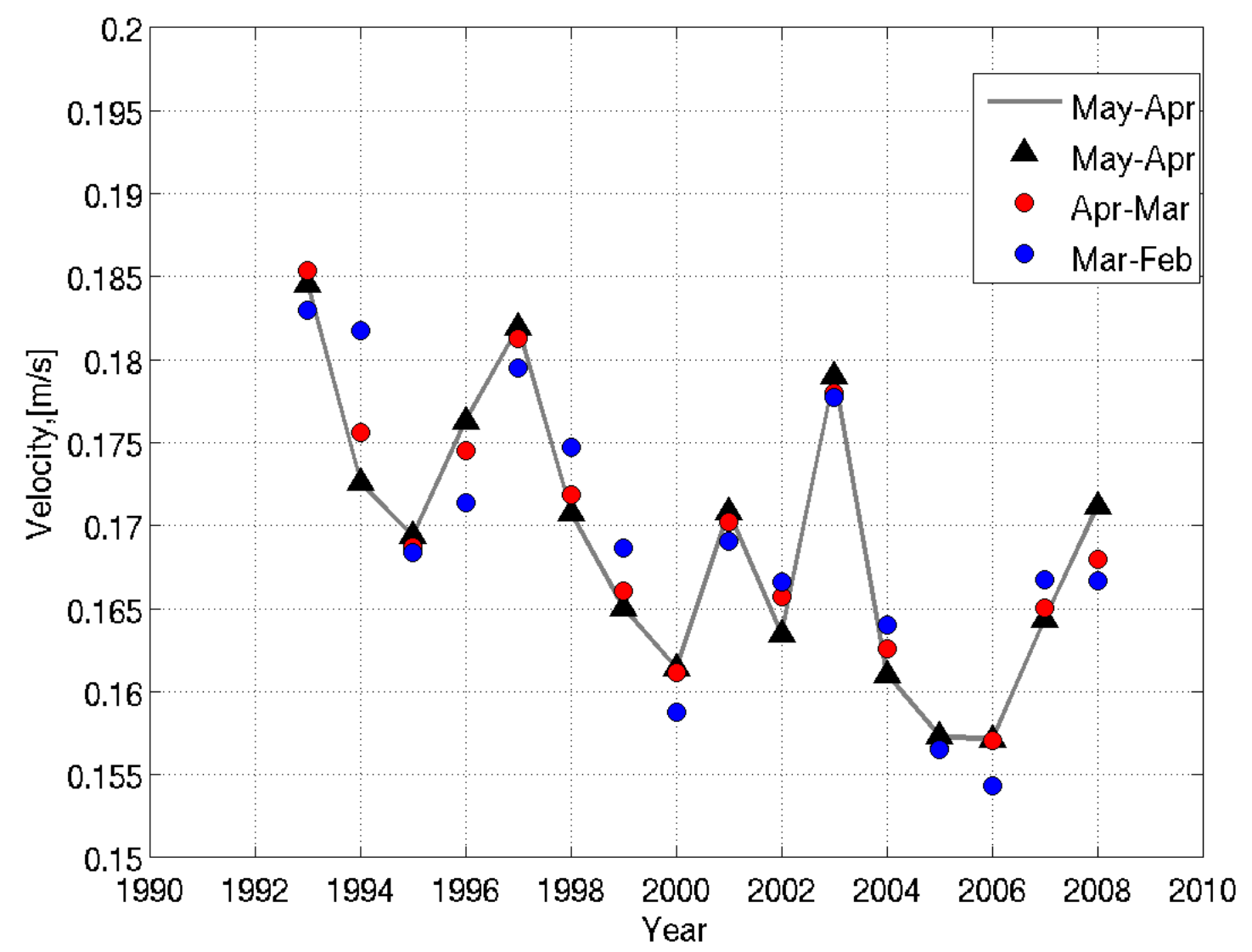

Figure 3-14: Interannual changes in the annual mean surface velocity (i.e. averaged over 12-months period and $150 \mathrm{~km}$ ) shown for different definitions of the year. Black triangles and gray line represent the year defined from, for example, May 1996 to April 1997, plotted against 1997 (as used in Hakkinen and Rhines, [27]), red circles represent the year defined from April to March of the following year (most commonly used, for example, in Straneo, [73]) and the blue circles represent the year defined from March to February of the following year (used in some modeling studies). 

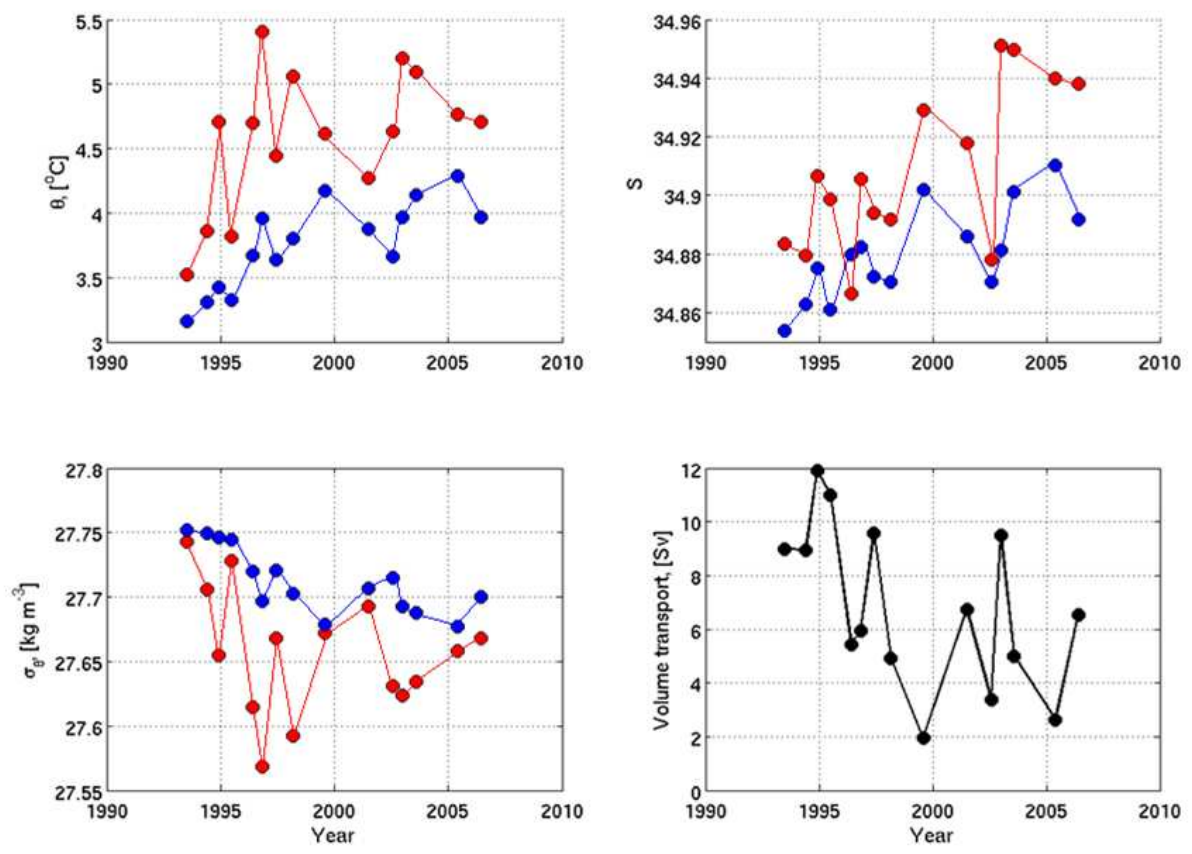

Figure 3-15: Properties of the of the inshore, centered at $75 \mathrm{~km}$ (red) and offshore, centered at $150 \mathrm{~km}$ (blue) boxes of the boundary current: a) potential temperature; b) salinity; c) potential density; d) volume transport of the inshore box. 


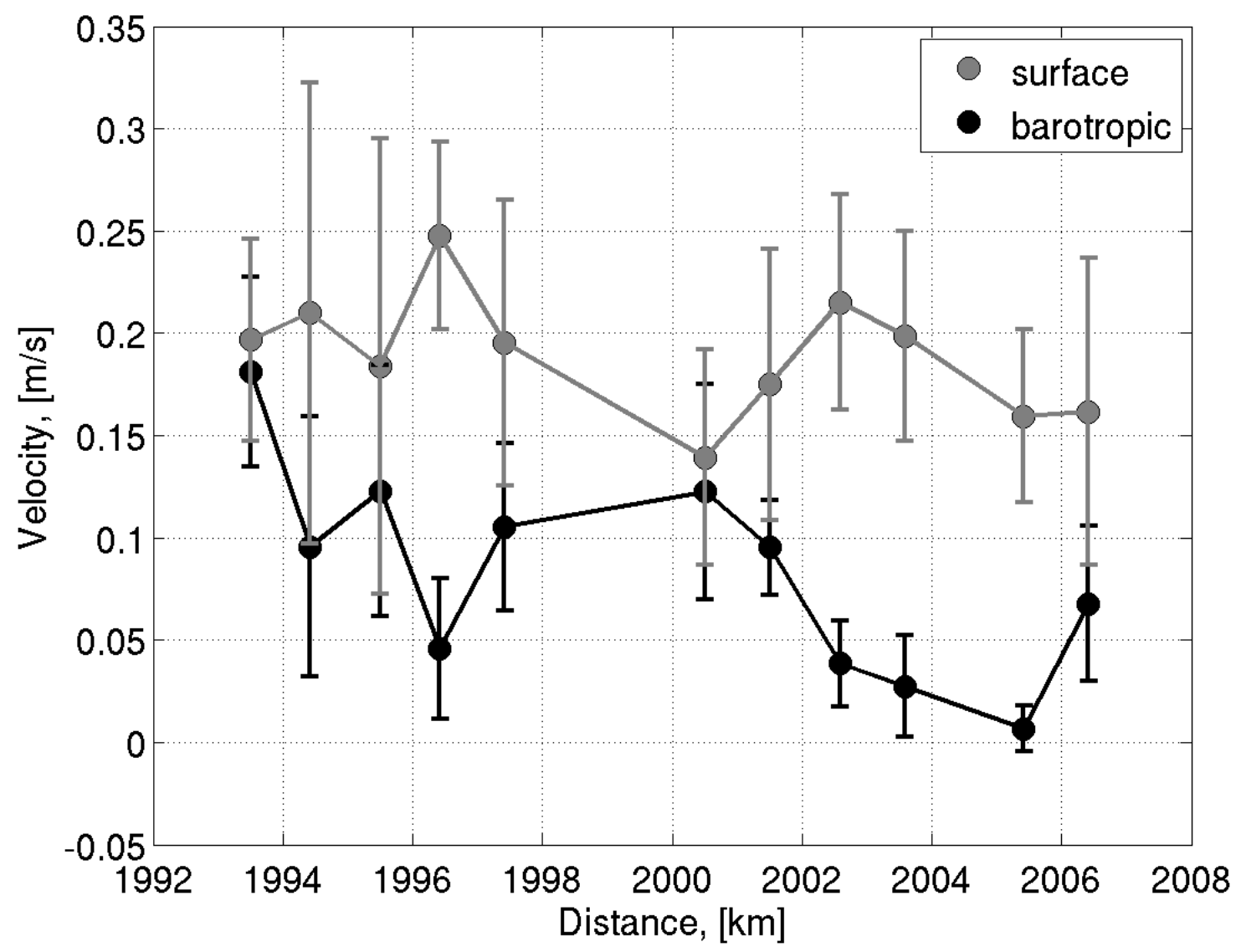

Figure 3-16: Surface (gray) and barotropic (black) velocity of the boundary current averaged over its width as a function of year. 
Table 1. Temporal distribution of the hydrographic data across northern portion of the AR7W section used in this study. The seasonal distribution used in the text is defined as spring $(\mathrm{S})$ and fall (F).

\begin{tabular}{|c|c|c|}
\hline Number & $\begin{array}{c}\text { Month } \\
\text { (season) }\end{array}$ & Year \\
\hline 1 & $6(\mathrm{~S})$ & 1993 \\
\hline 2 & $5(\mathrm{~S})$ & 1994 \\
\hline 3 & $11(\mathrm{~F})$ & 1994 \\
\hline 4 & $6(\mathrm{~S})$ & 1995 \\
\hline 5 & $5(\mathrm{~S})$ & 1996 \\
\hline 6 & $10(\mathrm{~F})$ & 1996 \\
\hline 7 & $2(\mathrm{~F})$ & 1997 \\
\hline 8 & $5(\mathrm{~S})$ & 1997 \\
\hline 9 & $2(\mathrm{~F})$ & 1998 \\
\hline 10 & $7(\mathrm{~S})$ & 1999 \\
\hline 11 & $6(\mathrm{~S})$ & 2000 \\
\hline 12 & $6(\mathrm{~S})$ & 2001 \\
\hline 13 & $7(\mathrm{~S})$ & 2002 \\
\hline 14 & $12(\mathrm{~F})$ & 2002 \\
\hline 15 & $7(\mathrm{~S})$ & 2003 \\
\hline 16 & $5(\mathrm{~S})$ & 2004 \\
\hline 17 & $5(\mathrm{~S})$ & 2005 \\
\hline 18 & $5(\mathrm{~S})$ & 2006 \\
\hline
\end{tabular}


Table 2. The seasonal distribution of the hydrographic properties (rows 2-4) and velocity (row 5).

\begin{tabular}{|l|c|c|}
\hline $\begin{array}{l}\text { Properties of the core } \\
\text { (seasonal weighted mean) }\end{array}$ & Spring & Fall \\
\hline Potential Temperature, ${ }^{\circ} \mathbf{C}$ & $4.35 \pm 0.47$ & $5.00 \pm 0.34$ \\
\hline Salinity & $34.90 \pm 0.03$ & $34.91 \pm 0.03$ \\
\hline${\text { Potential Density, } \mathbf{~ k g m}^{-3}}^{-3}$ & $27.67 \pm 0.04$ & $27.60 \pm 0.03$ \\
\hline Velocity, cm $/ \mathbf{s}^{-}$ & $12.4 \pm 10$ & $15.1 \pm 5$ \\
\hline
\end{tabular}

Table 3. Transports of the West Greenland Current (column 2), Irminger Current (column 3) and the full section (column 4) for the climatological mean (row 2), spring (row 3) and fall (row 4) sections.

\begin{tabular}{|l|l|l|l|}
\hline & WGC & IC & TOTAL \\
\hline CLIMATOLOGY & $\mathbf{1 . 8} \pm \mathbf{0 . 1 5} \mathrm{Sv}$ & $\mathbf{8 . 1} \pm \mathbf{0 . 9} \mathrm{Sv}$ & $\mathbf{2 9 . 1} \pm \mathbf{4 . 8 \mathrm { Sv }}$ \\
\hline SPRING (14) & $\mathbf{2 . 0} \pm \mathbf{0 . 1 7} \mathrm{Sv}$ & $\mathbf{7 . 5} \pm \mathbf{1 . 1} \mathrm{Sv}$ & $\mathbf{2 8 . 9} \pm \mathbf{5 . 8} \mathrm{Sv}$ \\
\hline FALL (5) & $\mathbf{1 . 7} \pm \mathbf{0 . 1 8} \mathrm{Sv}$ & $\mathbf{8 . 8} \pm \mathbf{1 . 6} \mathrm{Sv}$ & $\mathbf{2 9 . 2} \pm \mathbf{8 . 6 \mathrm { Sv }}$ \\
\hline
\end{tabular}




\section{Chapter 4}

\section{The impact of the boundary current changes on the interior: lateral fluxes.}

\subsection{Introduction}

The Labrador Sea's heat and fresh water budgets are topics of particular interest because they not only influence the local dynamics and circulation, but also contribute substantially to the budgets of the North Atlantic, and, ultimately, to the global ocean. Since the boundary current system is the main source of heat and fresh water for the Labrador Sea, the changes in the boundary current have a direct influence on the properties of the interior.

The heat and fresh water budgets of the Labrador Sea are tightly linked to the production of LSW, when the heat and fresh water are redistributed in the water column. Recently, LSW production has been the focus of many studies attempting to quantify its properties and location of formation (Marshall and Schott, [50]; Lilly et al., 47]; Lazier et al., [45]; Pickart et al., [58]; Yashayaev, 82]). The seasonal and interannual variability of the central Labrador Sea, where LSW is produced, have been 
documented (Lazier, 43]; Straneo, 73]; Avsic et al., [2]; Yashayaev, 82]), however, the observed changes still need to be better understood. A number of studies have argued that LSW production is correlated with the phase of the NAO, and, in particular, with the air-sea fluxes (Dickson et al., [18]; Våge et al., 78; ; Sarafanov 65]). Overall, the correlation worked well prior to the mid-1990s when the NAO switched from a positive to a non-persistent phase and the convective activity decreased. Since then, the Subpolar Gyre and the Labrador Sea seem to have entered a new regime in which the decrease in the surface fluxes does not simply explain the variability in the LSW production, the dynamics and heat balance of the region (Lazier et al., 45]; Lilly et al., 49]; Straneo, 73]). For example, during 1997 when the heat loss to the atmosphere was one of the largest in the 1994-2008 record, convection did not extend as deep as in 1994. It is important to understand why in the years with a relatively large heat loss (e.g. 1997) one doesn't see a bulk of the low-stratified convective product in the following year (Figure 4-1] and Figure 1 from Avsic et al., [2]). Two questions arise: Where did the heat arrive from to compensate the large heat loss and what was different in the driving forces of the restratification?

This chapter aims to find the answer to these questions by investigating the exchange between the boundary current and the interior, which, as suggested by numerous studies play a crucial role in the Labrador Sea system (Spall, 68, Katsman et al., 36]; Straneo, [73]). Specifically, the annual heat loss in the central Labrador Sea is balanced by the advection of heat from the warm boundary current system via the eddies which dominate the boundary current/interior exchange. This result is supported by theoretical (Spall, 68]; Straneo, [74]) modeling (Katsman et al., [36]) and observational (Lilly et al., [49]; Straneo, [73]) studies. Hence, it is important to understand the mechanisms which regulate this exchange on both seasonal and interannual time scales. In this chapter I focus on the interannual changes in the Labrador Sea.

All the components of the Labrador Sea have undergone variability on the in- 
terannual time scales over the last several decades: The interior has been shown to become warmer and saltier over the period of this study, in 1990-2008 (Yashayaev, [82]; Bersch et al., 3]; Straneo, [73]) and so have the boundary current system and the individually tracked ICAs (Chapters 2 and 3). What is the relation between the observed changes in the components of the Labrador Sea?

Here, I attempt to address these questions by estimating the lateral exchange between the boundary current and the interior and its interannual variability. I have shown (in Chapters 2 and 3) that both the boundary current system and the eddies undergo seasonal and interannual variations and here, I investigate how these changes influence the Labrador Sea's restratification. In particular, I am interested in finding out to what extent the variability in the properties of the interior water column are determined by that of the surface fluxes or by the variability in the lateral fluxes due to the changes in the boundary current. For example, Yashayaev and Loder, [84, claim that it is the surface fluxes that determine the amounts and properties of LSW formed but they do not take into account the changes in the boundary current. The theory developed by Spall, 68, and Straneo, 74], suggests that the exchange between the interior and the boundary current is proportional to the density gradient between the two regions and thus I expect the boundary current changes to have a direct impact on the rates and properties of the LSW formation.

\subsection{Approach}

The goal of this chapter is to understand how the changes in the boundary current affect the properties of the interior. I will use two distinct methods to infer the magnitude of the lateral fluxes: a theoretically based and a residual-based approach.

In the first "residual method" I use the interior heat balance and the air-sea fluxes from an OAFlux product (by Yu and Weller, [86]) to infer the lateral fluxes, and I further refer to it as "method 1". The heat budget for the Labrador Sea 
interior (defined in the Data section) can be expressed via six terms (assuming that the contribution from the ice cover is negligible because on average, ice does not form/melt in the interior of the Labrador Sea - Fenty, personal communication, 2010; Pickart and Spall, 61]). The changes in the interior heat content are due to the surface heat fluxes, the lateral fluxes from the boundary current, the lateral fluxes at the south-eastern boundary (with the open ocean), the fluxes due to the wind-driven Ekman transport and the vertical fluxes at the bottom of the water column. Consider each of these terms in detail.

The depth of the water column used in the study is limited to $1300 \mathrm{~m}$ and convection in 1996-2008 never reached this depth. Therefore, any vertical flux across this boundary must be due to the internal mixing alone:

$$
H F_{\text {vertical }}=\left.\rho_{0} c_{p}\left(\kappa_{v} \frac{\partial \bar{\theta}}{\partial z}\right)\right|_{1300}
$$

To estimate the diffusive vertical heat flux I use a reference density $\rho_{0}=1027 \mathrm{~kg} \mathrm{~m}^{-3}$, $\mathrm{c}_{p}=4200 \mathrm{~J} / \mathrm{kg}^{\circ} \mathrm{C}$, vertical eddy diffusivity $\kappa_{v}=10^{-5} \mathrm{~m}^{2} \mathrm{~s}^{-1}$ (Polzin et al., 62 ) and calculate the mean interior $\theta_{z}$ obtained from the float data at $1300 \mathrm{~m}$. The resulting vertical heat flux is much smaller $\mathrm{O}\left(0.01 \mathrm{~W} \mathrm{~m}^{-2}\right)$ than the annual net heat loss over the Labrador Sea $\left(35 \mathrm{~W} \mathrm{~m}^{-2}\right)$ and thus, I assume that this term can be neglected in the heat balance. The contribution from the Ekman layer is potentially important along the north-east and south-west boundaries (along the coasts of Greenland and Canada, respectively) due to the fact that the mean winds blow from the north-west (Pickart et al., [58]). To estimate this term, I calculate the heat flux associated with the transport in the Ekman layer on the Greenland side:

$$
E k=\rho_{0} c_{p} U_{E k} \Delta \theta H_{m x l} L .
$$

Given a realistic annual mean wind stress of $0.1 \mathrm{~N} \mathrm{~m}^{-2}$ obtained from the NCEP reanalysis, the estimated velocity in a $H_{m x l} \sim 50 \mathrm{~m}$ Ekman layer is equal to $U_{E k} \sim$ $0.01 \mathrm{~m} \mathrm{~s}^{-1}$. The temperature difference between the coast of Greenland and interior is $\Delta \theta \sim 2{ }^{\circ} \mathrm{C}$, so the contribution from the Ekman layer along the $\mathrm{L} \sim 300 \mathrm{~km}$ long 
Greenland shore is $\mathrm{O}(10 \%)$ of the annual mean surface fluxes. The exchange of the interior region with the south-eastern open boundary can be due to either the mean circulation or the eddies. There is no indication of the enhanced eddy activity on the south-eastern side of the Labrador Sea (Prater, 63]; L03) and the mean flow is weak, (V $\sim 1 \mathrm{~cm} \mathrm{~s}^{-1}$, Lavender et al., [42; Pickart and Spall, 61]). Assuming the temperature difference between the interior region and the open ocean of $\Delta \theta \sim 1{ }^{\circ} \mathrm{C}$ and the depth of the recirculation cells of $H_{c} \sim 1000 \mathrm{~m}$ and the width $\mathrm{W} \sim 60 \mathrm{~km}, \mathrm{I}$ estimate the heat flux associated with the mean flow as

$$
H F_{\text {mean }}=\rho c_{p} V \Delta \theta H_{c} W,
$$

that can account for $7 \%$ of the surface flux. Assuming the eddy diffusivity $\kappa_{H}=$ $0.6 \cdot 10^{7} \mathrm{~cm}^{2} \mathrm{~s}^{-1}$ (Straneo et al., [72]) and the same temperature gradient between the open ocean and interior, I estimate that the heat flux associated with the eddies is $\mathrm{O}(10 \%)$. Hence, I conclude that there are only three dominant terms left in the heat balance of the interior region: the heat content changes in the interior are mainly driven by the changes in the surface and lateral exchange with the boundary current. This, in turn, is dominated by the lateral eddy fluxes due to boundary current instabilities as shown by the numerical experiments of Spall, 68. The amount of heat that is contained in the interior varies monthly and interannually. These changes are mainly attributed to two terms: the changes in the heat extracted from the surface of the ocean during the winter and the amount of heat converged into the region by the eddies from the boundary current. This method has been successfully applied to the Labrador Sea by Straneo, [73], where she was able to reproduce the observed changes in the Labrador Sea interior's heat content on seasonal and interannual time scales.

Given this assumption, consider the balance of heat in the interior on the interannual time scales. It can be mathematically presented as:

$$
\Delta H C \sim(Q+L F) \cdot \Delta t,
$$


where $\triangle H C$ is the interannual heat content change in time $\Delta t ; Q$ - surface fluxes and $L F$ - lateral fluxes. The lateral fluxes can be inferred from this balance as the residual between the heat content change and the surface fluxes (see details below). The heat content of the interior region's upper $1300 \mathrm{~m}$ is calculated from monthly mean interior temperature profile, $\theta$, as done in Straneo, [3]. The heat was never extracted from the layers deeper than $\sim 1000$ m during the period of study and thus, the assumption (proposed by Straneo, [73]) that there is limited vertical heat flux through the $1300 \mathrm{~m}$ boundary in the interior is reasonable. (From the practical point of view $1300 \mathrm{~m}$ is the depth of data sampling common for both float data sets used in this study):

$$
H C=\rho_{0} c_{p} \int_{-1300}^{0} \theta(z) d z
$$

where $\rho_{0}$ is the reference density equal to $1027 \mathrm{~kg} \mathrm{~m}^{-3}, \mathrm{c}_{p}=4200 \mathrm{~J} / \mathrm{kg}^{\circ} \mathrm{C}$.

The surface fluxes used in method 1 are the average of the monthly mean net surface fluxes over the Labrador Sea obtained from OAFlux reanalysis (Yu and Weller, [86]). A more in-depth discussion of the surface fluxes can be found in the "Data" section of this chapter. I estimate the heat content change from one year to another and use the month of June as the starting month. This is based on the fact that the restratification of the interior has already started by June regardless of the duration of convection (more discussion of this choice is provided in the "Data" section). The uncertainties associated with this approach are discussed in the last section of this chapter.

Method 2, the theoretical method, follows the work of Spall, 68, and Straneo, [74], who used a theoretical parametrization of the lateral fluxes

$$
\overline{u^{\prime} T^{\prime}}=c V_{i n}\left(T_{i n}-T_{o}\right)
$$

where $\mathrm{c} \sim 0.025$ is an empirically determined constant for the Labrador Sea (Spall, [68], $\mathrm{T}_{\text {in }}-\mathrm{T}_{o}$ - is the temperature difference across the boundary current and $\mathrm{V}_{\text {in }}$ is 
the boundary current velocity to estimate the amount of heat that enters the interior as a function of density gradient between the interior and the boundary current. Both Spall and Straneo have used idealized models of the ocean to support their findings. Straneo also tested her model against the observations from the Ocean Weather Ship Bravo (years 1964 to 1973) and showed that the theory successfully reproduces the interannual variability observed in the Labrador Sea during those years including the shutdown of convection at the time of the Great Salinity Anomaly.

Method 2 relies on several assumptions. First, the exchange of properties between the interior and the boundary current is mainly the result of the baroclinic instability of the boundary current (Lilly et al., 49]; Spall, 68]; Straneo, 74]). Second, the interior region is spatially uniform and can be represented by a single water column. Here I utilize the hydrographic and float data to use in the theoretical formulation based on these assumptions. The theory assumes that the lateral fluxes are proportional to the density gradients (or temperature gradients, in case of the linear equation of state where salinity changes are small) between the boundary current and interior. In order to test this assumption I used the linear equation of state and estimate the contribution of temperature and salinity to the changes in density. Given the differences between the interior and the boundary current of $\theta \sim 3{ }^{0} \mathrm{C}$ and $\mathrm{S} \sim 0.06$, the temperature contribution dominates the salinity contribution by a factor of 10 . Assuming that density is mainly dominated by temperature I get:

$$
\overline{u^{\prime} T^{\prime}} \sim \frac{c}{\alpha} V_{b . c .} \frac{\rho_{b . c .}-\rho_{\text {int }}}{\rho_{0}}
$$

where $\alpha=-10^{-4} C^{-1}$ - is the thermal expansion coefficient; $V_{\text {b.c. }}$ - absolute velocity of the boundary current for a given section; $\rho_{\text {b.c. }}$ - density in the boundary current core; $\rho_{\text {int }}$ - density of the interior box or floats $\rho_{0}$ - reference density, same as in method 1 . 


\subsection{Data}

Both methods require to know the variability of the interior Labrador Sea properties. In method $1 \mathrm{I}$ need to estimate the heat content of the interior and in method 2 I need to know its density to obtain the gradients between the boundary current and interior regions. Following the definitions in the previous studies by Lilly et al., [49] and Straneo, [73, I define the interior as the region offshore of $3300 \mathrm{~m}$ isobath and assume that the properties of the Labrador Sea interior are spatially uniform. Assuming interior homogeneity, its properties can be represented as the properties of a single water column obtained as a spatial average over this area (similarly to the Ocean Weather Ship Bravo mooring that represented the whole interior region in the study by Avsic et al., [2, and Straneo, [73]). In order to obtain the interior properties, I complement the hydrographic data set described in Chapters 2 and 3 by the float data. Floats sample the different areas of the Labrador Sea interior weekly and thus, averaging of the profiles in most cases gives a reasonable representation of the interior region and its variability in time. The cases when the float data should be interpreted with caution are discussed in the subsection "Uncertainties".

The air-sea flux data product (OAFlux reanalysis, described in detail later in the text) is used to estimate the surface fluxes. The hydrographic data are described in Chapters 2 and 3 so I will only focus on the float data and objectively analyzed surface flux reanalysis, OAFlux (Yu et al., [86]).

The float data includes two different data sets: Profiling Autonomous Lagrangian Current Explorer (PALACE) and Argo floats. The PALACE float data set consists of the interior monthly mean profiles from January of 1996 until December of 2000. The time series of temperature and salinity for the Labrador Sea's interior were created by Straneo and described in detail in Straneo, [73]. The Argo float data (downloaded from http://www.usgodae.org/cgi-bin/argo_select.pl) became available in the Labrador Sea since May of 2002, however, the temporal and spatial coverage vary considerably during this period. The data were downloaded in the delayed mode where the variables have salinity calibration adjustments included. Argo data were 
grouped into the monthly mean profiles for the interior of the Labrador Sea similarly to the processing of the PALACE floats (done by Straneo, 73]). First, the Argo data set was quality controlled in order to eliminate all the property-depth profiles that contained spikes in either potential temperature or salinity that deviated from the mean by more than three standard deviations. For consistency with PALACE floats, where the interior is bounded by the $3300 \mathrm{~m}$ isobath, I use the same definition while constructing the Argo mean (see schematic in Figure 1-1). While constructing the time series, I carefully considered the spatial distribution of the float properties that appear in the mean. If the data were clustered far from the western/central part of the Labrador Sea and were located near the eastern side of the basin close to 3300 $m$ isobath, I excluded this monthly mean profile from the heat content calculation because it represented the properties of the boundary current rather than the properties of the interior. Another criterion for omitting the monthly mean profile was based on our knowledge of the boundary current and eddy properties. If the interior profile resembled the boundary current, it was likely sampling either a boundary current meander or a detached eddy. Such profiles were also eliminated from the interior mean as they would give a biased representation of the Labrador Sea's interior.

I also require at least four independent profiles to represent the interior in a monthly mean. The monthly means that are obtained from averaging of three and fewer profiles are not included in the time series (mainly during some months in 2002 and August of 2003).

The surface flux reanalysis, OAFlux product, needed for the estimation of the interior heat content is obtained from the objectively analyzed fields of the air-sea fluxes over the entire Labrador Sea (from $45^{0}$ to $60^{\circ} \mathrm{W}$ and $55^{0}$ to $62^{0} \mathrm{~N}$ ) produced by $\mathrm{Yu}$ and Weller, [86, that can be downloaded from the website http://oaflux.whoi.edu/data.html. This data product utilizes a combination of satellite products, ship reports and surface meteorology from numerical weather prediction (NWP) reanalysis outputs which makes it the most reliable air-sea product available in this region (see Yu et al., 85] for the comparison with NCEP and other products). The data product used in the analysis includes the monthly mean net surface heat flux available for the period from 
1990 to 2007. More details can be found in the project report by Yu et al., 85].

\subsection{Results}

\subsubsection{Lateral flux estimations}

From the analysis of the interior monthly mean potential temperature and salinity profiles (Figure 4-2) one sees a pronounced seasonal and interannual cycle of the central Labrador Sea that has previously been discussed in a number of works (Lilly et al., 47]; Straneo, [73]; Yashayaev, 82]). The interior of the Labrador Sea is coldest and freshest during the winter when convection mixes cool and fresh waters down from the surface. It is warmest and saltiest prior to the following cycle of convection, at the end of the fall, when the restratification has restored the water column to its pre-convective state. In an interannual sense, the coldest and freshest water column is observed at the beginning of the float period, in 1996, and then it gradually becomes warmer and saltier towards 2009.

Following the approach described in method 1, I obtain the time series of the heat content and the surface fluxes for the interior. The heat content itself is a measure of the accumulation or loss of heat by the water column. Having the time series of temperature profiles and applying the formula 4.5, one can estimate the Labrador Sea's interior heat content. Similarly, it can be done from the hydrographic data (discussed later in the text).

The seasonal cycle of the interior heat content calculated using formula 4.5 is shown in Figure 4-3. The lowest heat content of the interior is at the end of convection, in April-May and then the restratification begins, leading to the heat content increase. By the end of the fall season, the surface fluxes start extracting heat from the water column and the heat content decreases from its maximum in August towards the end of the year. The interannual variability of the monthly means is reflected in the stan- 
dard deviation of the mean (i.e. the standard error) over the 12-year record (Figure 4-3).

Seasonally, the property difference between the boundary current and interior are the largest during the fall/winter when the interior is being convected and the boundary current is warm and salty as seen from Chapter 3. During the winter, the observations document an increase in the eddy population (Prater, 63]; Lilly et al., 49]). During the summer, when the rapid phase of the restratification ends (Straneo, 73] ), the lateral fluxes are minimized, likely because the interior has already restratified and the radial density gradients are the smallest. This assertion is supported by the numerical simulations by S. Legg (personal communication, 2009) who showed that the fastest growth rate of the boundary current instabilities occurs in the fall, while the current is much more stable during the spring.

In order to estimate the heat content changes from one year to the following, one needs to choose a start and an end month. Based on the seasonal cycle and on the availability of the float and hydrographic data for most of the years, I choose June as a good representative of the post-convective state of the interior. If one had a perfect coverage, it would be better to use the April or May observations because in June the restratification has already begun. The May data, however, are sparse (April data are not considered for two reasons: i) the bad float coverage in three years of the record and ii) the fact that no hydrographic data are available for April for the substitution in the missing years) and in a few years are biased towards the eastern side of the interior basin. No float data are available for the year 2001, and no May-July float data, with an exception of one profile are available for 2003. In order to get a continuous record of the interior properties, I used the hydrographic data to calculate the heat content from the AR7W data set described in Chapter 2. For the hydrographic data, I define an interior profile as the average of all the profiles deeper than 3300 m excluding the Irminger Current Anticyclones and the meanders of the boundary current (see Chapter 2 for criteria). I estimate the heat content of the interior from the hydrographic data that are available mostly once a year during May-July, and compare it with the heat content from the float data obtained for the same month. 
The comparison shows a good agreement between the float and hydrographic data for the years when we have both data sets except for July 2002 value when the heat content calculated from the floats exceeds the hydrographic estimate (Figure 4-4). This discrepancy is mainly due to the fact that the hydrographic mean profile represents the central/western side of the basin while the mean from the floats is shifted to the eastern side and sampled the water column which has been quickly restratified by the boundary current fluxes. I conclude that it is reasonable to estimate the interior heat content from the float data in combination with the hydrographic data when the float record is unavailable.

Interannually, we see the warming of the central Labrador Sea that has been in part previously documented from 1997 to 1999 and from 2003 to 2005 by Avsic et al., [2]; from the Bravo mooring years to late 1990s by Straneo, [73]; and over the last decades by Yashayaev [82. The heat content of the Labrador Sea interior has increased from 1996 to 2009 with a local minimum in 2000, and after 2004 it slowly decreases until 2009. It is not evident from the heat content changes alone what role the eddies and the boundary current play in the restratification. In order to estimate the lateral fluxes, we first look at the air-sea fluxes for 1996 to 2007, the period for which the float data are available (Figure 4-5). The year is defined as a 12-month period that starts in May of one year, when the surface fluxes are small, to April of the following year (e.g. the year 1997 includes the months from May 1996 to April of 1997). The surface fluxes reached their maximum values in our record in 1997 (negative Q in figure 4-5 implies that the heat is lost from the ocean to the atmosphere). There is no distinguishable trend from 1996 to 2007 in the surface fluxes, however, there are a few local maxima besides 1997. If one infers the lateral fluxes as the difference between the heat content change from one year to the following, and the surface fluxes (Figure 4-5), it is obvious that the lateral fluxes were maximum in 1997 and 2003 and it is hard to find any trend in the other years (Figure 4-7). Overall, I find that the residual lateral fluxes roughly balance the surface fluxes with an exception of years surrounding 1997 and 2003. These are the years, as argued 
in Chapter 3, when the boundary current's properties and velocity experienced an abrupt increase, Figures 3-14, 3-15).

Next, I estimate the variability of the lateral fluxes using method 2 for 1996-2007 from theory and data (Spall, 68, and Straneo, [74). To obtain the density gradient between the boundary current and interior region I use the hydrographic data described in Chapter 3 for the interior and boundary current complemented by the interior float data to obtain a continuous coverage in time. I use the same definition as in Chapter 3 to define the boxes in the core and on the edge of the boundary current (Figure [3-7). I average the properties in the boxes $400 \mathrm{~m}$ deep and $20 \mathrm{~km}$ wide centered at $500 \mathrm{~m}$ and for the boundary current core - at $60 \mathrm{~km}$ offshore and for the interior - at $140 \mathrm{~km}$ offshore. Thus, the lateral fluxes estimated in this way are only representative of the 300-700 $\mathrm{m}$ water column. These estimated fluxes only qualitatively represent the observed lateral fluxes, however, this representation is reasonable to study the variability of the lateral fluxes. There are two reasons that support this method of the lateral flux estimation: i) the majority of heat in the water column is contained within the IW layer that is represented by the boxes here; and ii) even if it is known that the lateral fluxes decrease as the boundary current circulates around the basin (Straneo, [74]), the lateral flux variability estimated at the entrance into the Labrador Sea is indicative of the interannual changes in the boundary current. In practice, this is the depth of the maximum density gradient between the two regions and thus the dominant contributor to the lateral exchange. The density of the offshore box that represents the interior is compared to the density in the same depth range for the yearly mean float data (shown in triangles in figure 4-6). The interior density (in both data sets) is decreasing at the same rate as in the boundary current over 1996-2007 period. This similarity in the values where both data sets are available allows us to merge these data together for a continuous record in the interior box. On top of the lightening trend, the boundary current experiences a much larger variability than the interior, that is reflected in two local density minima in 1997 and 2003 (Figure 4-6). 
The changes in the boundary current and interior are related and both regions become lighter. However, the boundary current exhibits two special events (when the boundary current abruptly becomes warmer, saltier and faster), which are not directly reflected in the interior density data (1997 and 2003). This suggests that variations in the boundary current that originate upstream can rapidly affect the interior. This estimation of the lateral fluxes, however, is obtained from the boundary current values at the entrance into the Labrador Sea where the property gradient between the boundary current and interior is the largest. As a result of the continuous exchange with the interior the boundary current releases its anomalous properties via the eddies and thus this lateral flux calculation overestimates the true net value around the basin due to the decrease in the density gradient along the boundary current's path. If I substitute the values for density and velocity of the boundary current obtained from data into 4.7. I can estimate the lateral fluxes representative of the IW depth range (Figure 4-7). The variability in the lateral heat flux $\left(\rho_{0} c_{p} \overline{u^{\prime} T^{\prime}}\right)$ estimation based on the theoretical prediction qualitatively agrees with the estimation inferred from the interior heat balance. The same "special" years 1997 and 2003 stand out of the analysis. My conclusion is that the upstream changes in the boundary current's properties and velocity described in detail in Chapter 3 affected the magnitude of the lateral fluxes in these years. The lateral flux changes are, according to this analysis, due both to the decrease in density and the increase in boundary current velocity. A sensitivity study of the velocity changes shows that the difference between the average constant velocity $\left(V_{\text {b.c. }}=15 \mathrm{~cm} \mathrm{~s}^{-1}\right)$ and velocity of the individual sections only matters for the lateral flux estimation in the years 1997 and 2003 when there was an abrupt change in the boundary current properties.

\subsubsection{Uncertainties}

This work is the first attempt to show from the in situ data what controls the changes in the heat content of the Labrador Sea by computing the lateral fluxes and taking into account the changes both in the interior and the boundary current. The work utilizes two independent methods that allow to infer the lateral heat fluxes. The 
uncertainties associated with the hydrographic data are described in Chapters 2 and 3 so in this section I will focus on the errors that come from the float and air-sea flux data products.

One of the largest errors in the estimation arises from the fact that the floats are unevenly distributed in space and time. The estimate of the heat content obtained from the floats located in the eastern part of the basin can differ from the heat content estimate for the western part of the Labrador Sea obtained from the hydrographic section by $10-15 \%$. The changes in the mean heat content along the AR7W hydrographic line are shown in figure 4-8. They are calculated from the non-wintertime mean 1990-1997 hydrographic section across the Labrador Sea. This period is the time of the intense convection during the low NAO phase and the difference between the west and east is the most significant. I note that even during these years characterized by the intense convection, the heat content change across the basin is five times smaller than the interannual heat content variability.

Another uncertainty originates in the highly variable coverage of the Labrador Sea by the floats in time. The number of profiles in the interior ranges from 1 to 30 per month making the estimation of the monthly mean complicated during the months with coverage of less than four profiles. These monthly means are not included in the calculations. The reader should also keep in mind that due to the large number of float profiles over the 14-year period, individual profiles were considered only in the cases of unrealistic looking monthly mean profiles. Most of the eddies have been eliminated from the analysis by restricting the analysis of the interior profiles to the ones that only deviate from the mean by no more than 3 standard deviations and by applying the criteria described in Chapter 2 .

The air-sea fluxes from the OA Flux project used in this work have the smallest error of the available reanalysis products and climatologies based on the shipboard observations (da Silva et al., [14 and Josey et al., 38]). However, the total uncertainty in the air-sea flux is on the order of $10-20 \mathrm{~W} \mathrm{~m}^{-2}$ in the high latitudes, which is reflected in a $15 \mathrm{~W} \mathrm{~m}^{-2}$ error bar in Figure 4-5 (personal communication, L. Yu, 2010). The analysis of three major data sources: the shipboard data, the satellite data that 
particularly contributes to the increase in resolution/coverage of the Labrador Sea and the atmospheric reanalysis products (such as NCEP) allows to reduce the errors in the calculations of the various components of the net surface fluxes. It is possible that the error on the variability in the surface fluxes is smaller than the error in the absolute values of the product since the constant offset of the true value does not cause the increase in the uncertainty of the variability. The detailed discussion of the errors associated with the air-sea flux estimation is available in the project report by Yu et al, 85.

\subsection{Summary and discussion}

In this chapter I have studied the boundary current / interior interaction by focusing on the lateral fluxes and their interannual variability. I aimed to show that the changes in the boundary current and associated changes in the lateral fluxes can have a large influence on the interior properties. The lateral and surface fluxes are mainly in balance with an exception of some years when an increased inflow of the boundary current water into the interior occured: 1997 and 2003. It is likely that the enhanced eddy activity or changes in their properties associated with the changes in the boundary current are responsible for the enhanced restratification of the Labrador Sea during the years with the large heat loss. The changes in the boundary current that affect the magnitude of the lateral fluxes are responsible for the lack of preconditioning in the years following 1997 and 2003. The distinguishing result of this study is that, for the first time, I have provided evidence that changes in the boundary current impact the amount of heat that is transported to the interior of the Labrador Sea. This finding shows that the ocean-driven variability can be an important contributor to setting the conditions for convection in the Labrador Sea and should not be neglected.

Understanding of the interior/boundary current interaction is essential for understanding of the Labrador Sea's heat budget, its seasonal and interannual changes. 
Overall, the lateral exchange that supplies the necessary heat from the boundary current to the interior to compensate the loss of heat during the winter, is a crucial process in understanding of the water mass transformation within the Labrador Sea and the whole North Atlantic. 


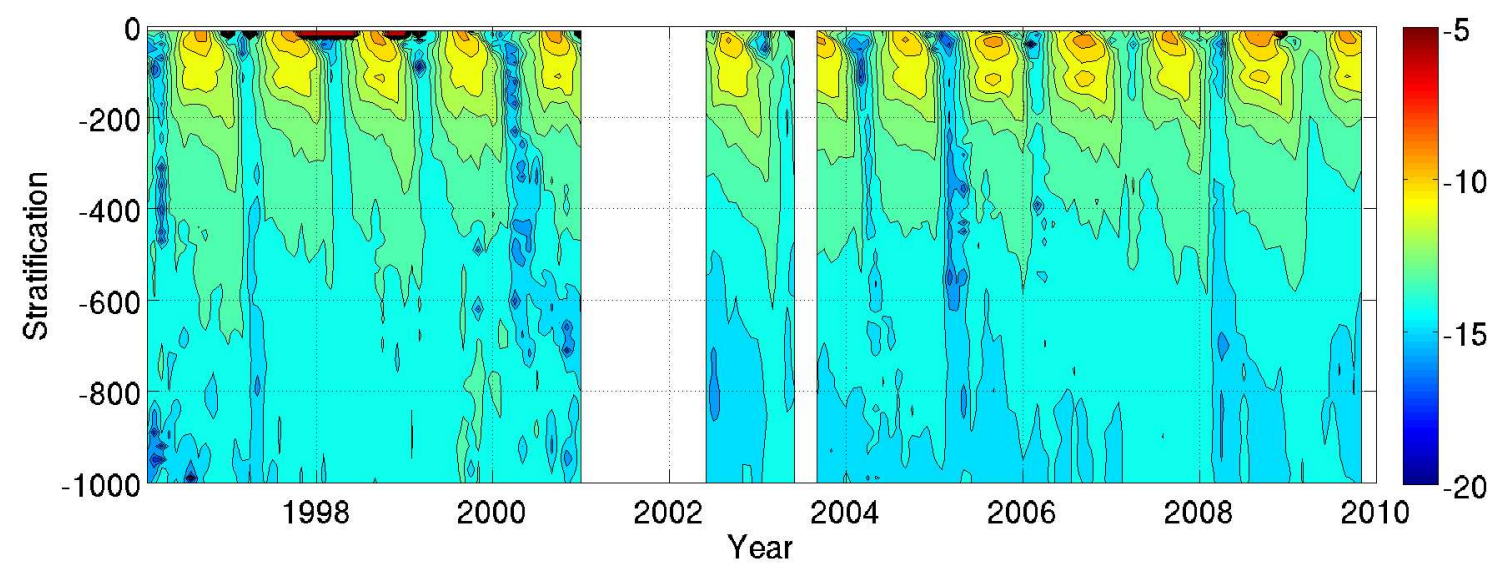

Figure 4-1: Stratification of the Labrador Sea interior water column based on the float data set. 

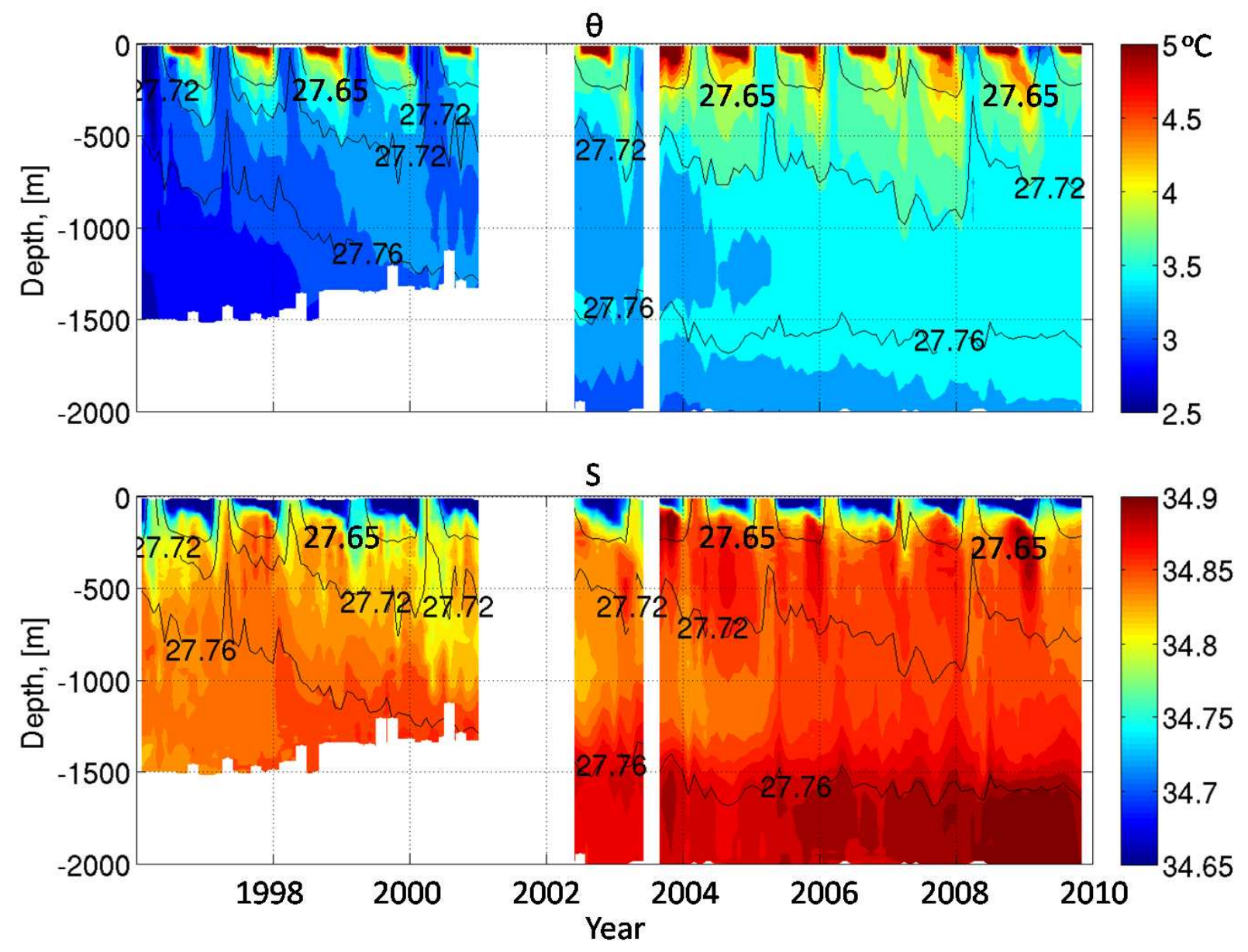

Figure 4-2: a) Potential temperature and b) salinity of the interior Labrador Sea with the contours of potential density overlaid. 


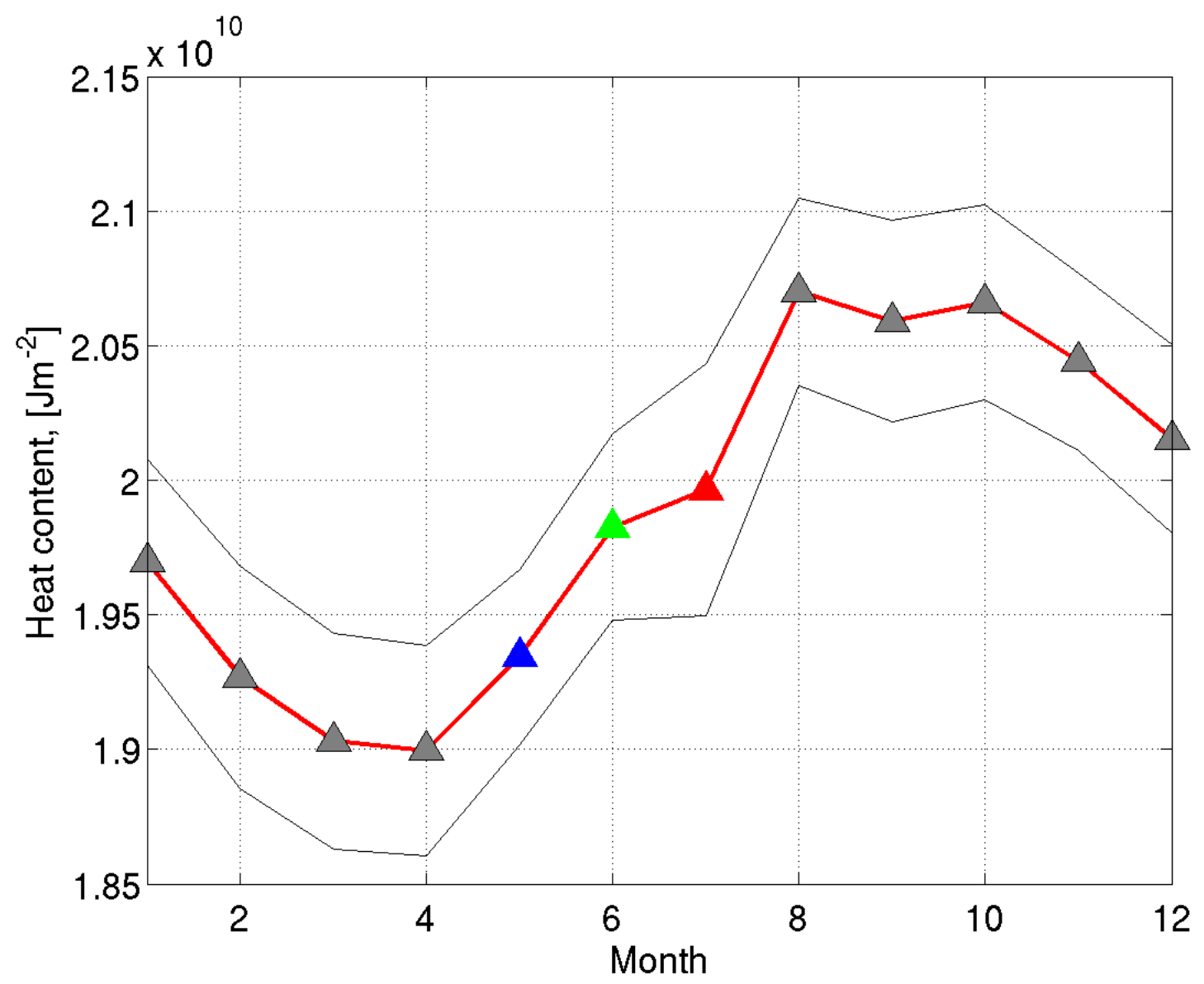

Figure 4-3: Mean seasonal distribution of the interior heat content with highlighted May (blue), June (green) and July (red) used in the future analysis. The thin black lines indicate the mean plus/minus standard error. 


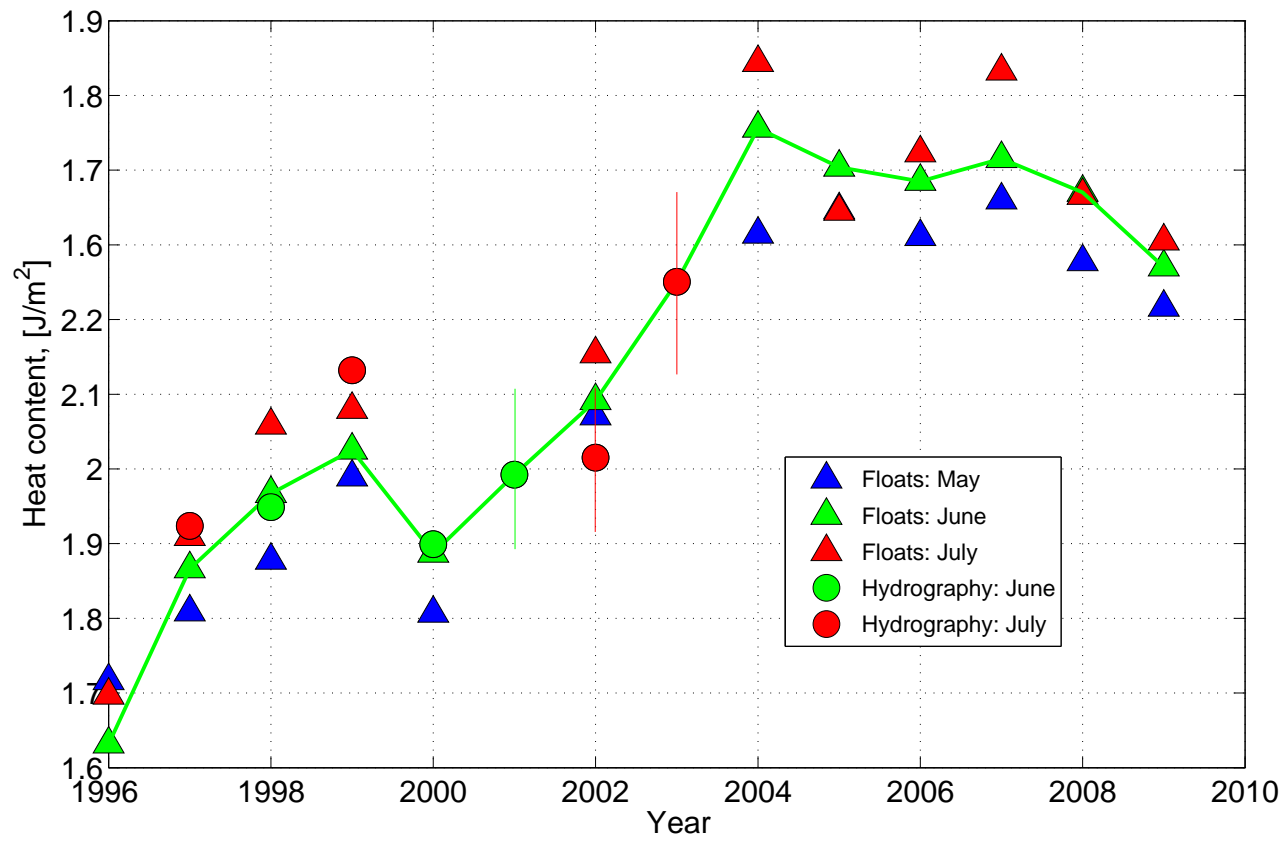

Figure 4-4: Interannual interior heat content changes calculated from the float (triangle) and hydrographic (circle) data. The uncertainties of the heat content estimation from some of the hydrographic sections is shown in thin lines of the corresponding color. 


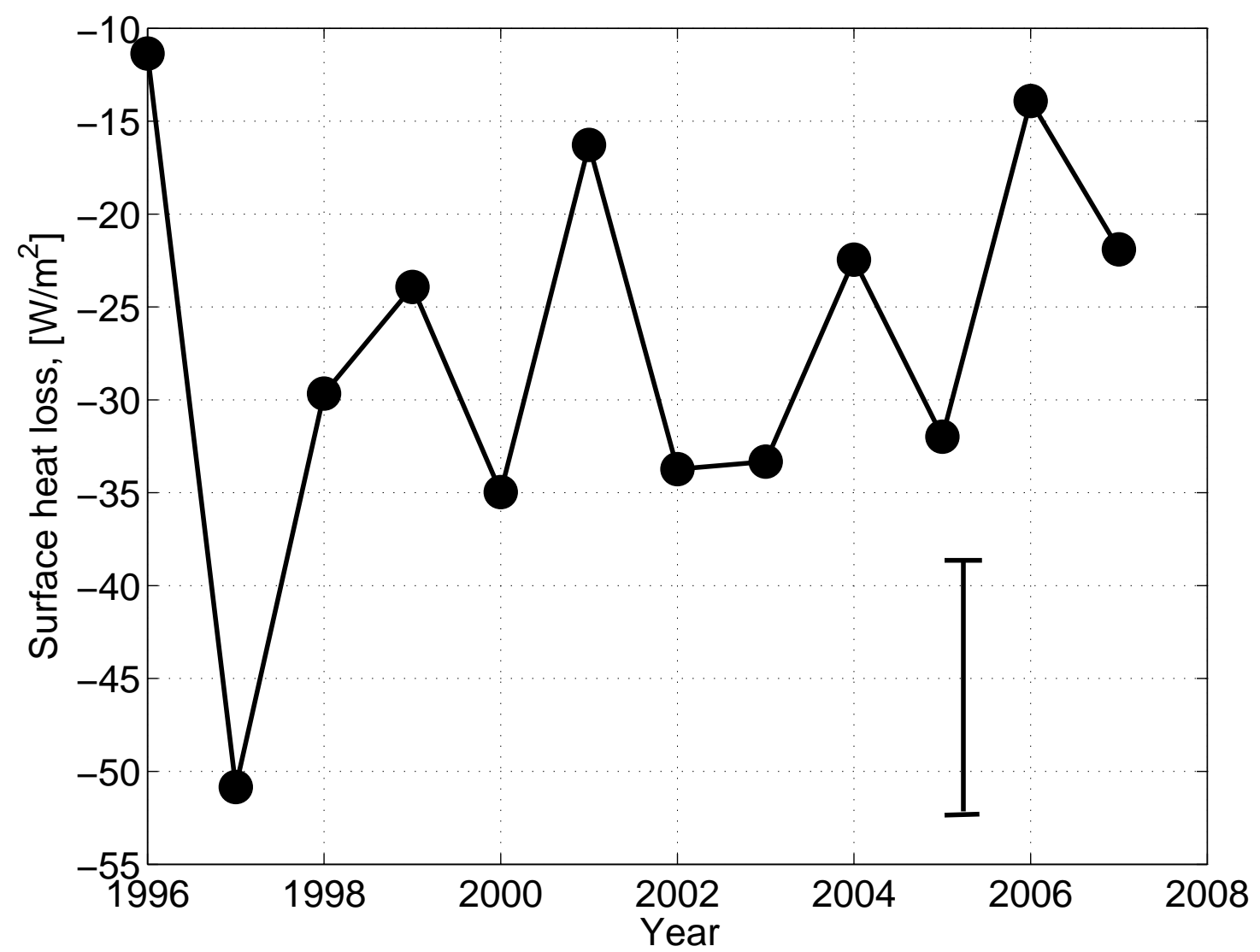

Figure 4-5: Net surface heat fluxes over the Labrador Sea. The uncertainty of 15 $\mathrm{Wm}^{-2}$ is shown in the right bottom corner (see text for details). 


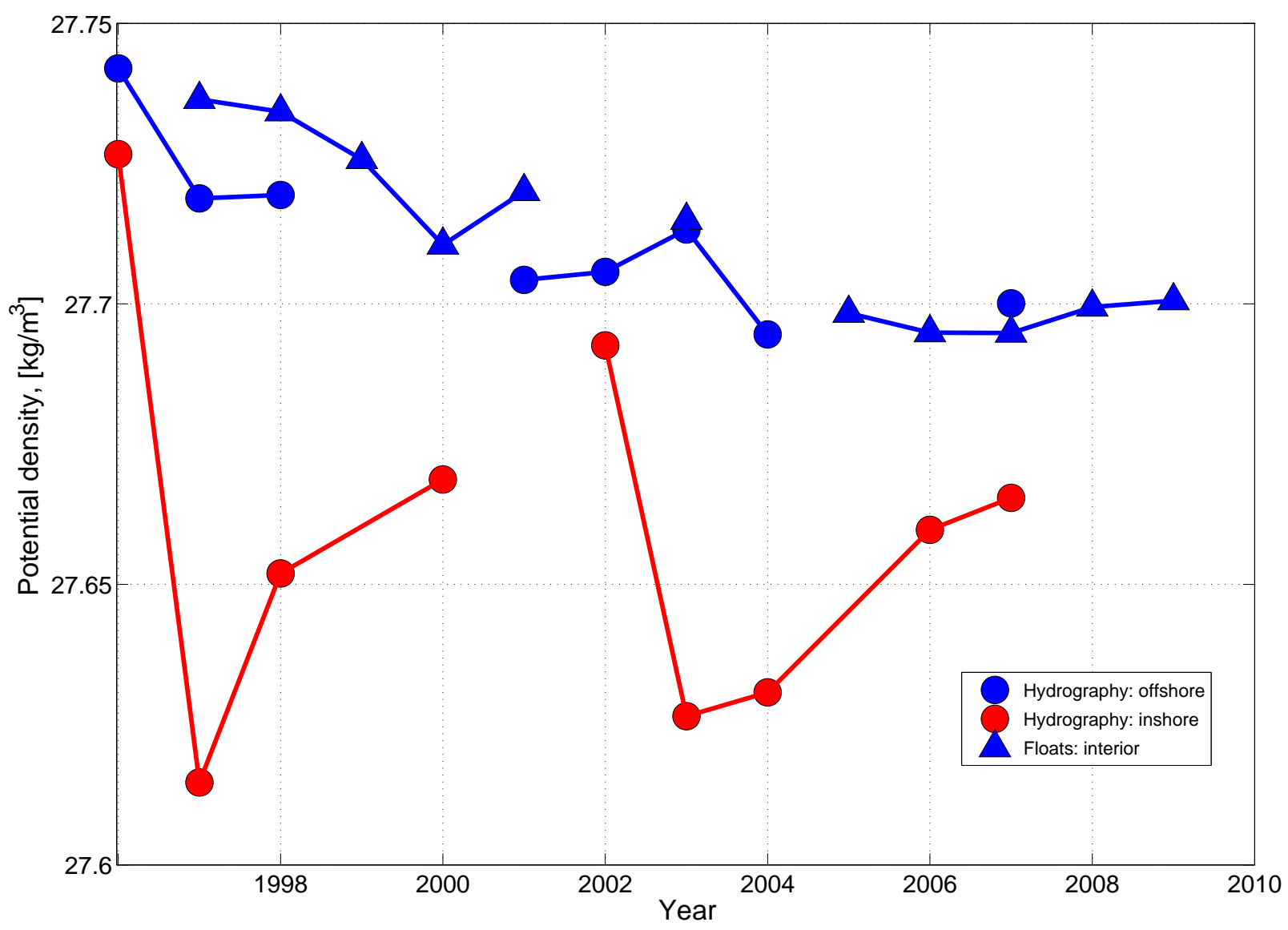

Figure 4-6: Potential density in the core of the boundary current (red) and the interior (blue) obtained from the hydrographic (circle) and float (triangle) data. 

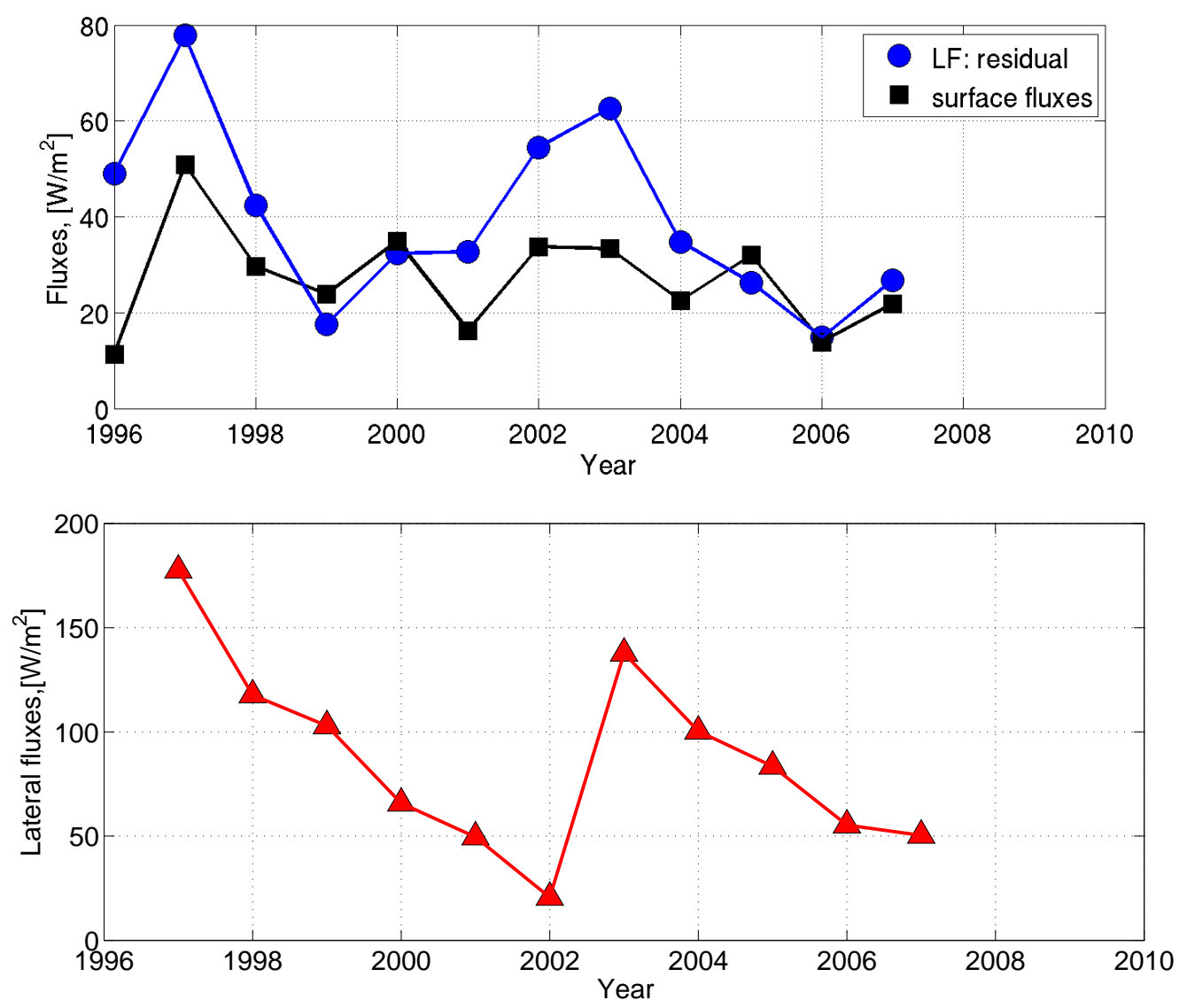

Figure 4-7: a) Lateral fluxes estimated by method 1 (blue circles) compared to the negative surface fluxes (black squares). b) Lateral fluxes estimated by method 2 . 


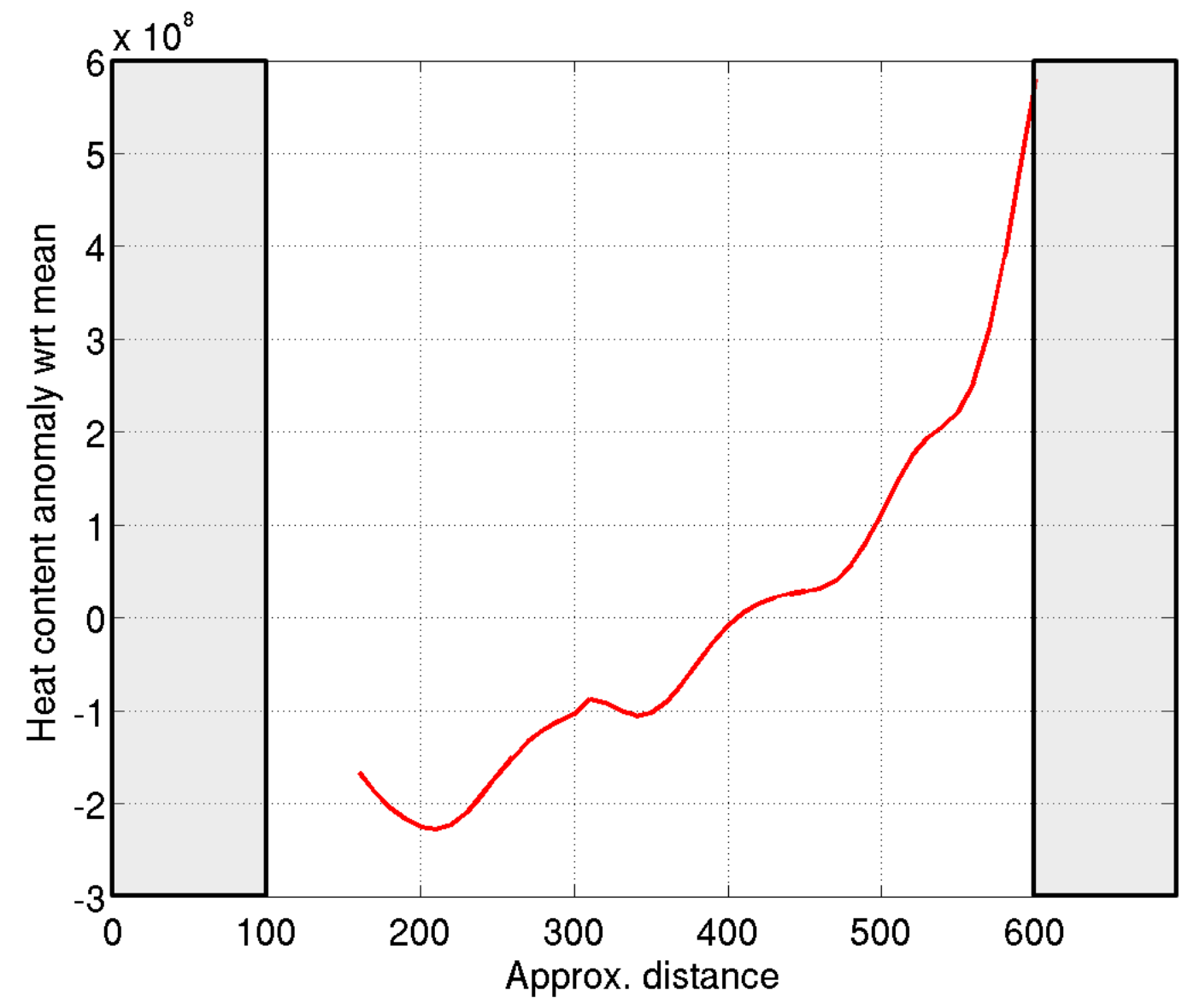

Figure 4-8: Changes in the interior heat content relative to the mean profile (deeper than 3300m) along the AR7W section for 1990-1997. The regions of the boundary current on both sides of AR7W are schematically shown in the gray boxes. 


\section{Chapter 5}

\section{Conclusions}

The central question addressed in this thesis is whether the seasonal and interannual changes that occur in the boundary current at the entrance into the Labrador Sea play an important role in shaping the interior properties and the formation of LSW. I have used various types of in situ data combined with the surface flux and satellite altimetry data products to address this question and to study the boundary current system and eddies' variability on different time scales as well as their influence on the restratification. The analysis presented in the thesis supports the result of the previous theoretical studies that argue that lateral fluxes, driven by the boundary current/interior gradients, play an important role in influencing the mean properties of the Labrador Sea and its seasonal and interannual variability. The magnitudes of the lateral fluxes depend heavily on the changes in the boundary current and thus, the variability of the boundary current has important consequences for LSW production.

\subsection{Summary of the results}

This thesis makes several important new contributions to our understanding of properties and dynamics of the Labrador Sea circulation. The seasonality in the structure of both West Greenland Current system components (the surface fresh portion and the warm and salty subsurface portion) is presented for the first time. By consid- 
ering the seasonal variability, I have been able to explain the inconsistencies in the previous estimates and improve the overall transport numbers. Explicitly, I have shown that previous studies, which utilized only summertime data, underestimate the property and velocity values by not resolving the seasonal cycle and hence, do not reproduce the true climatology values. Another important result of this study is the proof that the changes in the boundary current affect the Labrador Sea's interior properties and preconditioning to the convection. There have been studies where the theoretical models have shown the importance of the boundary current for the lateral exchange with the interior (Spall, 68, and Straneo, 74]). The models by Spall, 68, and Straneo, 74, predict that rates of the restratification depend not only on the interior properties and the surface fluxes but also on the properties and dynamics of the boundary current as a function of density gradient between these regions. Here, I document the variability in the boundary current properties and show for the first time that this variability is important for the interior region as it results in the lateral flux variability. And finally, by piecing together the largest available in situ eddy data base, I have been able to investigate the next link in the boundary current-interior exchange - the eddies. By investigating their evolution (both seasonally and interannually) I have been able to clarify their role in the heat and fresh water budgets of the Labrador Sea. The details on the main results from each of the chapters are presented below.

The main results of Chapter 2 start with the classification of the Irminger Current Anticyclones into the two distinctive classes by their properties: unconvected and convected eddies. Unconvected eddies are closer in properties to the boundary current system and, in particular, include a fresh layer at the surface. Convected eddies are characterized by a well-developed mixed layer and no surface fresh water cap. By using a one-dimensional mixed layer model, I show that convected eddies are the Irminger Current Anticyclones (unconvected ones) that have been modified by the large wintertime surface fluxes. In other words, by forcing an unconvected eddy with realistic surface fluxes, I have been able to reproduce the properties observed 
in convected eddies. These results showed, for the first time, that the fresh water cap from the West Greenland Current is mixed down in the water column within the eddy itself. Also, my results show that convection in the eddy can easily reach the Irminger Water and, therefore, allow the eddy to release its anomalous heat content directly to the atmosphere (again within the eddy itself). This mechanism of fresh water and heat delivery to the interior is different from the previous view that eddies simply advect heat to the convective region and give it up prior to winter. In the same chapter I also identified an additional fresh water pathway into the interior that could possibly explain the second fresh water pulse that is observed in the central Labrador Sea. Older studies had shown that eddies drift southward from the site of their formation but here I show that there also exists an alternative, faster route that follows the boundary current's cyclonic path and then gets entrained into the interior on the western side, thus, showing that ICAs are capable of bringing the fresh water to the Labrador Sea's interior from the West Greenland Current. Finally, I show that ICA properties and potentially, the quantities, have changed in the mid-1990s, similarly to the other components of the Subpolar Gyre, likely responding to both changes in the atmospheric and boundary current conditions.

Proceeding in the analysis of boundary current/interior exchange in the Labrador Sea I focused on the seasonal and interannual changes in the boundary current system which one expects to control in part the number and properties of the eddies generated by the boundary current system - including the ICAs. The goal of Chapter 3 is to demonstrate that the properties and the velocity of the boundary current system, as it enters the Labrador Sea, vary substantially on the time scales from months to decades. I show that previous studies that used only the summertime data and restricted analysis to less than $700 \mathrm{~m}$ depth underestimate the mean Irminger Current temperature and velocity by approximately 30\%. Which, in turn, implies an underestimation of the heat, fresh water, volume transports in the boundary current. Here I have shown that the subsurface portion of the boundary current system, the Irminger Current, is intensified in the fall (higher temperature, salinity and velocity) while the 
surface portion of the current, the West Greenland Current, is faster, thicker, colder and fresher in the spring. These findings are likely related to the seasonal cycle in the source waters of these currents: the fresh water export from the Arctic into the North Atlantic occurs at the end of the spring/beginning of the summer while the subsurface variability reflects the seasonality upstream. Despite having very different $\theta / S$ properties, the two components of the boundary current system are indistinguishable by their density and velocity structure. I showed that seasonal changes in velocity of the boundary current are due to the changes in the density of the current, i.e. to an increase in the lateral density gradient in the late fall. On the other hand, the overall decrease in velocity is attributed to the changes in the overall speed of the top-to-bottom current. The decline in the velocity of the boundary current from 1992 to 2008 is accompanied by a warming and salinization of the subsurface part. Both the boundary current and interior become warmer and saltier keeping the density gradient constant. There are two dramatically different years over the period of study, the years 1997 and 2003, which are characterized by the abrupt increase in the $\theta / S$ of the Irminger Current accompanied by the increase in the velocity of the whole boundary current system. The consequences of these changes are analyzed in Chapter 4 .

Chapter 4 focuses on the connection between the boundary current and interior and highlights the importance of the boundary current variability. I show that the interannual variations in the boundary current system affect the restratification and are indeed one of the key factors influencing the properties and amounts of LSW formed in the following year. Changes in the boundary current appear to drive changes in the lateral heat fluxes - presumably due to the differences in the number and properties of the eddies produced. To estimate the lateral fluxes from the boundary current to the interior and to show the importance of the boundary current for the interior, I have applied and compared two methods. The first one is based on the analysis of the hydrographic and float data and uses surface flux product (OAFlux reanalysis) and the second approach is based on the theory developed by Spall, 68. and Straneo, 
[74, and uses the available hydrographic and float data over 1996-2007. The first, residual method shows that the lateral fluxes roughly balance the surface fluxes with the exception of the years around 1997 and 2003 when the lateral fluxes exceeded the surface heat loss. In addition to that, the method based on the theory points to the dominance of the boundary current changes in modulating the lateral fluxes. These results suggest that changes in the boundary current system have significant consequences for the interior. The interior heat content has increased following the boundary current warming trend as a result of the advection by the lateral fluxes. Despite the increase in the heat content at a nearly constant rate, the arrival of heat to the interior from the boundary current occurs in pulses. In particular I show that there occurs a large increase in the inflow of the warm/salty boundary current water occurs around both 1997 and 2003 when the boundary current's properties and velocity abruptly increased. This suggests that the boundary current variability contributes to the interannual variability of the interior region and of LSW properties and formation. This finding emphasizes the importance of the boundary current system and impacts our understanding of the heat and fresh water balances.

As a whole, this research contributes to our understanding of the processes that influence the formation and the properties of the Labrador Sea Water and, in particular, to our understanding of the restratification process that needs to be properly represented in the climate models. Here I show that variability of the boundary current plays an important role in affecting the rates and timing of the restratification. Hence, both the boundary current dynamics and the lateral fluxes should be realistically represented and included in climate models in order to adequately represent the variability of the AMOC. 


\subsection{Discussion}

This study has been motivated by the idea that in order to represent the highfrequency variability in the MOC correctly, one needs to understand and correctly represent the variability in the deep water formation. In this thesis I have shown that the variability in LSW is, besides being affected by the surface fluxes, also affected by the changes in the lateral fluxes (provided by the eddies that result from the instability of the boundary current system) and hence, by the changes in the boundary current system itself. This result implies that in order to improve the representation of the deep water formation in the coarse-resolution general circulation models (GCMs), one needs to properly represent the instability and the effect of eddies on restratification as well as upstream variations in the boundary current. Since we are limited by the computational power in our resolution of the eddies in the large-scale climate models (that have the resolution on the order of $1^{\circ}$ as opposed to the desirable resolution of $0.1^{\circ}$ ) and will not be able to resolve them in the near future, we will need to parametrize the eddies in a way to account for the important details such as the fresh water cap in eddies, for example, that are important for the overall dynamics of the region. This work showed that the parametrization used by Spall, [68, and improved and adapted to the Labrador Sea case by Straneo [74], is able to reproduce the realistic variability in the simplified representation of the Labrador Sea. However, in the climate models, for example, it is crucial to account for the fresh water contribution and other specific properties of the eddies as well as for their variability. It will allow us to reproduce in a more realistic way the convective variability and deep water formation in the North Atlantic.

There are a number of important findings in this thesis that complement previous studies and improve our understanding of the boundary current and eddy field variability in the Labrador Sea. The seasonal cycle of the boundary current system documented for the first time in Chapter 3 reveals a clear difference between the spring and fall regimes of both parts of the West Greenland Current system. The spring 
intensification of the surface component of the boundary current is consistent with the observed increase in the fresh water transport documented by Schmidt and Send ([66]) in the upper $200 \mathrm{~m}$. The increase in the eddy production that has been shown to occur in January-March (Prater, 63]; L03) is likely explained by the observed increase in the Irminger Current isopycnal slope, related to the boundary current stability, that is typical for the fall. The Irminger Current is the most unstable in the fall (S. Legg, personal communication, 2009), which implies a conversion of potential energy into EKE. This suggests that the eddy generation is a result of the baroclinic instability in the boundary current while barotropic instability is less important. The boundary current section used in this study is located upstream of the eddy formation region and we observe the largest density gradient in the fall. One should keep in mind that our fall season includes the data from October to March which does not resolve the whole annual cycle. It points to the need for more observations to better understand the transition between the fall and spring regimes.

The observed warming of the boundary current system is consistent with the previously reported trend in Myers et al., [54]), however, their study was limited to a single profile that represented the boundary current and restricted to $700 \mathrm{~m}$ depth in vertical. The boundary current has become warmer and saltier over the last 16 years accompanied by the slow-down of the circulation throughout the water column. A similar trend was discussed in the studies by Hakkinen and Rhines, [27], 28] who attributed it to the reduced convective activity that resulted from the decline in the buoyancy forcing. The atmospheric variability has indeed changed over the period of study, however, it does not fully explain the interior warming which, according to my analysis, is to a larger extent due to the warming in the boundary current. In chapter 3 I show that a decline in the boundary current velocity is associated with the decrease in the barotropic flow as opposed to the decrease in the density gradient across the current. The fact that the boundary current and interior rapidly equilibrate (i.e. have the same trends) suggest that there is a rapid exchange between the two. 
Finally, an important result of this study is the documented abrupt increase in the boundary current and eddy properties, in the velocity of the boundary current and in the magnitudes of the lateral fluxes that occurs during two 2-3 year periods peaking in 1997 and 2003. All these changes occurred suddenly while the atmospheric circulation and the interior properties did not vary significantly. The 1996/1997 period is characterized by the switch in the NAO but there is nothing special about the atmospheric circulation in 2003 so the cause of these 1997 and 2003 events is still unclear. There are other observations that also point out to the outstanding nature of these years. For example, L03 documents an increase in the eddy activity in 1997 similarly to our study and suggests that prior to that year the eddies were present in the Labrador Sea in much smaller quantities. Having investigated the lateral fluxes into the interior of the Labrador Sea, I conclude that indeed, there was a sudden increase in the magnitudes of the lateral fluxes around 1997 (and 2003) associated with the abrupt changes in the boundary current that resulted in the increased heat and fresh water flux into the interior.

An additional contribution of this work is that the methods applied and results discussed are not limited to the Labrador Sea case alone. The techniques used for the eddy documentation and analysis can be applied to the other eddy-rich regions of the world. The theory developed for the heat balance in the Labrador Sea by Spall, 68], and Straneo, [74, is applicable to any marginal sea with convection. For example, there is some evidence that convection and formation of LSW also occur in the Irminger Sea (Pickart et al., 60]; Våge et al., 78] ) which also exhibits seasonal and interannual variability. The interior of the basin restratifies after wintertime convection but it is presently unknown what mechanisms are responsible for the post-convective restratification.

The findings from this work can be useful not only to the field of physical oceanography but also outside this field, for example in the biological studies as well as the 
local fisheries. The changes in the properties and velocity of boundary current system that circulates around Greenland can have significant impact on the melting of the Greenland Ice Sheet (as suggested by Straneo et al., [75]). It is possible in turn that the melting of the GIS triggered by the observed warming of the boundary current will lead to the increase in the fresh water inflow into the Labrador Sea and affect convection.

\subsection{Future work}

The attempts to explain the observed variability of the Labrador Sea system should continue, despite the fact that it is still challenging at this time. The available data record is relatively short, but we should continue to monitor the ocean circulation in the important places, such as the Labrador Sea. There are a lot of factors that contribute to the difficulty of understanding of the system: there are different time scales on which the variability is taking place, the ocean has a long-term memory of the previous forcings and overall, the system is very complex. It is crucial to keep monitoring the system because even the 15-year record that is available now is considered to be small for the robust evaluation of the trends such as, for example, a slow-down of the circulation. The continuous monitoring of the ocean provided by the Argo float data set and satellite altimetry provide us with the opportunity to constantly update our knowledge of the system. It is important to revisit the data set and analyze the unusual year 2008 when the convection has been shown to suddenly resume in the Labrador Sea (Våge et al., [78]). We should aim to understand if this year stands in the same line of the unusual years with increased lateral fluxes or if the mechanisms for regulating convective activity and post-convective restratification are different.

One of the future areas of research is the further investigation of the new fresh water pathway into the Labrador Sea interior that has been discussed in chapter 2 . Indeed, the ability of the eddies to transport the fresh water to the interior via the 
fast route in the boundary current raises the possibility of a faster restratification of the interior and the contribution to the pulses of seasonal freshening of the Labrador Sea. This new fresh water pathway should be studied and the mechanisms of the fresh water entrainment into the western part of the Labrador Sea as well as its effect on the stability of the convective interior should be investigated.

It is important to extend the studies on the stability of the boundary current and understand the governing mechanisms of the seasonality in the eddy production. Documenting the seasonal changes in the boundary current and their impact on the current's stability should be a priority, in order to understand the relation between the slope of the isopycnals and the EKE and the growth rates, and eventually improve their representation/parametrization in the climate models. Such approach can also contribute to the development of the theoretical model of the boundary current that can be used to understand what governs the interannual changes in the stability of the boundary current and its relation to the sudden increase in the eddy fluxes observed in 1997 and 2003.

Future work includes the development of the working parametrization of the eddy fluxes that includes both heat and fresh water component and realistically represents the variability of the heat and fresh water inflow into the Labrador Sea. This will provide the next step in our understanding of the connection between the formation of LSW and the AMOC.

The observations and analysis of this thesis would also be very helpful for validating the regional, large-scale coupled and data assimilation (such as ECCO, the Estimation of the Circulation and Climate of the Ocean) models. 


\section{Appendix A}

One of the objectives of the present work is to produce robust climatological mean fields for potential temperature, salinity, potential density and absolute velocity from hydrographic data and satellite altimetry products. To average the hydrographic sections we need to bring them to a common reference frame. Raw data cover different portions of the current, both laterally and vertically; they include measurement errors and eddies that need to be removed. Finally, the stations within each hydrographic section have different spacing, making the comparison complicated. To bring the sections to the same reference frame, I choose to follow the technique described in Fratantoni and Pickart, [23]. The approach is based on the interpolation and projection of the data onto a single line, which in this study is chosen to be the WOCE AR7W line (Figure 1-1). Since in the vicinity of the AR7W the topographic contours are nearly parallel to each other, one can project all the stations onto AR7W line along the isobaths preserving therefore the depth of the water column. The most difficult field to obtain is the velocity field as it requires additional assumptions and the referencing of the original hydrographic data to the satellite product. The property sections of the boundary current undergo similar steps so I focus here on the most complicated case of calculating the absolute velocity. There are four procedures that I perform with each section before I start the analysis. I remove the eddies, interpolate the stations onto the chosen grid, then compute the absolute velocity and finally, project onto AR7W line. These steps are described in detail below. 
Eddies. In addition to the boundary current, some of the sections also sample the eddies produced by the boundary current (Prater, 63] L03; Katsman et al., [36]). The eddies are located both in the interior of the Labrador Sea and near the Greenland coast. Many of them were identified and studied in detail in Chapter 2. Since the focus of this chapter is the construction of the boundary current system climatological section, and not the eddies, I remove the transient eddy signal from the data. The eddies have distinct properties (see Chapter 2 for clarifications) and in most cases can be easily identified and eliminated from the sections.

Interpolation. The following step includes the interpolation of the data onto a single regular grid. I have applied the Laplacian-spline interpolation routine as described in Fratantoni and Pickart, [23], and Sutherland, [76]. I interpolated the sections on a regular grid with $5 \mathrm{~km}$ horizontal and $10 \mathrm{~m}$ vertical resolution. To extrapolate the data down to the bottom topography, I used Smith and Sandwell, 67] satellite bathymetry to determine the shape of the topographic slope.

Absolute velocity. Both hydrographic data and AVISO product are needed for the calculation of absolute velocity, so I need to examine their behavior at the surface. AVISO product has a lower resolution compared to the hydrographic data, while for referencing at the surface, they should be brought to a common denominator. I have tried using a higher resolution AVISO product, the along-track data but I have encountered several problems. 1) The locations of the ground tracks are in the majority of the cases far from the locations of the hydrographic sections which makes it unjustifiable to match the two at the surface. 2) A single along track realization does not capture the place of the steep density front (about $70 \mathrm{~km}$ offshore). The gridded product influenced by several ground tracks does capture a front, however, at a lower resolution than in the hydrographic data. 3) Finally, the dates of the hydrographic observations did not match the dates of the along-track product. For several hydrographic sections the closest along-track velocity in time was available within more than a months period. Since it is so complicated to increase the resolution of 
the satellite product, I decided to modify the hydrographic data and lower the resolution of the sections. Prior to the relative velocity computation I apply a low-pass filter to the density field and decrease the horizontal resolution of the section to $30 \mathrm{~km}$.

To compute the absolute velocity from hydrography one needs to calculate the geostrophic velocity and reference it to a known value. Possible sources for the reference velocity are floats (Pickart and Spall, 61]), moorings (Meinen and Watts, 1998) and Acoustic Doppler Current Profilers (Hall and Torres, 29]). Here I reference geostrophic velocity at the surface to the AVISO gridded product. This method was first successfully applied by Tang and Han, 30, who used the along-track product to reference the relative velocities at the surface in the Labrador Current. The method consists of the following steps: i) thermal wind shear calculation from the density field; ii) referencing it to the surface absolute velocities; iii) projection of the velocity section on the common hydrographic line and taking the component of the flow that is parallel to the isobath.

To calculate the absolute geostrophic velocity one needs to obtain both the geostrophic velocity and the reference velocity that is added to the field as a result of integrating the shear.

The technique used for the relative geostrophic velocity calculation from the density field is the following. The velocity is referenced to the level of known motion (at $1000 \mathrm{~m}$ where the density gradients are the smallest) where the baroclinic reference velocity is set to zero. It is important to note that in order to obtain the velocity in the regions shallower than $1000 \mathrm{~m}$ I used the technique described in Helland and Hansen (1934) who suggest to extend the isopycnals horizontally into the ground. In this case the isopycnals below the bottom are parallel to each other resulting in the zero velocity. The advantage of this method is in the continuous velocity field without the irregularities near the bottom, that matter both for the velocity field itself and for the transport computations. 
The thermal wind relation is

$$
V_{z}=-\frac{g}{f \rho_{0}} \rho_{r} ;
$$

where $V_{z}$ is the velocity shear; $\mathrm{g}$ - gravity constant, $\rho_{0}$ - reference density, $\mathrm{f}$ Coriolis parameter and $\rho_{r}$ - density gradient across the section. After integration of this equation and taking into account the fact that velocity at the surface is chosen to be referenced to AVISO, that is a function of across-the-section distance $r$ only, one can get the final equation for the geostrophic velocity calculation:

$$
V(r, z)=V_{A V I S O}(r)-\frac{g}{f \rho_{0}} \int_{0}^{z} \rho_{r} d z ;
$$

One should remember that this velocity is only one component of the true, absolute velocity, in the direction "across" the hydrographic line. The component "along" the line cannot be found from a hydrographic section across the current.

Projection. Absolute geostrophic velocity is downloaded from the website in the form of the two components of the velocity vector in the Mercator system of coordinates. The two components of the velocity provide us with the information about the magnitude of the velocity $(\mathbf{U})$ and the direction of the flow with respect to the axes North-East (angle $\alpha$ ):

$$
\begin{gathered}
|U|=\left(U_{A V I S O}^{2}+V_{A V I S O}^{2}\right)^{1 / 2} ; \\
\alpha=\tan ^{-1} \frac{V_{A V I S O}}{U_{A V I S O}}
\end{gathered}
$$

where $U_{A V I S O}$ and $V_{A V I S O}$ are the zonal and meridional components of the velocity vector respectively in the north-east system of coordinates. One needs to know the component of this velocity in the direction perpendicular to the hydrographic section. In other words, it is desired to move to a new system of coordinates (dashed axes in Figure A-1) where one of the axes is parallel to the hydrographic line. The 
parallel axis is called for simplicity "along" the hydrographic line and the perpendicular direction is called "across" the line. Suppose that the angle of the hydrographic line in the absolute, North-East, system of coordinates is $\beta$.

Knowing $\alpha$ and $\beta$ one can obtain the angle at which the perpendicular to hydrogrpahy component of the full AVISO vector with respect to the grid is, $\gamma=\alpha-\beta$;

Finally,

$$
\begin{aligned}
& V_{\text {across }}=|U| \sin \gamma \\
& V_{\text {along }}=|U| \cos \gamma
\end{aligned}
$$

Further I will only use the "across" component of the velocity due to the fact that it is not possible to obtain the "along" one from the hydrographic data available.

To summarize, I have calculated the geostrophic velocity perpendicular to the hydrographic section (i.e. in the "across" direction) and referenced it to the AVISO surface velocity. The next step is to take the component that is parallel to bathymetry and bring all the sections to a new location.

I will show how the transformation if done on the example of one section. Since I do not know the full velocity from the data available, I need to make an assumption in order to find it. I assume now that the flow is following the contours of the isobaths and that the component of the flow that is perpendicular to the isobaths is zero. This assumption is supported by the observations (Cuny et al, [12]) and modeling studies (Haine et al., 2007).

Consider one point on the hydrographic section (Figure $\mathrm{A}-2$ ). I found the component of the flow, $\mathrm{U}$, that is perpendicular to the hydrographic line (that is the same as $\left.V_{\text {across }}\right)$, it is directed at an angle to topography. Now I choose a line perpendicular to the topography and shift the known velocity there. But prior to that I need to know the full velocity using an assumption of no-across flow. In other words, the true velocity, $U_{\text {topo }}$, must satisfy two conditions: it must be parallel to the topography and 
if projected, it should give the velocity component $\mathrm{U}$. The angle of the tilt can be found from the geometry of the lines (see Figure A-2).

Finally, the "true" velocity is:

$$
U_{\text {topo }}=\frac{V_{\text {across }}}{\cos (\gamma-\beta)}=\frac{U}{\cos (\gamma-\beta)}
$$

Note that it does not matter in what order we perform the transformation to a new line: finding the full velocity first and then projecting or vice verse.

Since this method of obtaining the absolute velocities has never been used in the exact same way as described here, I verified the obtained velocity fields by comparing them to the other studies. First, I compared the individual velocity section obtained by referencing the relative velocity to AVISO to the velocity section across the Labrador Sea boundary current obtained from the Lowered ADCP (Hall and Torres, [29]). Unfortunately, there are only two sections of the LADCP velocity were available at the time of our study but both of them agree qualitatively and quantitatively.

To test this method in a more robust way, I compare the average velocity section to the climatological mean obtained by Pickart and Spall, 61] choosing the same sections they have used from our data base. Since this study is limited by the AVISO years, I cannot include the sections prior to 1992 into the comparison with their 1990-1997 mean but 7 out of 10 sections are the same. I produced the section of the mean absolute velocity and compared it to their Figure 3a. Both the magnitudes of the velocity and the transport estimations agree: the volume transport across the boundary current in this study is $32 \pm 4 \mathrm{~Sv}$ while their transport is $28.5 \mathrm{~Sv}$.

The difference is small and can be explained by the different spatial coverage of 
the sections and different definition of the boundary current. Finally, I compare the velocity in the climatological section to the absolute velocity at $700 \mathrm{~m}$ obtained from the floats. The float velocity used for comparison is the mean over 1995-1999 and it agrees well by magnitudes and shape across the current with the described above values (Figure $\mathrm{A}-3$ ). 


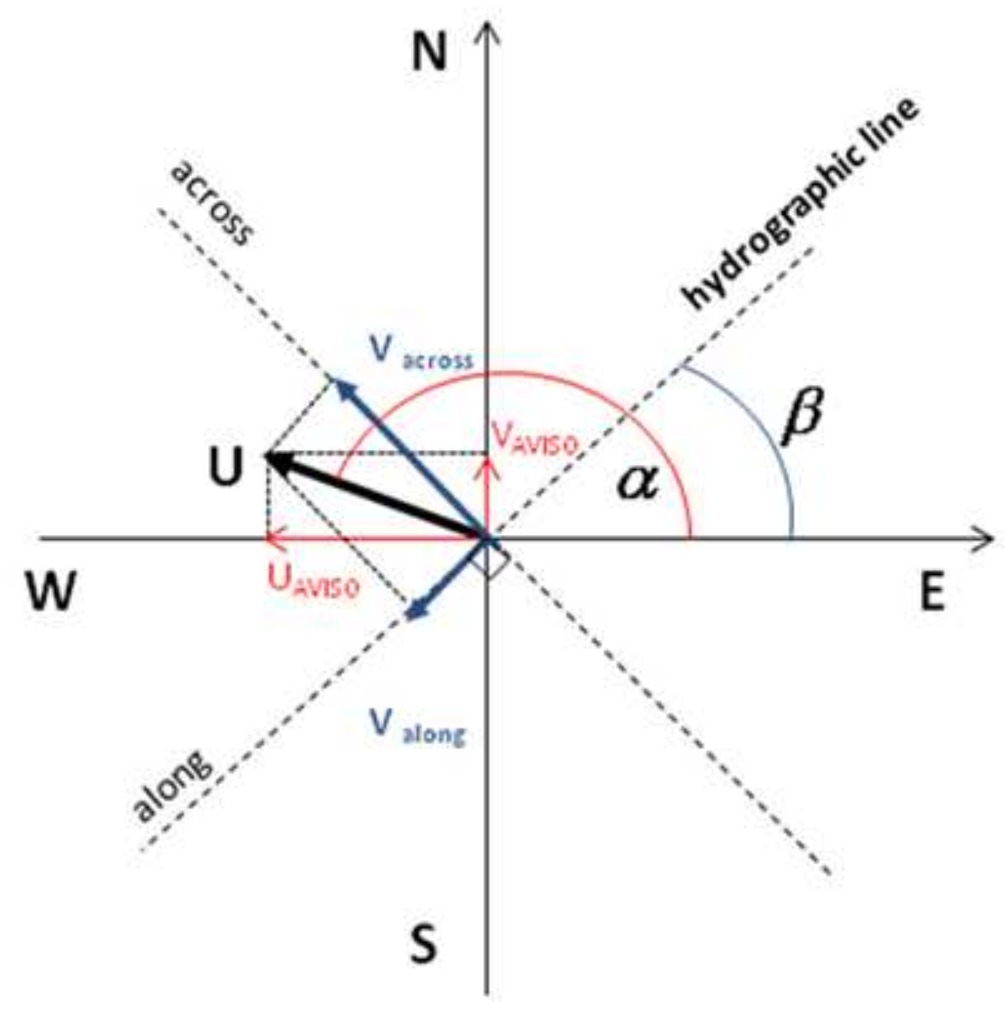

Figure A-1: Change of coordinate system from North-East to along-across hydrographic line. Red arrows are the zonal and meridional components of AVISO velocity vector, shown in a thick back line; blue arrows are the projected components of the same vector in the along-across system of coordinates tied to hydrographic line (dashed system). Red curve marked as $\alpha$ shows the angle between the velocity vector and the north-east system of coordinates and blue curve for the angle $\beta$ shows the angle between hydrographic line and axis of the north-east system of coordinates. 


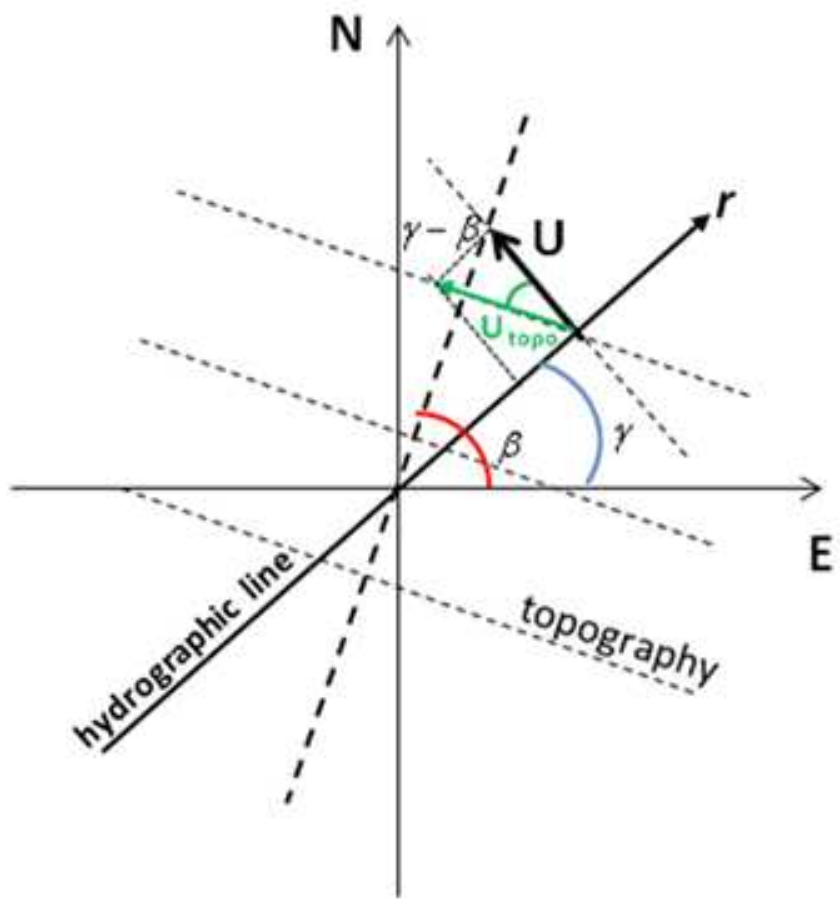

Figure A-2: Assumption: boundary current flows in a direction, parallel to the lines of topography (thin dashed lines), angle of hydrographic line with the north-east system of coordinates, , is shown by a red curve; ? the angle between the so-called acrosstopography axis (thick dashed line) and the axis of north-east system of coordinates; the angle needed for the projection, is shown by a green curve. Solid black line is the hydrographic section line. 


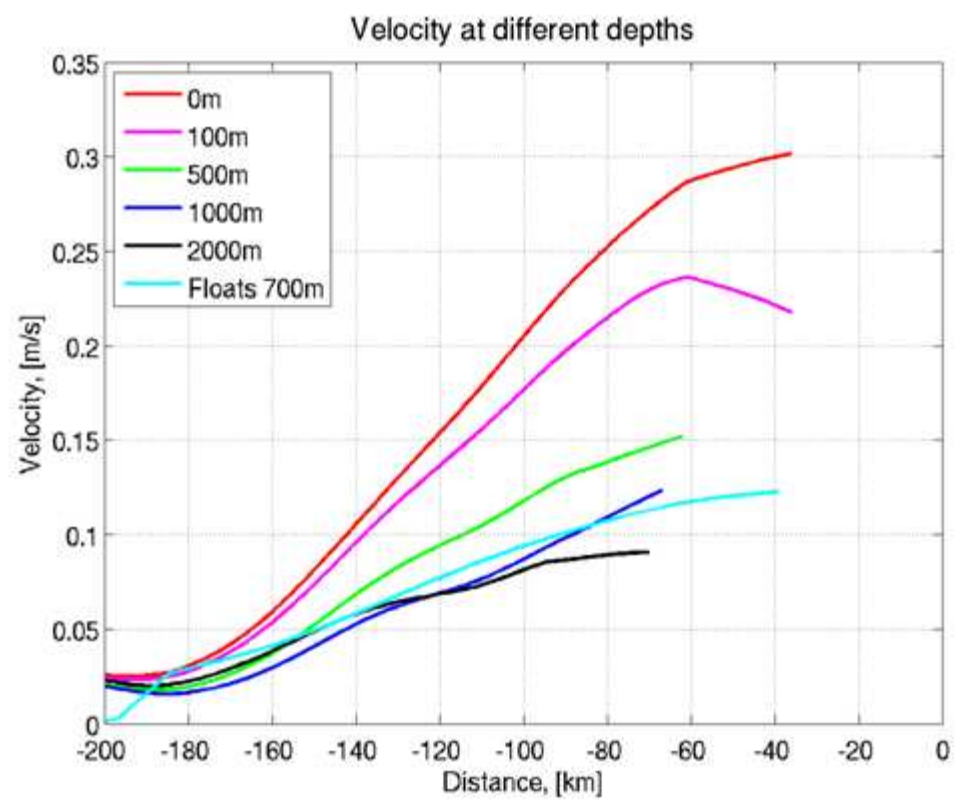

Figure A-3: Absolute velocities at different depths obtained from the mean section over 1992-2008 referenced to AVISO to the mean absolute velocity measured by floats for 1995-1999 at $700 \mathrm{~m}$. 


\section{Appendix B}

There are two definitions of the Irminger Current used in the text. The strict definition of the core is called "the inshore box = box1" and the broader definition of the Irminger Current itself bounded by the 34.4 isohaline at the top, the depth of $1000 \mathrm{~m}$ at the bottom and by including only the water shallower than $3000 \mathrm{~m}$ isobath referred to as the maroon box, or Full IC" (Figure 3-7). The choice of these parameters will be justified further in the text. The "inshore box", further always referred to as "the core" is used for monitoring the interannual and seasonal variability of the core while the broader definition, "Full IC" is used for calculations of the thickness, volume and heat transports.

There are a number of transport estimates for the West Greenland and Irminger Currents but the range of the values is enormous. It is crucial to know how much water with certain properties enters the Labrador Sea region because the properties of the inflow matter for the values and amounts of the final product in the water mass modification in the Labrador Sea, Labrador Sea Water. The published volume transport values range from 3Sv (Myers et al., [54]) to $13.6 \mathrm{~Sv}$ (Pickart and Spall, 61]). It is important to understand if this variability is a physically significant finding, for example, the result of the interannual changes, or an artifact of the definition of the water masses.

In this part I show that the definition of the water mass plays a crucial role for the transport estimates and that it is possible to obtain any of the values from the published range by just slightly varying the boundaries of Irminger Water. The sensi- 
tivity of the transport estimation as a function of different boundaries is presented in Table B-1. The sketch with different boxes that define the Irminger Current is shown in Figure 3-7. Indeed, Myers et al., 54], limited their observations to the upper 700 $\mathrm{m}$ thus, not captured the bulk of the Irminger Current and obtained the smallest transport of 3 Sv. Pickart and Spall, 61, do not explicitly define the Irminger Water in their work but from their figures and description I conclude that they have used a much broader portion of the flow in their transport calculations and included a part of the weak interior flow together with a large barotropic component. As seen from the table, both extreme low and high values of Myers et al., [54], and Pickart and Spall, 61, respectively can be obtained from this data set. However, I choose to proceed with a different and validated definition of the current, the one defined by the isohaline 34.4 at the upper boundary to separate the fresh West Greenland Water; by $1000 \mathrm{~m}$ depth - that bounds the lower boundary of the warm and saline water (as was found out by looking at all the individual sections that compile the mean). The offshore boundary is defined by topography based on the earlier studies and the one-by-one section validation: the current is most often confined within $3000 \mathrm{~m}$ isobath and thus, the crossing of the section by this isobath can serve as a horizontal offshore boundary. The volume transport or the Irminger Current in the climatological mean section is $7.9 \pm 1.3 \mathrm{~Sv}$. 


\begin{tabular}{|c|c|c|c|c|}
\hline Definition & $100 \mathrm{~km}$ & $3000 \mathrm{~m}$ & $150 \mathrm{~km}$ & $200 \mathrm{~km}$ \\
\hline $700 \mathrm{~m}$ & $4.5 \mathrm{~Sv}$ & $6.2 \mathrm{~Sv}$ & $8.1 \mathrm{~Sv}$ & $9.6 \mathrm{~Sv}$ \\
\hline $1000 \mathrm{~m}$ & $5.6 \mathrm{~Sv}$ & $7.9 \mathrm{~Sv}$ & $10.3 \mathrm{~Sv}$ & $12.4 \mathrm{~Sv}$ \\
\hline $1200 \mathrm{~m}$ & $6.3 \mathrm{~Sv}$ & $8.8 \mathrm{~Sv}$ & $11.7 \mathrm{~Sv}$ & $14.1 \mathrm{~Sv}$ \\
\hline $1500 \mathrm{~m}$ & $7.2 \mathrm{~Sv}$ & $10.2 \mathrm{~Sv}$ & $13.6 \mathrm{~Sv}$ & $16.6 \mathrm{~Sv}$ \\
\hline
\end{tabular}

Figure B-1: The sensitivity of the Irminger Current's volume transport to the definition of Irminger Water for various boxes. The first column shows the vertical cut-off and the columns 2-5 show different horizontal boundaries 


\section{Bibliography}

[1] M. Ablain, A. Casenave, G. Valladeau, and S. Guinehut (2009). "A new assesment of the error budget of global mean sea level rate estimated by satellite altimetry over 1993-2008", Ocean Sci., 5, pp. 193-201.

[2] T. Avsic, J. Karstensen, U. Send and J. Fischer (2006). "Interannual variability of newly formed Labrador Sea Water from 1994 to 2005", Geophys. Res. Lett., 33.

[3] M. Bersch, I. Yashayaev, K. P. Koltermann (2007). "Recent changes of the thermohaline circulation in the subpolar North Atlantic", Ocean Dynamics, 57, pp. 223-235.

[4] C. W. Boning, M. Scheinert, J. Dengg, A. Biatoch, and A. Funk (2006) "Decadal variability of subpolar gyre transport and its reverberation in the North Atlantic overturning." G. Res. Lett., 33.

[5] Bower A. S., Lozier S, Gary S.F., Boning, C. W. (2008), "Interior pathways of the North Atlantic meridional overturning circulation", Nature, 459

[6] P. Brandt, F. Schott, A. Funk, and C. Sena Martins (2004). "Seasonal to interannual variability of the eddy field in the Labrador Sea from satellite altimetry". J. Geophys. Res., 109.

[7] Bracco A. and J. Pedlosky. (2003). "Local baroclinic instabilities over variable topography in channel flows". J. Phys. Ocean., 33, pp. 207-219. 
[8] Bracco A., J. Pedlosky and R. Pickart (2008). "Eddy formation near the West Coast of Greenland." J. Phys. Ocean., 38, pp. 1992-2002.

[9] E. Buch, S. Pedersen, M. Ribergaard (2004). "Ecosystem Variability in West Greenland Waters", Journal of Northwest Atlantic Fishery Science, 34, pp. 1328.

[10] J. Chanut, B. Barnier, L. Debreu, W. Large (2003) "Restratification after deep convection in the Labrador Sea: a high-resolution model study.", Geophysical Research Abstracts, 5.

[11] R. Clarke (1984). "Transport through the Cape Farewell - Flemish Cap section.", Int. Council for the Exploration of the Sea Rep., 11 pp.

[12] J. Cuny, P. Rhines, P. Niiler, S. Bacon (2002). "Labrador Sea boundary currents and fate of Irminger Water", Journal of Physical Oceanography,32, pp. 627-647.

[13] R. Curry, M. McCartney, T. Joyce (1998). "Oceanic transport of subpolar climate signals to mid-depth subtropical waters", Nature, 391, pp. 575-577.

[14] da Silva, A., A. C. Young, and S. Levitus, (1994) "Algorithms and Procedures". Vol. 1, World Ocean Atlas 1994, NOAA Atlas NESDIS 6, 83.pp.

[15] Deshayes, J. and C. Frankignoul, (2008) "Simulated variability of the circulation in the North Atlantic from 1953 to 2003." J. Climate, 21, pp. 4919-4933.

[16] Deshayes,J., F. Straneo, M. Spall, (2009). "Mechanisms of Variability in a Convective Basin", J. Mar. Res., 67, pp. 273-303

[17] Dickson, R., Lazier, J., Meincke, J., Rhines, P., and Swift, J.(1996). "Long-Term Coordinated Changes in the Convective Activity of the North Atlantic", Progr. Oceanogr., 38, pp. 241-295.

[18] R. Dickson, I. Yashayaev, J. Meincke, B. Turrell, S. Dye, J. Holfort (2002). "Rapid freshening of the deep North Atlantic over the past four decades.", $N a$ ture, 416, pp. 832-837. 
[19] Dong, S., S. Garzoli, M. Baringer, C. Meinen, and G. Goni (2009), "Interannual variations in the Atlantic meridional overturning circulation and its relationship with the net northward heat transport in the South Atlantic", Geophys. Res. Lett., 36

[20] C. Eden and C. Böning (2002). "Sources of eddy kinetic energy in the Labrador Sea.", Journal of Physical Oceanography, 32, pp. 3346-3363.

[21] Frajka-Williams, E., Rhines, P., and Eriksen, C. (2009). "Mesoscale variability in the Labrador Sea spring phytoplankton bloom observed by Seaglider." Deep Sea Research I, 56 pp. 2144-2161.

[22] Fratantoni, D. M. (2001). "North Atlantic Surface Circulation during the 1990's observed with satellite-tracked drifters", J. Geophys. Res., 106.

[23] Fratantoni, P. S. and R. S. Pickart (2007). "The western North Atlantic shelfbreak current system in summer". J. Phys. Ocean., 37, pp. 2509-2533.

[24] L.-L. Fu, E. Christensen, C. Yamarone, Y. Menard, M. Dorrer, and P. Escudier (1994) "TOPEX/POSEIDON mission overview". J. Geoph. Res., 99, pp. 54935512 .

[25] L.-L. Fu and A. Cazenave (2001). "Satellite Altimetry and Earth Sciences. A handbook of techniques and applications". Academic Press, pp. 463.

[26] A. Ganachaud, and C. Wunsch (2000). "Improved estimates of global ocean circulation, heat transport and mixing from hydrographic data.", Nature, 408, pp. $453-457$.

[27] Hakkinen, S. and Rhines, P. B. (2004). "Decline of subpolar North Atlantic gyre circulation during the 1990s". Science, 304, pp. 555-559.

[28] Hakkinen, S. and P. B. Rhines (2009). "Shifting surface currents in the northern North Atlantic Ocean". J. Geoph. Res., 114. 
[29] Hall, M. and D. Torres (2009). "Absolute Velocity in the Labrador Sea: ADCP Observations along AR7W", poster at IABO-IAPSO, Montreal, Canada

[30] G. Han and C. Tang (2001). "Interannual Variations of Volume Transport in the Western Labrador Sea Based on TOPEX/Poseidon and WOCE Data.", Journal of Physical Oceanography, 31, pp. 199-211.

[31] R. Harcourt, E. Steffen, R. Garwood, E. D’Asaro (2002). "Fully Lagrangian floats in Labrador Sea deep convection: comparison of numerical and experimental results.", Journal of Physical Oceanography, 32, pp. 493-510.

[32] Hatun, H., A.B. Sando, H. Drange, B. Hansen, H. Valdimarsson (2005). "Influence of the Atlantic subpolar gyre on the thermohaline circulation". Science, 309, pp. 1841-1844.

[33] H. Hatun, C. Eriksen, P.Rhines, J. Lilly (2007). "Buoyant eddies entering the Labrador Sea observed with gliders and altimetry". J. Phys. Ocean., 37, pp. $2838-2854$.

[34] Holland, D. M., Thomas, R. H., de Young, B., Ribergaard, M. H., and Lyberth, B. (2008). "Acceleration of Jakobshavn Isbrae triggered by warm subsurface ocean waters." Nature Geoscience, 1, pp. 656-664.

[35] Hurrell, J. W., Y. Kushnir, M. Visbeck (2001). "Climate. The North Atlantic oscillation." Science, 26, pp. 603-605.

[36] C. Katsman, M. Spall, R. Pickart (2004). "Boundary current eddies and their role in the restratification of the Labrador Sea.", Journal of Physical Oceanography, 34, pp. 1967-1983.

[37] de Jong, M., Drijfhout, S. S. Hazeleger, W., van Aken, H.M., Severijns, C.A. (2009). "Simulations of hydrographic properties in the northwestern North Atlantic Ocean in coupled climate models." Journal of Climate, 22, pp. 1767-1786. 
[38] Josey, S. A., E. C. Kent, and P. K. Taylor (1999) "New insights into the ocean heat budget closure problem from analysis of the SOC air-sea flux climatology." J. Climate, 12, pp. 2850-2880.

[39] The Lab Sea Group (1998). "The Labrador Sea deep convection experiment.", Bulletin of the American Meteorological Society, 79, pp. 2033-2058.

[40] K. Lavender, R. Davis, W. Owens (2000). "Mid-depth recirculation observed in the interior Labrador and Irminger seas by direct velocity measurement.", Nature, 407, pp. 66-69.

[41] K. Lavender, R. Davis, W. Owens (2002). "Observations of open-ocean deep convection in the Labrador Sea from subsurface floats.", Journal of Physical Oceanography, 32, pp. 511-526.

[42] Lavender, K, W. B. Owens, and R. E. Davis (2005). "The mid-depth circulation of the subpolar North Atlantic Ocean as measured by subsurface floats". Deep Sea Res. I, 52, pp. $767-785$.

[43] Lazier, J. R. N. (1980). "Oceanographic conditions at Ocean Weather Ship Bravo, 1964-1974." Atmos.-Ocean, 18, pp. 227-238.

[44] J, Lazier, and D. Wright (1993). "Annual velocity variations in the Labrador Current.", Journal of Physical Oceanography, 23, pp. 659-678.

[45] Lazier J. R. N., A. Clarke, I. Yashayaev, and P. B. Rhines (2002). "Convection and restratification in the Labrador Sea, 1990-2000". Deep Sea Res., 49, pp. $1819-1835$.

[46] Legg S., and J. C. McWilliams (2001). "Convective modifications of a geostrophic eddy field." J. Phys. Ocean., 31, pp. 874-891.

[47] J. Lilly, P. Rhines, M. Visbeck, R. Davis, J. Lazier, F. Schott, D. Farmer (1999). "Observing deep convection in the Labrador Sea during winter 1994/95.", Journal of Physical Oceanography, 29, pp. 2065-2098. 
[48] J. Lilly and P. Rhines (2002). "Coherent eddies in the Labrador Sea observed from a mooring.", Journal of Physical Oceanography, 32, pp. 585-598.

[49] J. Lilly, P. Rhines, F. Schott, K. Lavender, J. Lazier, U. Send, E. D’Asaro (2003). "Observations of the Labrador Sea eddy field.", Progress in Oceanography, 59, pp. $75-176$.

[50] J. Marshall and F. Schott (1999) "Open-ocean convection: observations, theory and models.", Reviews of Geophysics, 37, pp. 1-64.

[51] M. McCartney (1992). "Recirculating components to the deep bpundary current of the northern North Atlantic.", Progress in Oceanography, 29, pp. 283-383.

[52] Msadek, R. and C. Frankignoul (2008) "Atlantic multidecadal oceanic variability and its influence on the atmosphere in a climate model." Climate Dynamics, DOI $10.1007 / \mathrm{s} 00382-008-0452-0$

[53] P. Myers (2005). "Impact of Freshwater from Canadian Arctic Archipelago on Labrador Sea Water formation", Geophysical Research Letters, 32

[54] Myers, P.G., Kulan, N., and Ribergaard, M.H. (2007). "Irminger Water variability in the West Greenland Current." Geophys. Res. Lett., 34.

[55] Myers, P.G., C. Donnelly and M.H. Ribergaard, (2009) "Structure and Variability of the West Greenland Current in Summer Derived From 6 Repeat Standard Sections" Progress in Oceanography, 80, pp. 93-112

[56] Niiler, P.P., N.A. Maximenko, and J.C. McWilliams, (2003). "Dynamically balanced absolute sea level of the global ocean derived from near-surface velocity observations." Geophys. Res. Lett., 30

[57] R. Pickart (1997). "Adventure in the Labrador Sea. A wintertime cruise to the North Atlantic.", Oceanus, spring-summer issue.

[58] R. Pickart, D. Torres, R. Clarke (2002). "Hydrography of the Labrador Sea during active convection.", Journal of Physical Oceanography, 32, pp. 411-427. 
[59] Pickart, R.S., F. Straneo, and G.W.K. Moore, (2003). "Is Labrador Sea Water formed in the Irminger Sea?" Deep-Sea Research, 50, pp. 23-52.

[60] Pickart, R. S. M. A. Spall, M. H. Ribergaard, G. W. K. Moore, and R. F. Milliff, (2003). "Deep convection in the Irminger Sea forced by the Greenland tip jet." Nature, 424, pp. 152-156.

[61] Pickart, R. S. and M. A. Spall. (2007). "Impact of Labrador Sea convection on the North Atlantic Meridional Overturning Circulation". J. Phys. Ocean., 37, pp. 2207-2227.

[62] K. L. Polzin, J. M. Toole, J. R. Ledwell and R. W. Schmitt. (1997). "Spatial variability of turbulent mixing in the abyssal ocean." Science, 276, pp. 93-96.

[63] M. Prater (2002). "Eddies in the Labrador Sea as observed by profiling RAFOS floats and remote sensing.", Journal of Physical Oceanography, 32, pp. 411-427.

[64] M. Rhein and J. Fischer, W. Smethie, D. Smythe-Wright, R. Weiss, C. Mertens, D.-H. Min, U. Fleischmann and A. Putzka (2002). "Labrador Sea Water: Pathways, CFC Inventory, and Formation Rates.", Journal of Physical Oceanography, 32, pp. 648-665.

[65] A. Sarafanov (2009). "On the effect of the North Atlantic Oscillation on temperature and salinity of the subpolar North Atlantic intermediate and deep waters." ICES Journal of Marine Science, 66, pp. 14481454.

[66] Schmidt S. and U. Send (2007). "Origin and composition of seasonal Labrador Sea freshwater." J. Phys. Ocean., 37, pp. 1445-1454.

[67] Smith, W. H. F., and D. T. Sandwell. (1997). "Global seafloor topography from satellite altimetry and ship depth soundings." Science, 277, 1pp. 957-1962.

[68] M. Spall (2004). "Boundary currents and water mass transformation in the marginal seas.", Journal of Physical Oceanography, 34, pp. 1197-1213. 
[69] E. Steffen and E. D'Asaro (2002). "Deep convection in the Labrador Sea as observed by Lagrangian floats.", Journal of Physical Oceanography, 32, pp. 475492.

[70] Stein, M. (2005). "North Atlantic Subpolar Gyre warming impacts on Greenland offshore waters". J. Northw. Atl. Fish. Sci., 36, p. 112.

[71] R.J. Stouffer, J. Yin, J.M. Gregory, K.W. Dixon, M.J. Spelman, Coauthors, (2006), "Investigating the causes of the response of the thermohaline circulation to past and future climate changes", J. of Climate, 19, pp. 1365-1387.

[72] Straneo F., R. S. Pickart, and K. Lavender. (2003). "Spreading of Labrador Sea Water: an advective-diffusive modeling study based on Lagrangian observations." Deep Sea Res. I, 50, pp. 701-719.

[73] F. Straneo, "On the heat and freshwater transport through the central Labrador Sea.", Journal of Physical Oceanography, 36, pp. 606-628.

[74] F. Straneo, "On the connection between dense water formation, overturning and poleward heat transport in a convective basin.", Journal of Physical Oceanography, submitted.

[75] F. Straneo, G. Hamilton, D.Sutherland, L. Stearns, F. Davidson, M. Hammill, G. Stenson, A. Rosing-Asvid, (2010) "Rapid Circulation of warm subtropical waters in a major glacial fjord off East Greenland", 10.1038/NGEO764.

[76] Sutherland, D. and R. S. Pickart, (2008). "The East Greenland Coastal Current: structure, variability, and forcing." Progr. in Ocean., 78, pp. 58-77.

[77] L. Talley and M. McCartney (1982). "The distribution and circulation of Labrador Sea Water.", Journal of Physical Oceanography, 12, pp. 1189-1205.

[78] Vage, K., Pickart, R. S., Thierry, V., Reverdin, G., Lee, C. M., Petrie, B., Agnew, T. A., Wong, A., and Ribergaard, M. H. (2009). "Surprising return of 
deep convection to the subpolar North Atlantic Ocean in winter 2007-2008." Nature Geoscience, 2, pp 67-72.

[79] M. Vellinga, R.A. Wood "Global climatic impacts of a collapse of the Atlantic thermohaline circulation" Climatic Change, 54, pp. 251-267.

[80] C. Wolfe and C. Cenedese, (2006). "Laboratory Experiments on Eddy Generation by a Buoyant Coastal Current Flowing Over Variable Bathymetry." J. Phys. Oceanogr., 36, pp. 395-411

[81] Yashayaev, I., Lazier, J. R. N., and Clarke, R. A. (2003). "Temperature and Salinity in the Central Labrador Sea", ICES Marine Symposia Series, 219, pp.32-39.

[82] I. Yashayaev (2007). "Recent changes in Oceanographic Conditions in the Labrador Sea.", submitted to Progress in Oceanography.

[83] I. Yashayaev (2007b). "Hydrographic changes in the Labrador Sea, 1960-2005." Progr. in Ocean., 73, pp. 242-276.

[84] I. Yashayaev and J.W. Loder (2009). "Enhanced production of Labrador Sea Water in 2008.", Geophys. Res. Lett., 36.

[85] L. Yu, X. Jin, and R. A. Weller (2008). "Multidecade Global Flux Datasets from the Objectively Analyzed Air-sea Fluxes (OAFlux) Project: Latent and sensible heat fluxes, ocean evaporation, and related surface meteorological variables." Woods Hole Oceanographic Institution, OAFlux Project Technical Report. OA2008-01, 64pp.

[86] L. Yu and R. A. Weller (2007)." Objectively Analyzed air-sea heat Fluxes (OAFlux) for the global oceans." Bull. Ameri. Meteor. Soc., 88, pp. 527-539. 